\title{
Christian experiences and imaginings of the Secular in New Zealand
}

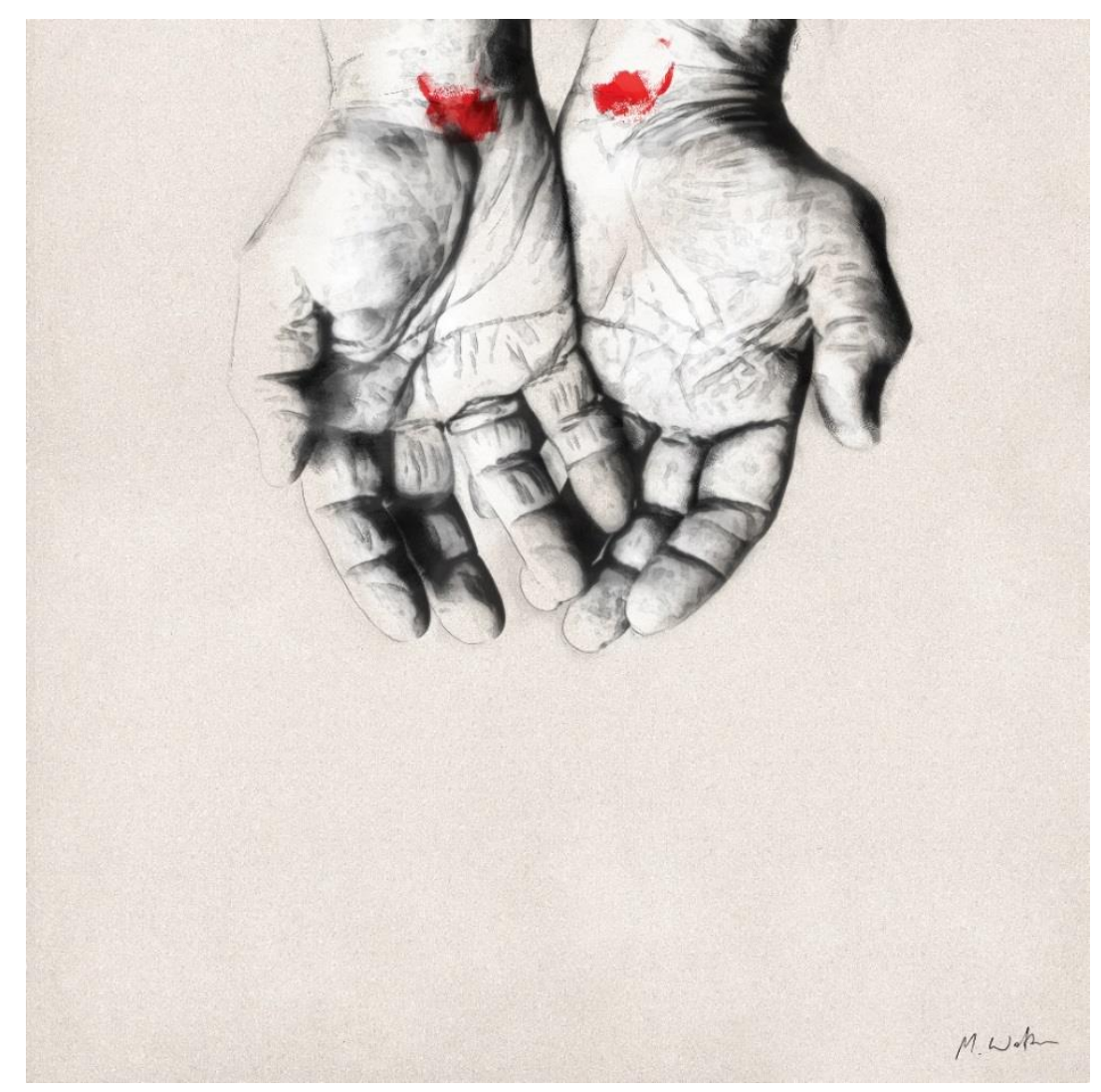

\section{Jessica Carter}

\author{
A thesis \\ submitted to Victoria University of Wellington \\ in fulfilment of the requirements for the degree of \\ Master of Arts in Cultural Anthropology
}

VICTORIA UNIVERSITY OF WELLINGTON

February 2018 


\section{Abstract}

This thesis explores how the Secular comes to materialise in the lives of a small group of Pentecostal-Charismatic Christians in Wellington, New Zealand. It presents an ethnographic account of how Christians experience and imagine the intertwined relationship between the religious and the Secular as they navigate social spaces, construct their identity, and make sense of the world. I argue that the Secular is not simply a residual state following the demise of religion, but rather, it is a discursive sensibility that produces religious subjects, and shapes a particular way of thinking about religion and its place in society. The Christians in this study seek to reject, counter and shape secular sensibilities, but they are also embroiled in producing the Secular. Consequently, they problematise dominant understandings of the Secular and religion as intrinsically separate and opposed domains. Based on four months of fieldwork in a Pentecostal-Charismatic church, and interviews with nine church congregants, this thesis reveals that Christian lives involve complex and multifaceted ways of being both Christian and secular.

Cover image: "Hands" by Matt W, church member ${ }^{1}$. For him, this image represents the hands of Jesus and serves as a visual representation of the church. I also see this image as illustrating the discussion presented in Chapter Five of Christian belief as a posture.

\footnotetext{
${ }^{1}$ I have obtained written permission to use this image.
} 


\section{Acknowledgements}

First and foremost, thank you to my participants and Trustpeak church ${ }^{2}$ for your generosity, time, and friendship. I am extremely grateful for, and humbled by, your hospitality and the ease with which you welcomed me into your family-thank you, and I hope I have done your stories justice.

I wish to acknowledge my supervisors Dr Jeff Sissons and Dr Eli Elinoff whose guidance-while each was extremely busy with their own projects-was instrumental in completing this thesis. I am grateful not only for your practical and intellectual wisdom, but also for believing in this project and challenging me to reach my potential. Jeff, I also want to thank you for meeting with me before I had even committed to the idea of doing my Master's and convincing me to go for it. Thank you also to the Victoria University Scholarships Committee for funding this research.

I am indebted to Tonya, who proofread my thesis with enthusiasm and astonishing efficiency, and to Sarah, who provided feedback at short notice. Thank you both. I also want to acknowledge my office colleagues Sam, Rara and Bryony (plus honorary office colleague Ben) for your support, conversation and friendship-a special thanks to Bryony to whom I owe a great deal.

Thank you to Dr Matthew S for taking the time out of your schedule to meet with me every few weeks-your guidance and insights are much appreciated. I am also grateful to Dr John D of the Victoria University Anglican Chaplaincy for taking the time to speak with me openly and warmly about my project. Special thanks also to Rebecca K for supporting me in pursuing this Master's, you continue to be an inspiring figure to me in my goals and ambitions.

I would like to thank my family and friends for their encouragement and support; of which there are too many to name here. However, thank yous must go to my parents, Craig and Angela, for always believing in me, to my grandparents, Wendy and Frank, for motivating me from an early age to do my best, and to my sister, Ange, for always having an ear to lend-good times and bad. Thanks also to Dave for your reassurance and advice.

Finally, thank you to my partner Jon-to whom my gratitude is beyond words. Your unwavering support (emotional and practical), patience, and encouragement has been fundamental in enabling me to do this thesis. You have put your priorities and goals aside over this last year to allow me to pursue mine, a sacrifice I do not take for granted-thank you.

\footnotetext{
${ }^{2}$ A pseudonym.
} 


\section{Table of Contents}

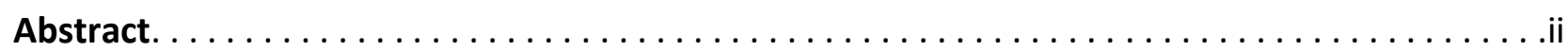

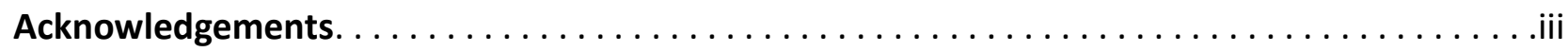

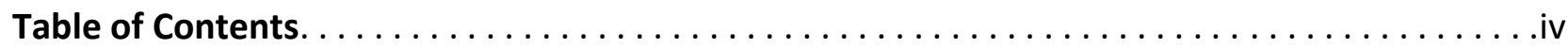

\section{Chapter One}

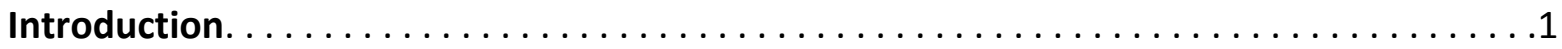

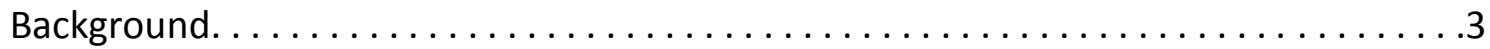

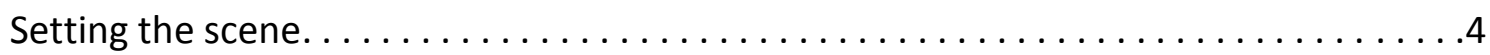

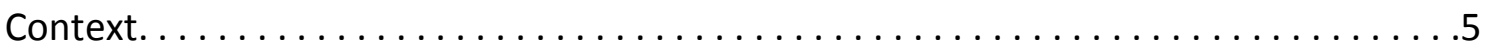

Theoretical concepts. .............................. 10

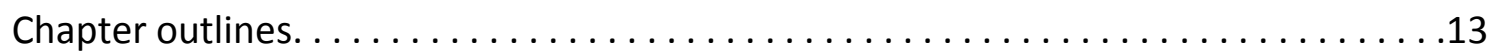

\section{Chapter Two}

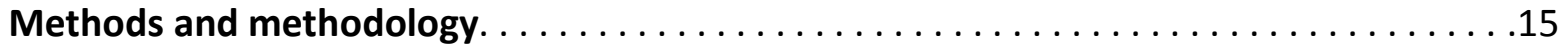

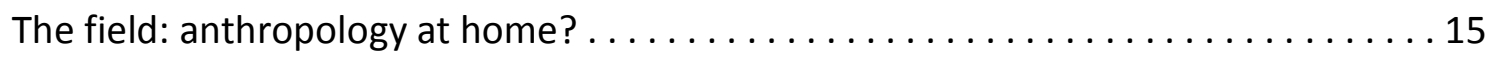

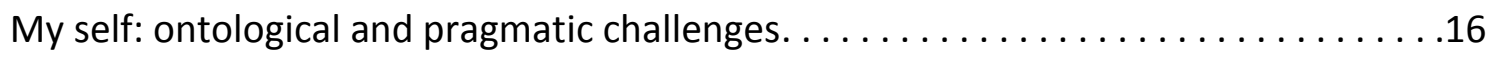

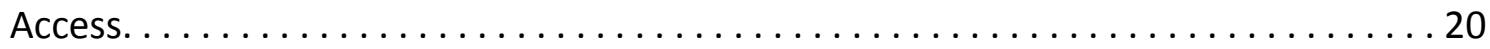

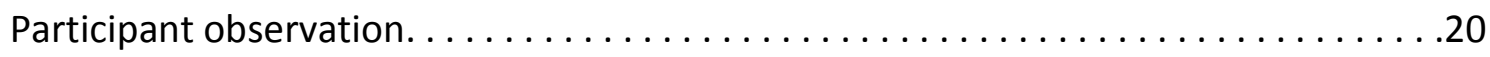

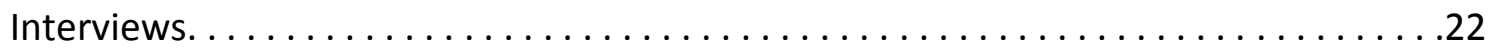

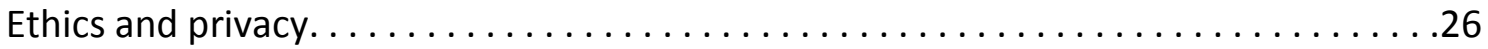

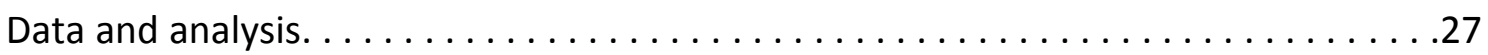

\section{Chapter Three}

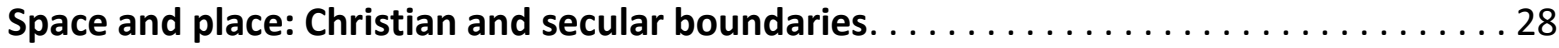

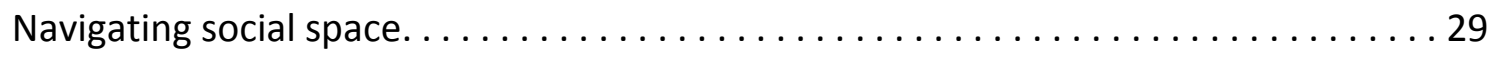

Reproducing and crossing symbolic boundaries - when is a space secular? . . . . . . 32

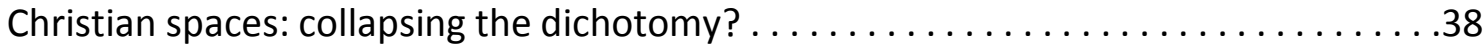

The Prayer Room as resistance. . . . . . . . . . . . . . . . . . .

Conclusion. ........................... 44

\section{Chapter Four}

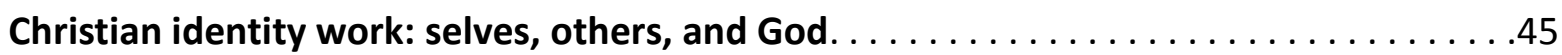

The Looking Glass Self and significant others. . . . . . . . . . . . . 47

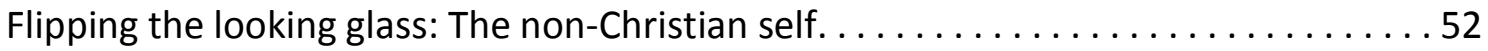




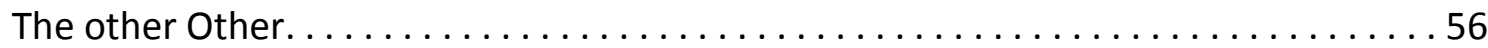

A counter-cultural identity and cultural critique. ................. 58

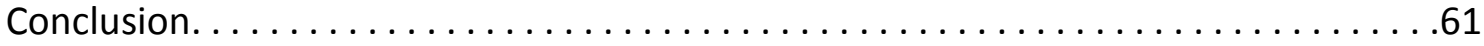

\section{Chapter Five}

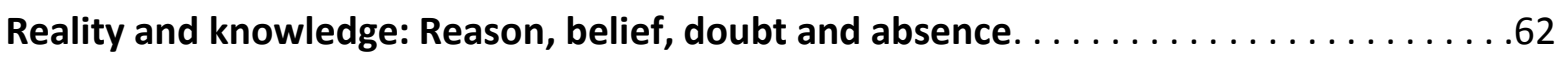

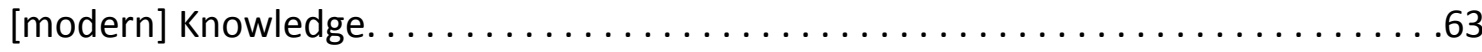

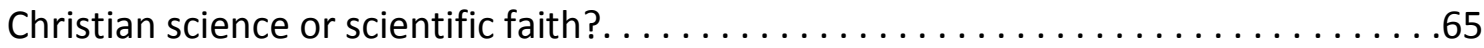

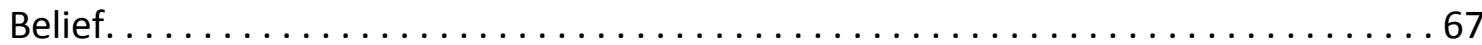

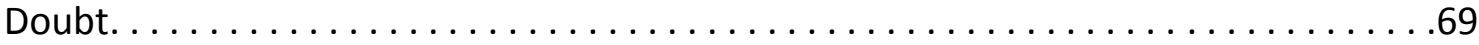

Absence and nonsense. .............................

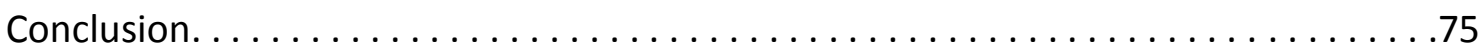

\section{Chapter Six}

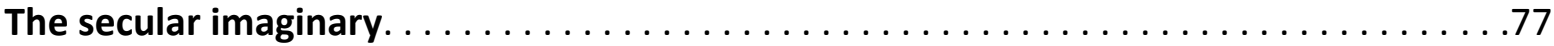

Imaging the Secular. ........................... 77

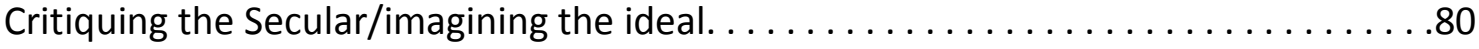

A circular imaginary: constructing a repugnant Other? . . . . . . . . . . . 85

"Christianity can no longer be avoided": the secular imaginary in academic

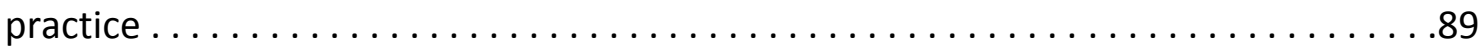

Conclusion: "Because I'm a person and I believe in God, you know? I'm not just a Christian" ....................................... 93

\section{Chapter Seven}

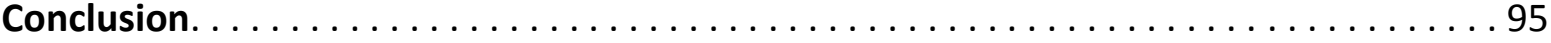

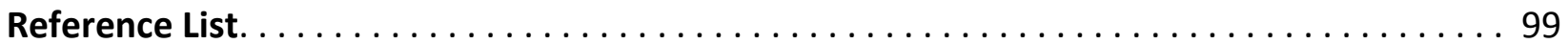




\section{Chapter One}

\section{Introduction}

What is the lived experience of Christianity in an increasingly secular society? With the generous benefit of hindsight, I now see that contained within this overarching research question is a raft of personal, cultural, ontological and disciplinary assumptions. As a non-Christian who until recently had given little thought to Christianity, I wondered what it meant to identify with a faith that was once inextricable from New Zealand's national identity, but which is now declining in adherence, visibility and influence ${ }^{3}$. Of course, implied in this question is that Christianity and the Secular/secularism ${ }^{4}$ are naturally opposed. However, as I conducted fieldwork in a Christian church in Wellington, spoke to Christians in conversation and in interviews, I had this - and many otherassumptions repeatedly challenged.

I realised that for the Christians I spoke to, the distinctions between Christianity and the Secular, faith and reason, belief and knowledge, and spiritual and material were blurred, intertwined, and at times indistinguishable. Rather than seeing Christianity as simply in opposition to the Secular, I began to see Christianity as an inherently emergent phenomenon that "is made and remade through moments of interaction and encounter, rather than a cultural object filled with a particular content" (Garriott and O'Neill 2008, 388). Of course, opposition may be one component of this interaction and encounter, but it does not convey the rich complexity of the relationship between Christianity and the Secular. This thesis therefore seeks to explore how Christianity, notions of the Secular, and discourses of secularism, come to materialise and interact in the lived experiences of Christians in New Zealand.

\footnotetext{
${ }^{3}$ I discuss changes to religious adherence in New Zealand later in this chapter under Context. Of course, visibility and influence are more difficult to quantify; however, there is a wealth of evidence suggesting that Christian-established and/or influenced practices and laws in New Zealand have been subject to secular reform over the last fifty years (Ahdar 2006).

${ }^{4}$ The Secular and its derivatives are theoretically, discursively and culturally charged concepts. As such, when referring to 'the Secular' as an ideological concept, the $S$ is capitalised. When using 'secular' to describe an institution or practice (for example, 'a secular school'), a lowercase s is used. I specify the theoretical underpinnings of the Secular and how I use the concept throughout this thesis later in this chapter under Theoretical Concepts.
} 
My research is based on four months of ethnographic research in a Pentecostal-Charismatic church called Trustpeak ${ }^{5}$, four individual interviews, a group interview with five participants, as well as the numerous conversations that occurred in the margins of my fieldwork. When thinking about whether this is a thesis about Christianity or the Secular, I've come to decide it is about neither, and it is about both. It is about both because of the inherently dialogical relationship between religion and the Secular. As Asad $(1999,186)$ points out, in discourses of modernity, the Secular posits itself as that which has emancipated itself from the "false consciousness" of religion-one cannot refer to secular ideas, nations, or people, without evoking the idea of religion, even if it is only the idea of religion's absence. The concept of the Secular can thus only form itself in contrast to religion. Religion too, particularly Christianity, is deeply implicated in ideas about the Secular and secularism. As Weberian secularisation theses predicting the decline in adherence, visibility, and influence of religion have become central to political and public debate in places like New Zealand, Christians have sought to alter, reject, and resist these theses as they emerge via various discourses, sensibilities, and narratives.

Contemporary Christianity then, must be seen as a phenomenon that has both responded to, and been shaped by, changing ideas about the role and place of religion. Further, Christians in New Zealand, are in many ways 'secular' themselves-they are embedded in secular institutions, engaged in secular practice, and imbued with secular sensibilities. Consequently, a Christian/secular binary becomes rather slippery when applied to individuals. Given this slippage, this thesis is also not strictly about either Christianity or the Secular: it is about how a set of individuals' lived experiences come to be labelled, narrated, and situated in relation to certain categories. I seek to show in this research that these day-to-day experiences-which are categorised as 'religious' or 'secular' dependent on context and who is doing the categorisingchallenge the notion that the concepts of the Secular and Christian have an essential or universal meaning.

\footnotetext{
${ }^{5}$ A pseudonym. After consulting with my participants and Trustpeak's pastor I decided to use a pseudonym for the church to protect its privacy.
} 


\section{Background}

One day a university colleague dropped by my office to introduce me to another new student, who asked me what my research topic was. I was still narrowing down my research questions at this stage, so I told her "Christianity in New Zealand", and that I was doing fieldwork with a PentecostalCharismatic church. The new student was intrigued by this and said I would probably be interested in a South Korean cult who had been recruiting students at Auckland University through means of deception and manipulation. My colleague added that she had a connection to a Christian cult, noting that a family friend converted to Christianity, joined a cult up North and hasn't been heard from in 30 years. At this point, they turned to leave my office, but on the way out they both solemnly cautioned me to "tread carefully".

I began my research interested in megachurches and consumerism; however, as I canvassed the literature in the Anthropology of Christianity, and experienced conversations like the one outlined above, I became less interested in consumerism, and more interested in how assumptions and sensibilities about Christianity shaped, or were seen to shape, the experience of being Christian. When I spoke to congregants at Trustpeak at the beginning of my research, it became apparent that the ways non-religious others perceived, narrated, and labelled them played a central part in their experience of being Christian in New Zealand. Of course, Christianity is not homogenous, and experiences of Christianity will be shaped not only by particular denominations, but also how that denomination interacts with the surrounding social and cultural context. I came to be interested in the Pentecostal variety of Christianity for several reasons. Firstly, according to secularisation predictions, denominations like Pentecostalism seemed the least likely to survive processes of modernisation. Not only has Pentecostalism continued, but in regions like Africa, Latin America, Asia, and Oceania it has flourished (Robbins 2004a, 114). Likewise, in New Zealand, the Pentecostal branch is one of the few Christian denominations that have experienced an increase in adherence amongst a considerable drop in both Christian and religious adherence overall ${ }^{6}$. Secondly, the reasons why secularisation theses predicted denominations like Pentecostalism to struggle-a

\footnotetext{
${ }^{6}$ I provide more information on religious adherence in New Zealand later in this chapter under Context.
} 
literal interpretation of the bible, the enchantment of daily life, and the cultivation of a close relationship with God-make churches like Trustpeak an intriguing ethnographic object.

Thus, the role of secular perceptions, labels, and narratives quickly emerged as significant to how my participants experienced and thought about being Christian in New Zealand. Consequently, my guiding research questions became: How do Christians engage with secular individuals, institutions, and ideas? What role does the secular play in the construction of Christian identities? Where, how, and why does the secular come to exist for Christians, and how does this shape the experience of being Christian? Finally, what connections can be drawn between Christian experience and the wider discursive context of modern, liberal, society?

\section{Setting the scene}

Trustpeak is an inner city Pentecostal-Charismatic Christian church, located on a quiet street in a residential-cum-industrial area of Wellington, New Zealand. It is likely far from what many people imagine when they hear "church". The building is part of a large, but modestly fitted complex, with the church itself on the second floor. Sunday services take place in a large hall, the kind reminiscent of a community hall you find in most small New Zealand towns. The room is devoid of any obvious religious iconography, apart from a rather large abstract portrait of a lamb above the stage. The hall is far from sterile, however: the walls are adorned with photographs and storyboards that narrate mission work done by the church and partners, and display the church's values and motto. The pastor described Trustpeak to me as very "low-church", referring to the church's minimal ornamentation and lack of formalised ritual ceremonies, compared to what one might find in a Catholic cathedral, for example. Next to the worship hall is a rabbit warren of rooms and hallways which includes the Prayer Room ${ }^{7}$, children's rooms, a reading room, restrooms, a large kitchen, and a series of offices. Early into my fieldwork I excused myself from the sermon to use the restroom-located down several halls and turns away from the main room-and had to use the sound of worship song emanating from the congregation to guide me back. On a typical Sunday morning, I would buy coffee on my five minute walk to church from home, and arrive just before the service began, collecting a pamphlet about the morning's service and week's notices. Settling

\footnotetext{
${ }^{7}$ This is discussed in more detail in Chapter Three.
} 
into a chair (no pews here), I'd almost always be greeted with a smile, and some small talk about my week-or if they knew me, about how my research was going. The service usually began with worship song, led by a band on the stage, but participated in by the whole congregation. After about 60 to 90 minutes of worship song, church notices, prayers, periods of silence, and a sermon, the coffee and tea that had been bubbling away at the back of the hall was served to the congregation by weekly-rostered volunteers. Over coffee and biscuits, small groups would form to talk about what they learnt from the sermon, pray for one another, take rest if it was a particularly involved service, or just chat-before slowly dispersing to a church member's house for lunch, or to continue their Sunday elsewhere.

\section{Context}

Before I locate my research in the anthropology of Christianity, it is necessary to situate Trustpeak and its practice in the surrounding Christian landscape, and a New Zealand context. In order to do this, and to provide the reader with a referential framework for what my participants mean when they evoke certain concepts and ideas, this section attempts to provide some working definitions of Christian denominations and affiliations. It does not seek however, to develop a robust taxonomy of Christian denominations, as this would be a near impossible task. Defining exactly what constitutes 'Pentecostal' or 'Charismatic' in relation to other possible 'types' of Christianity (whether that be those demarcated as denominations, affiliations or movements) is a project fraught with challenges, because the term 'Christianity' is itself problematic and highly unstable (Garriott and O'Neill 2008). Some anthropologists even express suspicion that there is one thing called Christianity, and discussions in the discipline tend to operate on the basis that "at best we are dealing with Christianities rather than with Christianity, and that at worst these Christianities really have rather little in common with one another" (Robbins 2003, 193; emphasis added). Hence, the debate around what constitutes Christianity is itself a core theme in the anthropology of Christianity.

It would come as no surprise then that the use of Christian labels has not been standardised in either anthropology or social science research (Robbins 2004a). The terms 'Pentecostal' and 'Charismatic' could be used to refer to quite dissimilar formations of Christian worship. However, inconsistent label usage in the anthropology of Christianity is not simply due to lack of 
standardisation by anthropologists - the use of labels by Christians themselves are highly inconsistent, and often loosely discursive. To identify and label oneself as a certain type of Christian is not simply a shorthand for specifying particular religious doctrine, but is also part of a multifaceted project comprising historical, political, cultural and economic elements. Christian labels therefore represent complex negotiations, strategies and narratives by various groupsincluding anthropologists and most importantly, Christians themselves (Marshall 2014, 345).

With these caveats and nuances in mind, there are some loose boundaries that we can sketch out of a Christian topography. The three major branches of Christianity are Roman Catholic, Eastern Orthodox and Protestant. Protestantism is the second largest, comprising 800-900 million people (Pew Research Center 2011), and easily the most diverse branch. It includes Baptist, Methodist, Anglican, Lutheran, as well as Pentecostal. In turn, Pentecostal Christianity is the largest of the Protestant branch and is often associated with the following 'streams': neo-/charismatic, born-again, Evangelical, Fundamental, prosperity, emerging, and emergent. These streams are not neatly distinguished formations of Pentecostalism, and each could be used interchangeably or hyphenated as hybrid forms in various contexts (for example, Hovland (2016) refers to the Vineyard church as a nondenominational, neo-Pentecostal church planting movement that is evangelical in theology but charismatic in worship style). Further, what these streams see as their defining feature may not be a theological position, but a political and/or cultural one.

While there are no doubt significant and at times tangible differences between these streams, it is possible to make some generalisations around the high-level similarities which thematically link churches within a Pentecostal grouping. For example, Pentecostal churches generally value cultivating a direct and intimate relationship with God, spontaneous worship styles, egalitarian congregation structures, and prayer through song and music. They tend to practice adult baptism ${ }^{8}$, embodied spiritual experiences such as speaking in tongues, and believe in divine intervention. In contrast to more liturgical branches of Christianity ${ }^{9}$, Pentecostal churches tend to avoid spiritual

\footnotetext{
${ }^{8}$ This emphasises the role of choice and agency in choosing to be born again.

9 'Liturgy' tends to refer to more ritualised forms of Christian worship, such as those found in Catholic or Orthodox traditions.
} 
intermediaries ${ }^{10}$ and formally ritualised ceremony. Trustpeak, which identified as a PentecostalCharismatic church, emphasised all of these to varying degrees.

There are two opposing points to make here: every church, as a distinct and unique community, will practice Christianity differently. We must therefore be careful not to extend the teachings, practice, or discourse of one church or group to others, or to Christianity in general. However, as discussed later in Chapter Three and Four, the term 'Christian' is also culturally significant - thus, while it is important to distinguish between Christian denominations in academic discussion, this distinction will likely not be made by others in a social context. In other words, while Trustpeakers' Pentecostalism is significant to them and (at times) this thesis, we must also recognise that in their conversations and interactions with non-Christians or in secular contexts, the general category 'Christian' is likely the one that is at play, not 'Pentecostal' or 'Charismatic'.

The number of individuals stating adherence to a Christian faith has dropped considerably over New Zealand's history; the 1912 census recorded Christian adherence at 95.71\% (Statistics New Zealand 2013), in 2001 this number was at 60\%, and by 2013 had dropped to $48.9 \%$ (Statistics New Zealand 2014). Correspondingly, those stating adherence to no religion has increased; in 2001 $29.6 \%$ claimed adherence to no religion, in 2006 this sat at $34.6 \%$, and by 2013 this was $41.9 \%$ (Statistics New Zealand 2014). While Christian adherence in New Zealand has been steadily declining, almost half of the population still claim adherence to a Christian religion. Although some non-Christian religions have experienced relative increases in New Zealand ${ }^{11}, 90 \%$ of the population either claim adherence to Christianity or to no religion, meaning that the religious landscape in New Zealand is considerably polarised. The debates about religion and secularism are therefore likely between, or in relation to, these two groups.

Determining the number of New Zealanders who adhere specifically to a Pentecostal branch of Christianity is challenging, primarily as a result of the aforementioned challenges of delineation and definition. For example, census data shows that there has been a $6.2 \%$ decrease in adherence to Pentecostalism between 2006 and 2013, yet "Protestant not further defined" shows a 26.4\% increase, "Evangelical, Born Again, and Fundamental" shows an 11.2\% increase and "Christian not

\footnotetext{
${ }^{10}$ Such as saints or priests.

${ }^{11}$ Over the last 10 years, some non-Christian religions, such as Muslim, Sikh, and Hindu have all experienced significant increases relative to immigration trends (Statistics New Zealand 2014).
} 
further defined (Christian but with no denomination specified)" shows a 6.1\% increase (Statistics New Zealand 2014). As previously stated, Evangelical, born-again, and Fundamental all fall under the Pentecostal branch of Christianity, so these statistics are not particularly helpful. As adherence to all 'mainstream' branches of Christianity (Catholic, Anglican, etc.) in New Zealand have all experienced a decrease in adherence, all we can meaningfully gauge from this data is that churches like Trustpeak are likely experiencing an increase in popularity relative to liturgical or traditionorientated churches.

Turning to the global context, adherence to Pentecostal/Charismatic Christianity in 2002 was placed at approximately 250 million (Martin 2002), and by 2011 was estimated to have at least 600 million followers worldwide (Robbins 2004a). It is undeniably the fastest growing branch of Christianity in the world. Arguably, it is this sudden and unexpected worldwide explosion of Pentecostal, Charismatic, Evangelical and Fundamentalist Christianities, combined with their parallel (re)emergence into the public and political spheres, that has prompted the very recent solidification of the anthropology of Christianity into a sub discipline (Bialecki et al. 2008) ${ }^{12}$. Somewhat surprisingly, "Christianity was the last major area of religious activity to be explored in ethnographic writing" (Cannell 2006, 8), and while there have been a small number of exceptions, Christianity was largely ignored within the anthropology of religion until the last 15-20 years (Bialecki et al. 2008, 1140). Further, as Robbins $(2003,191)$ points out, there is a distinction to be made between Christianity becoming a more frequent object of study in anthropology, and the development of the anthropology of Christianity as a "self-conscious, comparative project".

Indeed, anthropologists in this field have been particularly reflexive not only in thinking about why Christianity has been neglected, but also considering the ways in which anthropology itself has been shaped by Christianity (Robbins 2014, 159). As Jenkins $(2012,466)$ points out, there is a double relationship between Christianity and anthropology which problematises the disciplinesocial science discourse tends to marginalise Christian practices while being itself the product of Christian thought. Susan Harding (1991; 2000), whose work on US fundamentalism and language has been one of the catalysts for the growth of an anthropology of Christianity, argues that

\footnotetext{
${ }^{12}$ This has also lead to criticisms that the anthropology of Christianity has unwittingly established itself as the anthropology of Pentecostalism, neglecting other forms of Christianity such as Catholicism and Eastern Orthodoxy (see, for example, Hann 2007).
} 
anthropologists must be critical of the discursive nature of the categories we use to understand fundamentalism, and Christianity more broadly. Following Harding, the ethnographic focus on Christianity has become incredibly diverse, including; prosperity, money, and the economy (Bielo 2007; Keane 2007; Comaroff 2009); speech, language, and semiotics (Coleman 2006; Keane 2002); conversion and rupture (Robbins 2010; Engelke 2004; Daswani 2013); the interaction between Christianity and local culture (Robbins 2004b; Whitehouse 2006) as well as social outreach (Elisha 2011), disaster relief (Fountain et al. 2004), doubt (Luhrmann 2012), ritualisation (Lindhardt 2011), and the role of media (Meyer 2004). Some have focused their work on particular movements, such as the Emerging Church (Bielo 2011) and the Vineyard (Bialecki 2017), or on Christianity in certain types of space, such as urban contexts (Strhan 2015; Elisha 2010).

Despite the breadth and depth of ethnographic focus in the anthropology of Christianity, very few anthropologists have explored the relationship between Christianity and the Secular, particularly how Christians conceptualise, contribute to, or resist secular idea(I)s. As Asad (2003, 21) notes, "anthropologists have paid scarcely any attention to the secular". This is exemplified by Robbin's (2014) review article on the future direction of the anthropology of Christianity, in which he not only briefly mentions the Secular and only refers to one ethnography focused on secularismEngelke's (2014) fieldwork on secular humanists in Britain. Although Cannell's (2010) call for more ethnographic exploration of lived experiences of the Secular indicates there is appetite for this work, there remains no coherent 'anthropology of secularism', nor is there a dedicated focus on the Secular in the anthropology of Christianity (Lebner 2015). Further, it is worth making explicit that the study of secular people is a different focus from how the Secular comes to shape, impact, and exist in people's lives.

Of particular relevance to my research has been scholarship within the anthropology of Islam which has explored Islam's relationship with the Secular and secularism ${ }^{13}$. While anthropologists should be cautious of comparing potentially polarised religions and cultural contexts, a number of

\footnotetext{
${ }^{13}$ A number of factors likely contribute to the presence of anthropological work that specifically explores the Secular and Islam, and not Christianity. First, the anthropology of Islam is more mature than the anthropology of Christianity. It arguably originated as a focus in the anthropology of religion in the late 70s, and experienced rapid growth thereafter (Robbins 2003, 191). Secondly, given that secularism is intimately linked to the West and processes of colonisation (Cannell 2010, 89), exploring the 'influence' of secularism on Islam and Muslim cultures is arguably more intuitive than its relationship with Christianity.
} 
authors in this area have shaped my thinking in writing this thesis. Göle's (2002) examination of the visibility of Islam in non-Western public spheres illustrates the ways in which the Islamic subject is shaped by, but also resists, the discursive role of secularism in public domains. Jouili (2009) also focuses on the visibility of Islam, in Germany and France, and way that Islamic women subvert secular sensibilities through micro-practices of religion. Finally Mahmood's (2009) discussion of free speech and Islamic blasphemy encouraged me to be cognisant and critical of the ways in which taken-for-granted sensibilities about both religion and secular reason can be deeply political, normative, and discursive.

Thus, while my research is firmly located within the anthropology of Christianity, I have also engaged with a number of interlocutors from other disciplines, and anthropologists whose work has been focused on non-Christian religions. In attempting to show how daily lived experience reveals the reciprocal, entwined, and interrelated nature of Christianity and the Secular in New Zealand, this thesis contributes to both the anthropologies of Christianity and secularism, and provides an ethnographic account of religious experience in New Zealand.

While my research draws on the literature discussed above, and the theory presented in the following section, I have taken heed from Garriott and O'Neill's $(2008,383)$ proposal that anthropologists studying Christianity should adopt a dialogical approach to their participants, and focus on "the problems posed by Christianity to Christians themselves" (emphasis added).

\section{Theoretical concepts}

The concept that most prominently informs and shapes this thesis, and the one that is arguably the most elusive, is that of 'the Secular'. The concept of the Secular, and its derivatives (secularism, secularity, and secularisation), is difficult to define because it has been formative of Western academic theories of social change, subsumed into normative discourses, and, at the same time, used as a neutral descriptor of social activity and processes. In this section I seek to establish a working framework for the use of the Secular throughout this thesis.

Contemporary dominant understandings of secularism generally define it simply as "the absence of religion", a definition influenced by Weberian and Durkhemian-inspired theories of 
secularisation (Engelke 2014, 294). These secularisation theories position secularism in evolutionary terms; namely, that secular nation-states are the inevitable outcome of a process of human advancement, modernisation and rationalisation ${ }^{14}$. Consequently, the Secular has come to be seen, especially in Western societies as the "taken-for-granted normal structure of modern reality" (Casanova 2009, 1052).

In academia, the Secular, secularism, secularity, and secularisation are highly unstable concepts. Their meanings, origins, and relationships to one another have been subject to rigorous debate across a broad range of disciplines (Cannell 2010, 86). While secularism has been the object (or outcome $!^{15}$ ) of academic scrutiny since the enlightenment, there has been a recent resurgence in interest in academia (Gorski et al. 2012) - coalescing around watershed works such as Formations of the Secular (Asad 2003) and A Secular Age (Taylor 2007). While obviously related, for Asad $(2003,1)$, the Secular and secularism are not synonymous-he argues that the Secular is an epistemic category that is regulated by secularism as a political doctrine.

Thought of in this way, the Secular is "a space of thought and practice" (Lebner 2015, 63), a realm of existence which is constructed as distinct from a religious realm (Casanova 2009, 1049). In Asad's $(2003,16)$ formulation, the Secular is thus discursively prior to secularism -it is a concept which brings together a certain collection of "behaviors, knowledges, and sensibilities in modern life"-and consequently, it is both a domain of thought and practice "operating at some remove from the state" (Lebner 2015, 63). While the Secular must be seen to operate in lived practice, Asad $(2003,255)$ also argues that secular nation states are not simply 'neutral' social arrangements that have managed to emancipate themselves from religion, but rather they represent "a complex arrangement of legal reasoning, moral practice, and political authority". Accordingly, we must recognise how both the Secular, as an idea, and secularism as a doctrine, operate as forms of discursive power (Asad 2003). In contrast to Asad (2003), Taylor (2007) sees the secular as a condition, not an epistemic category or expression, which he refers to as secularity. Taylor (2007) argues that what denotes secularity, at least in the West, is not the absence of religion, but that it

\footnotetext{
${ }^{14}$ Particularly in science and technology.

${ }^{15}$ Some scholars have suggested that the focus on secularism, particularly the multitude of secularisation theories that emerged in academia in the late nineteenth and twentieth centuries, have become a self-fulfilling prophecy, in that they possibly caused the phenomena they sought to predict (see Cannell 2006).
} 
provides the conditions which allow non-belief to be a viable option among many options. The Secular therefore "is not simply a remainder; it is a sum, created by addition, a product of intellectual multiplication" (Smith 2014, 26).

As a result of the persistent (and in some areas of the world, increasing) adherence to religion, most academics of religion and/or secularism consider secularisation- either as an accurate description of modern society over the last 100 years, or as a future prediction - to have been thoroughly debunked (Bandak and Jørgensen 2012). The failure of secularisation theories to account for the current state of religion in the world has led many academics to take a post-secular perspective in their analysis, which "accepts that the dominant secularisation theses have been destabilised and that this means the role of religion in modernity may have to be rethought, sometimes substantially" (Lyon 2010, 648). Arguably the most notable of post-secularists, Jürgen Habermas (2008), argues the post-secular society refers to a change in consciousness brought about by the persistence of religious presence, belief, and influence, and the pluralism fostered by worldwide immigration trends.

While in many ways I take a post-secular perspective throughout this thesis, and am informed by the theoretical debates discussed above, I have been cautious of extending this beyond an academic context where it may not apply. In other words, although theoretical formulations of the Secular and secularism are useful analytical tools, I have avoided over-theorising concepts that are also operating within the 'common-sense' framework applied by Trustpeakers. It is precisely the common-sense, popular understandings of the Secular that are the most accessible and relevant to Trustpeakers as embedded citizens in a secular liberal nation-state. Thus, I use 'the Secular' in this thesis as cultivated by Asad: as both a discursive, conceptual domain, and one that is embodied in everyday lived practice, which lends to thinking about the world in particular ways ${ }^{16}$. Consequently, I explore my participants' understandings, narratives, and imaginings of the Secular-which are periodically from secular, Christian, or hybrid vantage points -, and locate these in a wider discursive context. This has enabled me to understand how Trustpeakers' day-today experiences comes to be labelled, narrated, and situated in relation to categories like secular,

\footnotetext{
${ }^{16}$ Defined in this way, 'the Secular' could also feasibly include 'secularism'; however, I have tried to use 'secularism' when referring specifically to secular doctrine, or institutionalized secular discourse.
} 
Christian, and religious-without a priori applying these categories in their hegemonic formulation. In Chapter Six I extend Asad's (2003) notion of the Secular, in tandem with Taylor's (2004) concept of the social imaginary, to develop the idea of the Secular as a secular imaginary.

\section{Chapter outlines}

The next chapter details my methods and methodological approach in undertaking this research. I discuss how I positioned my fieldwork through asking reflexive questions about anthropology at home, how to approach my participants' ontological claims, and the role of the self in ethnography. In this chapter I attempt to honestly examine how my position as a non-Christian has directly shaped my research and research questions, but has also served as a legitimate ethnographic resource. I detail how the ethnographic material obtained via participation observation, group and individual interviews, and my own reflections was complementary, stimulating, and layered.

In Chapter Three, I introduce how Christianity and the Secular come to be categorised and experienced as such through a spatial analysis of my participants' day-to-day life. I explore the tension between the perceived expectation that faith is excluded from most public and social spaces, with the fact that the binaries which inform this distinction-religious/secular; private/public; sacred/profane-are not always intuitive to Trustpeakers as PentecostalCharismatic Christians. I argue that my participants problematise in their narratives, and challenge them through micro-practices of resistance.

Chapter Four explores Christian subjectivity, identity and identity work. I show how my participants' identity work is deeply dialogical and involves the ongoing negotiation and navigation of real and imagined expectations of the Christian self by a range of actors. Core to Trustpeakers' identity work was balancing the desire to dispel or minimise actual and perceived secular-based misunderstandings of Christianity and Christians, with a desire to also set themselves apart as counter-cultural. In this chapter I argue that to be Christian in New Zealand is to be in conversation with, and attempt to redefine, secular-applied labels, values, beliefs and sensibilities. 
In Chapter Five, I explore the distinctly Christian ontological reality of my participants and the ways in which claims about this reality are both narrated and experienced as true. Rather than justifying, explaining, or rationalising these claims, I attempt to show how in collapsing the distinctions between intellectual or scientific 'knowledge' and spiritual 'belief', Christian experiences, and conceptualisations of the world, present interesting epistemological and ontological challenges. I argue that Trustpeakers demonstrate that alternative ontological realities and epistemological tools to understand those realities, can be found 'inside' the West, and do not have to be monolithically unique in order to be alternative.

Chapter Six is a theoretically reflexive discussion in which I reframe the preceding three chapters. I argue that Trustpeakers actively participate in the construction and maintenance of the Secular, and that they do so via what I refer to as a secular imaginary. This imaginary is the means by which people conceptualise their social existence as secular. I show that the participation in this imaginary demands a reformulation of how we position religious actors in relation to the Secular. I conclude this chapter by suggesting that while the secular imaginary is maintained by both religious and secular others, it remains a structure with discursive power. Hence, I also seek to explore the ways in which this imaginary can be seen to operate on my participants, highlighting the discursive role of anthropology in the enactment of this imaginary. 


\section{Chapter Two}

\section{Methods and methodology}

In this chapter I detail the advantages, limitations and challenges of the methodological approach I employed in this research. In particular, I discuss on how my fieldwork has prompted me to reflect on the nature of anthropology at 'home', and the pressures this can exert on the (anthropologists') self. As a non-Christian living in the same social world as Trustpeak congregants, I often felt that I was either too culturally proximate to them, or not enough. Unhelpfully, I found that much of the literature on doing anthropology at home assumed that the researcher was culturally intimate with their participants and inadvertently reified categories of 'home' and 'away'. In addition, as this research is focused on ideas, narratives, and everyday experiences, rather than more traditional foci in anthropology of religion ${ }^{17}$, at times I felt anxious about where and what my field actually was. Since finishing my fieldwork however, I have come to think of the field in terms of a "play of social relationships established between ethnographers and informants" (Coleman and Collins 2006,12 ) instead of a physical location or place. Thus, the aims of this chapter-in addition to specifying how I did my fieldwork-is to show that anthropology at home does not always entail familiarity, and can generate its own unique set of challenges when it does not. I also illustrate that my position as a non-Christian in this research was not simply a limiting one. Although being non-Christian certainly shaped this research in particular ways, I argue that, at times, being non-Christian was also methodologically productive. Hence, this chapter also seeks to show how my self has served as an ethnographic resource in carrying out this research.

\section{The field: anthropology at home?}

From a physical standpoint, this research was conducted 'at home'. My participant observation took place about five minutes' walk from my apartment, and the interviews I conducted all occurred in the same city; a city I've lived in for almost a decade, in the country of my birth. Beyond the physical context, my participants and I also share many cultural resources and connections-

\footnotetext{
${ }^{17}$ Such as rituals, symbols, or transcendence.
} 
such as language, demographics, and social practices. Despite this familiarity however, I am not a Christian, nor was I particularly familiar with Christian culture, doctrine, or practice when I began this research. As such, my fieldwork felt misplaced within a traditional mode of anthropology at home because I did not have intimate knowledge of, or a cultural affiliation with, the group I was studying. I do not want to flog the proverbial dead horse when it comes to discussing - or perhaps reminding - that the field is always constructed by the anthropologist (Coffey 1999, 23); however it is worth noting that anthropology at home tends to be still be defined as fieldwork conducted in "the context studied by any ethnographer when working on his or her 'own' culture" (Coleman and Collins 2006, 9). Problematically, it is often spoken about in the same context as native anthropology and insider anthropology. These types of "endo-ethnography" (Van Ginkel 1998), despite requiring quite different epistemological approaches, are often used interchangeably due to the emphasis placed on the physical location of the research (see, for example, Gallinat 2010).

As I discuss throughout this chapter, having a shared cultural context with my participants did not necessarily prescribe ease of research. If there is specific epistemological terrain to be navigated when doing fieldwork with a group or society that one is intimately familiar with, as Ryang (1997) points out, then there must also be specific-and separate-epistemological and pragmatic challenges with studying a group who are embedded in the same society as the anthropologist, but who are, in many ways, also deeply foreign. Thus, in response to Van Ginkel's $(1994,5)$ provocation "Does speaking of anthropology at home (here) and abroad (there) create a meaningful distinction or a false dichotomy?", I would suggest that while there are significant differences between conducting fieldwork abroad and at home, we should not assume that anthropology at home is homogenous, or that it inherently entails shared familiarity and intimate knowledge. For me, doing research at 'home', in a context that was at once familiar and strange, emphasised the role of the self in fieldwork.

\section{My self: ontological and pragmatic challenges}

Writing about the significance and impact of biography and the self on fieldwork has become almost cliché in contemporary anthropology. It is conventional to acknowledge that one's "facesheet" characteristics (Coffey 1999, 4) have impacted and shaped our fieldwork-however, 
acknowledgement is often where this discussion ends. Although a number of anthropologists have made the self present in their ethnographic writing since the 1980s (Collins and Gallinat 2010,4), the impact of biography is rarely accounted for in conducting fieldwork (Van Ginkel 1994, 8), and issues of "identity, selfhood and emotionality" are rarely centered in anthropology (Coffey 1999, 1). Acknowledgement of the self consequently tends to serve as a claim of ethnographic legitimacy, by focusing on how the anthropologist's biography shapes and impacts the field and data (Collins and Gallinat 2010, 4). That is, 'the self' becomes synonymous with bias, and the ethnographer must explain how that has impeded or constrained their objectivity. I am not suggesting anthropologists should not be reflexive or identify possible bias, but I have been conscious of Lynch's (2000) critique that simply being reflexive does not necessarily achieve or do anything simply by virtue of it being done. As such, below I attempt to show how my status as a non-Christian, and thinking about that status, was not only something to be recognised as a 'constraining' force, but was also ethnographically productive.

The relevance of my non-Christianity was most apparent in thinking about how I should approach Trustpeakers' ontological claims about God. Bielo $(2015,34-42)$ outlines the core methodological approaches to studying religion in anthropology; methodological atheism (questions of truth are bracketed); methodological agnosticism (questions of religious truth are unknowable); methodological ludism (religious truth claims are engaged with 'as if' they were true); and methodological theism (religious truth claims are knowable to the anthropologist). Methodological atheism, a stance popularised by the famous sociologist of religion Peter Berger, is "the default position in the anthropology of religion" (Bialecki 2014, 34). With this approach, the anthropologist does not engage with religious truth claims, except to explain their human or social cause (Bielo 2015, 34-35). Such a stance is problematic as it necessarily entails a series of ontological assumptions: that 'reality' must conform to a naturalist framework in order to be 'true', and that "agency is to be located solely in human agents, and that human creations cannot exceed the capacities endowed by their creators" (Bialecki 2014, 34). Consequently, religion becomes "entirely subsumed within a materialist framework" (Fountain 2013, 314) in which the anthropologist seeks to explain what religious belief and experience is 'actually' about. The problem of methodological atheism is exemplified by the fact that God is not mentioned in most research in the anthropology of Christianity (Bialecki 2014). As discussed in Chapter Four and Five, God is a social actor in my participants' lives; He exists for them, even if I do not believe in Him. 
Hence, I have attempted to approach my fieldwork and writing process from a stance of ludism, which Droogers $(2002,53)$ defines as "the capacity to deal simultaneously and subjunctively with two or more ways of classifying reality". This approach "implies a double view of reality" (Droogers $2002,53)$, and does not seek to resolve contradictions or paradoxes, but treats different versions of reality as though they were true. For my participants, their limits of reality allow the existence of a Christian God, while the limits of my reality do not-but both realities 'exist'. Ludism enabled me to have both an etic and an emic perspective and to "render judgment where necessary from one or both of these perspectives" (Yong 2012, 27). Further, Ludism was an appropriate stance for me because as Droogers $(2002,62)$ highlights, and as I discuss in Chapter Five, religious practice is in itself ludic. Trustpeakers also traversed multiple realities in their lived experience of being Christian in New Zealand, and thus 'bracketing out' the aspects of my research which / categorised as religious truth would not only distort their reality, but would also not necessarily align with what they saw as being religious and non-religious truth. Accordingly, I have taken inspiration from Susan Harding's (2000) research experience and tried to embrace spaces of discomfort, ambiguity and subjectivity throughout my fieldwork. As she states:

"I was given to think that my credibility depended on my resisting any experience of bornagain belief. The irony is that this space between belief and disbelief, or rather the paradoxical space of overlap, is also the space of ethnography. We must enter it to do our work" (Harding 2000, 58).

A ludic approach did not absolve me from a whole raft of challenges-straddling multiple realities or, rather attempting to, is not easy. As there was nothing to visually mark me as a non-Christian, revealing my status as such was at times ethically and pragmatically problematic. Due to the relatively small size of the church, for most congregants, it was obvious I was new, and therefore a target for welcoming and friendly questions about myself-namely what church I had attended previously, and how long I had been a Christian. Consequently, I tried to introduce my status as a non-Christian as an early into conversations with congregants as possible, but despite my best efforts, I did not always get an opportunity to do so. Further, in some contexts (such as a group situation) I had to make judgement calls about when and how to announce that information. For some congregants, the revelation that I was not Christian was noticeably unsettling, and they would hastily, albeit politely, withdraw their contact. Claiming status as a researcher in and of itself 
necessarily creates distance between ethnographer and participants; however, there is no doubt that my relationships would have been vastly different if I identified as Christian. Indeed, the first time I attended Trustpeak, a church elder cheerfully informed me "I don't care if you judge us" it was clear this statement was directed at me in my capacity as a non-Christian, not as an anthropologist. As I discuss later in this chapter, while being non-Christian meant that I was, at least initially, treated with some caution, it also meant that for some congregants I was someone to be educated, an interested party, and/or a potential convertee. This third status of convertee at times made fieldwork challenging. As Coleman $(2008,43)$ points out, it can be emotionally and methodologically difficult studying Pentecostal Christianity, because your participants likely have an interest in seeing you convert or being saved. On more than one occasion I was told by members of the congregation that they wished for me to find God, that I had been brought to the church for a purpose; and, in striking resemblance to a conversation Harding (2000) had with a reverend, that I would let God into my heart.

During one period that I was feeling particularly immersed in the church I had several disturbing dreams, including a rather graphic dream about the crucifixion of Jesus. The experience of particular dreams after cultural immersion is not uncommon in fieldwork, and is seen by some anthropologists as an adaptive response to being in the field (Ewing 1994, 571). While I did mention the dreams to a few friends and family, I did not tell anyone from church. It is only in hindsight that I think this was due to a-likely unfounded-concern that they would assign significance to the dreams which would undermine my position as a researcher; either that they would interpret the dream as a religious experience or message, or consider the dreams as evidence that I was inviting conversion. Given my methodological stance of ludism, if I had told my participants about my dreams and they had responded in such a way, this would not have been particularly problematic - I could consider the two realities (just a dream, and a divine message from God) simultaneously. But I did not tell my participants, and this highlights the unconscious decisions we might make during research due to our own biases, fears, or stances. As fieldwork is "personal, emotional, and identity work" (Coffey 1999, 1), the pragmatics of conducting research, especially in areas that might make us feel uncomfortable, are often much more complicated, messy, and instinctual than we would like to admit. 


\section{Access}

As Sikic-Micanovic (2010) discusses, access is not simply an issue of practicality, but how it is gained also shapes the trajectory, substance, and outcome of fieldwork. I contacted a number of charismatic and/or Pentecostal churches about my research, and obtained a meeting with the pastor of Trustpeak, Joel ${ }^{18}$, to discuss my fieldwork. He expressed interest in my topic, and we agreed on a trial period where I could come along to church to see if it was something that was going to work for both of us. After discussing my ethical approach, Joel (in consultation with the leadership team) agreed that I could continue my fieldwork with them, on the condition we would continue to meet periodically to resolve any issues that might arise. With respect to access to individual participants, it was important to Trustpeak leadership that I obtained research connections and interviewees through my own relationship cultivation. This occurred mostly during and after church services, and occasionally over coffee.

\section{Participant observation}

I spent about four months conducting participant observation at Trustpeak ${ }^{19}$. This involved attending Sunday worship services, Wednesday worship evenings, and other meetings and events outside of church. I participated in almost everything a regular Trustpeaker would do: I attended services, sang worship song, went on the coffee roster and participated in group chat. I did not pray during prayer sessions, although I did allow others to pray for me if they asked. In talking to several leaders at church, we agreed that I would not attempt to pray for others.

Throughout my fieldwork, 'participant observation' sounded like an odd, ill-fitting, and clinical way of describing what felt to me like getting to know Trustpeak and its people. I think this was primarily due to the fact that the focus of my research couldn't necessarily be observed at church, and I was faced with justifying not only to myself, but also to Trustpeak congregants exactly why I was there. I see now that the months of conducting participant observation were invaluable. My interviews would have almost certainly produced different data had I not attended Trustpeak, and

\footnotetext{
${ }^{18}$ A pseudonym.

${ }^{19}$ I obtained ethics approval from the Victoria University Ethics Committee for this project in March 2017.
} 
this was not only because it allowed me to build rapport beforehand. As Shah $(2017,47)$ argues, "participant observation enables us to understand the relationship between history, ideology, and action in ways that we could not have foreseen, and indeed, attending church allowed me to experience a Christian-saturated space, and what that space meant to my participants. It allowed me to think of the Christian-specific things that my participants spoke to me about (prayer, worship, God, fellowship, transcendence, etc.) in a Christian context. In coding and writing this thesis, I did not see participant observation as a prelude to my interviews. Rather, these data sets became entwined and complementary in identifying vignettes, arguments and narratives.

\section{Interview participants}

I have not created detailed profiles for my interview participants. Given the small, close-knit nature of Trustpeak, even providing what could be consider basic details could easily give away the identity of my participants. I discuss this in more detail below in Ethical considerations. For reference, I include below a table that lists my interview participants, who were aged between 20 and 60 years old.

\begin{tabular}{|l|l|}
\hline Pseudonym ${ }^{20}$ & Gender \\
\hline Elijah & Male \\
\hline Simon & Male \\
\hline Jacob & Male \\
\hline Rebecca & Female \\
\hline Isaac & Male \\
\hline Susanna & Female \\
\hline Esther & Female \\
\hline Lydia & Female \\
\hline
\end{tabular}

Only one of my interview participants, Elijah, was not a Trustpeaker. I met him at a Christian discussion evening, and I agreed to interview him due to his explicit interest and proactive contact in being involved in my research. I do not see this undermining the validity of my data. Firstly, as aforementioned, my research does not seek to represent the views of all Christians, or all Pentecostal Christians in New Zealand. But it also does not seek to even represent this specific church. Trustpeak is culturally, socially, and theologically diverse and the stories I tell here would

\footnotetext{
${ }^{20}$ All interview participants referenced in this thesis are referred to by a pseudonym to protect their identity.
} 
no doubt have been different if I had talked to different congregants. Moreover, even within the group of individuals I spoke to, there was significant variation in time spent at Trustpeak, what had drawn them to, and kept them at church, theological and denominational backgrounds, life experiences, and views about God. While a congregant's church, as a formalised, communal institution, will no doubt shape how they think about their faith, we must also be careful to not exaggerate its position in individual narratives and experiences. I draw on my fieldwork from the church to highlight and enrich my participants' narratives, but ultimately the aim of this research is not to tell a story about any one denomination or church, but rather ethnographically explore the lives of a small number of individuals who identify as Christian. Consequently, I saw Elijah's contribution as one that enhanced my research, rather than limiting it.

\section{Interviews}

I conducted four individual semi-structured interviews, and one focus group interview with five participants. As Holstein and Gubrium $(2003,68)$ posit, understanding how meaning is being produced in an interview context is just as important as its content. For my interviews, 'the how' and 'the what' were intimately entwined: as Christians talking with a non-Christian, my participants and I came to embody the topic of study in and through our dialogue. These interviews did not occur in a vacuum, and my participants were not afraid to summon and insert our respective theological and cultural positions in order to explain themselves. How my participants spoke to and engaged with me, in addition to what they told me, has been a rich source of ethnographic data for this thesis.

After a month or so of attending Trustpeak, I began thinking about people who I might want to approach to take part in an interview, although by this point I had also had a few Trustpeakers offer to be interviewed unprompted ${ }^{21}$. I did not employ specific criteria for recruiting interview participants, and I didn't aggressively attempt to get a 'representative' sample of either Trustpeak,

\footnotetext{
${ }^{21}$ When participants indicated they might be interested in being interviewed I emailed them with an information sheet, a consent form, and an indicative list of questions. The purpose of this was to provide more information in a setting where the participants could digest it in their own time and then return to me with questions, or alternatively decline to be interviewed without having the pressure of having to do so face-to-face. I emphasised to my participants that they were definitely not 'obliged' to talk with me.
} 
or the general population. Although I mentioned earlier in this chapter that some people I met at church were clearly uncomfortable with interacting with me as a non-Christian, the majority of responses were, if not very positive, then definitely curious. As Simon remarked after I thanked him for his interview:

No, thank you. How often do people come to Christians to ask about their faith? It's usually the other way around!

At their request (and sometimes insistence) every one of my individual interviews occurred at my participants' homes ${ }^{22}$. Their requests were partly for convenience, as well as the comfort and security provided by familiar surroundings. However, to refuse my participants' requests to hold the interviews at home would not simply cause them inconvenience, but would also ignore the specific Christian context of this request. Hospitality, by way of hosting and providing food, particularly to strangers and non-Christians, is arguably fundamental to the Gospel and a critical expression of Christian faith (Pohl 1999, 4-5). Likewise, hospitality was imbued in the culture at Trustpeak. Most Sundays were followed by a lunch for 18-30 year olds hosted by rotating Trustpeakers at their home, and the idea of hospitality was referenced, either overtly or symbolically, in almost every service I attended (including a whole sermon on Luke 14:12-24; The Parable of the Great Banquet). While I was initially resistant to the idea of not having control over the interview space, I came to see and accept this invitation as an exertion of my participants' autonomy in deciding how they wanted to engage with me, and that this request was not only an expression of my participants' Christian identity but also an invitation for me to step into Christian space. I wanted my interviews to be as conversational as possible, although they were semistructured in the sense that every interview began with me asking for a brief history of their faith ${ }^{23}$. The remainder of the interview, for the most part, was a conversation where my questions grew organically from what my participants told me. The home-based location of the interview also

\footnotetext{
${ }^{22}$ As part of ensuring my own safety in conducting these interviews I made sure that my next of kin where aware of my location and took my own transportation to and from the interview.

${ }^{23}$ Each interview also began with a review of the written material I had emailed to them previously; particularly emphasising their right to stop the interview at any time, ask questions, and to withdraw from the research process in the future. We also talked about the consent form, and what information the interviewee would like to receive after the interview. Every interviewee signed a written consent form, and I encouraged my participants to contact me after the interview if they wanted to discuss any aspect of our discussion.
} 
contributed to the informal nature of the conversation by creating comfort that would otherwise not be present in a formal interview setting. Despite feeling relatively comfortable in these interviews, due to the rapport my participants and I built with each other over the last several months, I was made to be very conscious of my position as a non-Christian since my participants drew on the fact of my non-faith in their responses. My non-faith was made visible as participants told their stories and paused to ask if I knew what certain Christian-specific terms meant, or took it as a given that I would not know and educate me as a side tangent within the interview:

Elijah: (...) she went up to the alter call-Do you know what those are?

Jess $^{24}$ : Like when you come up to receive prayer?

Elijah: Yeah, yeah, but it was more like (...) they would put the gospel message out, plead with people to accept The Message and to become Christians, and they would call people to the front to do that.

At other times, the absence of my Christian faith was specifically and personally invoked to illustrate a point:

Rebecca: And I don't know if God wants church to be full of just Christians. We shouldn't be so shocked that there is a non-Christian [at church] ${ }^{25}$. My friend said "you young people, you just get so hung up on if you're Christian or non-Christian!" and I'm like "yeah, we do". And even though I'd like to say it doesn't affect anything, or change anything, it does! [...] Rather than just taking the risk of living vulnerably, alongside Jess, even though she...believes something different to me ${ }^{26}$.

As Collins and Gallinat $(2010,16)$ highlight, anthropologists don't have the monopoly on the self as a resource, and it "might be drawn upon by others" during fieldwork. In these examples, drawing upon my non-belief also shows how my participants and I came to embody the very social relationships we were discussing - they explained and narrated things to me both in sensu lato, and specifically directed at me, the non-Christian.

Recognising the embodied performance of secularism and Christianity appearing in my individual

\footnotetext{
${ }^{24}$ Preferred name of the author.

${ }^{25}$ Closed square brackets, [ ], indicate text added by the author to clarify meaning.

${ }^{26}$ Emphasis added.
} 
interviews, and given the relational nature of my research questions, I decided early into my fieldwork that I wanted to conduct a focus group discussion ${ }^{27}$. Intuitively, I felt a focus group scenario would complement the personal and in-depth reflections of the individual interviews by creating generative space for participants. While focus groups still involve the presence of the researcher, the emphasis is on participant-led discussion, and therefore allows them to produce their own "questions, frames and concepts, and to pursue their own priorities" (Kitzinger and Barbour 1999, 5). Indeed, before the focus group began proper, a participant asked what I meant when I used the term "secular". I extended this question to the group, and this initiated the discussion without me having to propose my own formal question.

I recruited participants much in the same way as the individual interviews except Simon facilitated contact with two participants outside of my age demographic who he thought might be interested in my research ${ }^{28}$. This was incredibly helpful, as not only did Simon introduce me to these individuals but also validated me as a researcher by revealing to them that I had already interviewed him and he had enjoyed the experience.

The focus group was somewhat unusual in that the participants were all known to one anotherpre-existing groups are not the norm in focus group research (Barbour 2008, 66). Confidentiality is problematised when focus group participants know one another. I was also cognisant that there could be particular historical relationship dynamics at play that I would not necessarily be aware of. I felt this risk was mitigated by the fact that confidentiality was not an unfamiliar topic for my participants; the sharing of personal stories is a weekly occurrence at Trustpeak, and my participants are veterans in talking about their faith with other Christians in a private setting. As such, privacy implications of the discussion were readily understood ${ }^{29}$.

The advantage of this type of focus group is that my participants all shared the same "cultural framework" as one another (Barbour 2008, 108-9), and as a result, individuals in the group could

\footnotetext{
${ }^{27}$ Although this ended up taking place at the end of my fieldwork due to the inherent challenges of organising one day and time to interview five people at once.

${ }^{28}$ Confirming group interview participants entailed the same information process as my individual interviews.

${ }^{29}$ After lunch, I again went through an almost identical process to the individual interviews where we reviewed the written material. We discussed the information sheet and consent form as a group, emphasising both their rights as participants but also the confidential nature of the discussion.
} 
'just talk', without stopping to check whether I understood specific terms or ideas. Indeed, the number of Christian terms, ideas and references was considerably higher in the group discussion compared to the individual interviews. Although I did ask the occasional probing or clarifying question, in contrast to the individual interviews, I was largely absent from the discussion. The tone of the discussion was therefore orientated towards sharing, and working through opinions and experiences together, as opposed to explaining a Christian point of view to the non-Christian interviewer.

\section{Ethics and privacy}

Before I began fieldwork I did not expect that my research topic would invoke particularly emotional or sensitive issues. On the contrary, my participants and I have discussed in the context of my research: marital sex, dysfunctional family and familial estrangement, emotional distress and trauma, struggles with sexuality, as well as love, death, and loss. For one participant in particular, her experiences of, and relationships with God, faith, and Christian identity were inseparable from significant events in her life, some of which had been especially traumatic and emotionally distressing. Ellis and Berger $(2003,6)$ discuss the "interactional construction of meaning in the interview context", noting that "interactive interviews" do not avoid emotional or sensitive topics. To avoid the content of this participant's interview because of its 'sensitive' nature would not only demonstrate an acute lack of empathy, but would also dictate that she must respond to my questions on my terms, within my boundaries, using only experiences that I found to be appropriate. Therefore, this interview required thinking about the ethics of analysing and presenting this information, but also meant I was much more open than my other interviews, as I too shared personal information and experiences during the course of our discussion. This is known as "reflexive dyadic interviewing", where the interviewer has a reciprocal desire to disclose "given the intimacy of the details being shared by the interviewee" (Ellis and Berger 2003, 8). I believe this reciprocal exchange of information provided a degree of assurance to this participant that I would treat her information delicately and respectfully as we had both put our personal information on record. 
As aforementioned, I have not provided detailed profiles for my participants given the relatively small size of Trustpeak. For the same imperatives, I have also removed details from my participants' vignettes that I assess could be used to identify them. For example:

Esther: We met a few people when we were living in [overseas country], and we had a few friends from America...

From my time attending Trustpeak, and my knowledge of this participant, I believe that including the first country she mentioned would reveal her identity to most of the church; however, having friends from America is general enough that it does not need to be removed. I have also edited my participants' interview vignettes in light of privacy and ethical imperatives.

\section{Data and analysis}

I maintained a fieldwork diary in which I wrote notes following every church attendance. These were then typed up at the end of my fieldwork. I manually transcribed each recorded interview. I did not follow a formal coding process; instead I conducted a high-level theme analysis across my notes and transcripts, and grouped information together based on theme and frequency. I felt an intuition-guided approach was appropriate given that my research did not obtain linear-narrated life stories, but rather fragmented recollections of experiences, reflections, and relationships. I wanted this thesis to be guided by what mattered to my participants, and as such, the most prominent themes from their interviews served as the skeleton for this thesis. The first of these themes, space and place, serve as the focus of the following, and first ethnographicallyfocused, chapter. 


\section{Chapter Three}

\section{Space and place: Christian and secular boundaries}

And so I think one of the hard things for me is, when we don't have a public debate about spiritual stuff, it feels like I can't talk about spiritual aspects in a large part of my life. But then that means it's only when I'm in a church context that I can start to really talk about spiritual things, but then you don't have as much language for it...

-Abigail (interview participant)

In this chapter, I explore how, when, and where does the Secular come to be experienced, and for whom? As alluded to in Chapter One, identifying formal or institutionalised expressions of secularism is relatively straightforward. In contrast, the ubiquitous nature of the Secular in modern life makes it much more difficult to grasp, and consequently, Asad $(2003,16)$ suggests that the Secular is best approached "through its shadows", rather than directly. As space emerged as a central theme in Trustpeakers' narratives of how they identified and experienced the Secular, I explore the above question via notions of social space(s). I examine how spaces came to materialise for my participants - that is, become visible and have some sort of effect-as secular, Christian, or even hybrid spaces. As Abigail's quote above illustrates, Trustpeakers often felt that spiritual dialogue was strictly confined to a church context. The Secular was seen to revolve around a number of binary categories-secular/Christian, sacred/profane, and private/public - and thus the Secular materialised as a disciplinary force that regulated their religious expression in social space. I show in this chapter how this caused frustration for my participants as, for them, these categories were not so intuitively separate or opposed, but were often experienced as overlapping, intertwined, contradictory, and sometimes even indistinguishable. While Trustpeakers often abided by what they perceived to be social rules that governed religious expression, $I$ argue that they also attempted to subvert them through micro-practices of resistance. 


\section{Navigating social space}

As my participants told me their experiences of day-to-day life as a Christian in what they felt was both a demonstratively and increasingly, secular society, they often evoked concepts of space as opposed to religious adherence or belief. This was evident in Rebecca's explanation for why she felt New Zealand was secular compared to other countries she had visited ${ }^{30}$ :

Rebecca: Because in six months I met-we did a lot of different talking to a lot of different people, because it was a mission-trip-thing - I met in that six months, only one person who did not believe that there was a spiritual world. He was like "nah I believe in nothing", so what's that called? When you believe in nothing?

Jess: Atheist?

Rebecca: He's an atheist. Like, "I don't believe in anything". Every other person was like "oh yeah there's definitely god, but just they're [a] Hindu god". So people were willing to engage in that, and it was just so nice! Because it felt like - because I guess you are kind of wearing a mask here in New Zealand. Because it's like you're gonna think I'm an airy fairy princess because I believe in something that we can't see. Yup (...) But the biggest difference overseas was that people were just so open and willing to talk about their spirituality (...) As a Christian going there you could just say to someone "Hey can I tell you a story?" and you just tell them a story from the bible, and they'd say "Gosh, fascinating-but good, good"

By referring to only meeting one atheist overseas, Rebecca's explanation seems to conform to a normative understanding of the Secular as simply the absence of religious belief, or the absence of religious adherence. Upon closer inspection however, her narrative reveals more nuance. She does not say "there are very few religious people in New Zealand". Rather, New Zealand feels secular in comparison to other nations because people are unwilling to engage in dialogue about faith, God, or belief. In Rebecca's experiences overseas, even in countries that weren't Christian,

\footnotetext{
${ }^{30}$ I have not specified which countries as this could potentially reveal Rebecca's identity. These countries included both Western and non-Western nations.
} 
there was space that could accommodate a spiritual conversation, and she felt this was in strong contrast to New Zealand.

Another participant, Abigail, also discussed her experience of being Christian in terms of space:

Yeah and I think that's like saying, how should we, as people of faith, engage in this secular space? And I feel like I'm comfortable with [going in the opposition direction], but what I sometimes find harder is how do is-what space do I make for friends in a secular area to engage with something that is spiritual, or a faith?

Here Abigail illustrates that to be Christian in New Zealand is to be a certain way in space. She feels challenged as to how she should navigate secular space as a Christian, but also how she can make space- not Christian space per say, but space that tolerates dialogue about faith.

Space and place have become of recent interest to social science scholars of religion (what Knott (2010) refers to as the "spatial turn"), as well as those concerned with secularism. Religious faith is obviously enacted in specific spaces and places, but secularism also effects a distinctive organisation of public and social space (Connolly 1999, 20). Casanova (1994) shows the importance of space in his discussion of secularisation. He argues that the core thesis of the theory of secularisation is societal modernisation, a process of functional differentiation of "the secular spheres-primarily the state, the economy, and science-from the religious sphere" (Casanova $1994,19)$. As a result of this differentiation-which is an organisation of public spacesecularisation posits that religion will decline in adherence, and that which does remain will recede into the 'private' domain (Casanova 1994, 20). The privatisation of religion is not only one expression of the 'logic' of secularism, but is also "mandated ideologically by liberal categories of thought which permeate modern political and constitutional theories" (Casanova 1994, 39). Indeed, arguably one of the core and continuous threads of liberal thought in the West is the distinction between public and private spheres. As Casanova $(1994,40)$ argues, "The private/public distinction is crucial to all conceptions of the modern social order and religion itself is intrinsically connected with the modern historical differentiation of private and public spheres". In modernity, religion is assigned to the private realm of subjectivity and passion, not the public realm "of objectivity and reason" (Gedicks 1992, 675). Thought in this way, secularism as a political doctrine 
is less about whether people adhere to religion or not, and more about where and how religious activity is enacted and seen.

While scholars disagree on the extent to which secularisation theses are empirically valid (Asad $1999,178)$, it is undeniable that in most modern liberal societies, religion has in many ways receded from public and social life (Casanova 2008, 104) ${ }^{31}$. Consequently, religious spaces and places tend to be unambiguous - they are churches, shrines, and temples. In contrast, however, spaces are rarely labelled as 'secular' due to the discursive construction of the secular as natural and neutral (Gökarıksel 2009, 660) ${ }^{32}$-in other words, in normative understanding, secular space is just 'space'.

But what does it mean to speak of space and not place? Conceptually, space and place tend to evade concrete classification. For the purposes of this chapter, I see places as embodied spaces which are imbued with specificity - place denotes a place; it is a "materialisation of social forms and practices as well as affective experience" (Gieseking et al. 2014, xx). In contrast, space denotes something beyond the physical. Space is something "mental (psychological or imagined), and social, and of course, bound up with power and politics" (Day et al. 2013, 3-4). As space is "socially constituted" (Massey 1992, 155), it is also produced-social space is a social product (Lefebvre 1991, 26). As Lefebvre $(1991,26)$ states "the space thus produced also serves as a tool of thought and of action; that in addition to being a means of production, it is also a means of control, and hence of domination, of power". Consequently, experiences of space are never neutral, and always involves power, struggle, and resistance.

Spaces don't passively exist, or just 'happen', but are made "through the construction and manipulation of boundaries", which are "are used to include and exclude" (Knott 2005, 26). For example, the city, as Lefebvre $(1991,31)$ tells us, is not just a collection of things and people in space, but through its own distinct spatial practice, forges space. Thus, building upon Lefebvre's $(1991,38)$ claim that "the spatial practice of a society is revealed through the deciphering of its

\footnotetext{
${ }^{31}$ Although as Casanova $(2008,4-5)$ points out, we should be careful not to homogenise the diverse processes of differentiation that have occurred around the globe into a single historical process.

${ }^{32}$ Asad $(2003,192)$ explains that the Secular is thought of in terms of neutral and natural because it is constructed as being prior to the distorting forces of religion.
} 
space", I explore how my participants narrate and experience being Christian by examining how different spaces are demarcated and by whom-by examining the boundaries that include and exclude.

\section{Reproducing and crossing symbolic boundaries - when is a space secular?}

For my participants, identifying as Christian, discussing Christian faith, or engaging in Christian practice (such as prayer) outside of a Christian community was considered socially ambiguous at best, and a cultural taboo at worst. In our group interview, Abigail highlighted that she found it difficult to bring her spirituality into her social life outside of Trustpeak:

And so that's harder to invite someone into...yeah, so I find it hard. I struggle with how do I-what does it mean in a secular space to bring in spiritual elements? Whereas I'm quite comfortable in a spiritual space embracing parts of the secular world and going "well there's awesome brass band music, let's bring that in" \{laughing $\}^{33}$, or whatever it is (...). But it's harder the other way around, when it feels like a secular space, I assume, generally, would just reject something named with Jesus...

Abigail does not struggle with "embracing parts of the secular world"; however, bringing her faith into non-Christian domains feels problematic. Abigail's struggle with talking about her faith is predicated on the assumption that "anything named with Jesus" will be rejected, demonstrating the degree to which these boundaries are imagined-insofar as they are conceptual distinctions (Lamont and Molnar 2002)-but also how in imagining that there is a boundary, also reproduces it. Further, the boundaries which differentiate social spaces are often implicit and taken-forgranted (Van Houtum and Van Naerssen 2002, 126). This was illustrated by Jacob as he reflected on whether it was appropriate to talk about his faith in social or work situations:

Jacob: I think it's like politics-

Lydia: Yes!

\footnotetext{
${ }^{33}$ Closed curly brackets, \{\} , indicate a participants' action or gesture which is deemed by the author to modify the meaning of the text.
} 
Jacob: - bring it up in certain situations and it's fine, but you have to be careful, because people don't know how to react necessarily.

Jacob infers that there is an implicit cultural understanding that religion, like politics, can be off-limits in certain situations, and indeed, contemporary dominant Western liberal conventions generally construct religion as a private matter (Cochran 2014, 4). While not all non-religious others necessarily share this understanding, or would enforce it, the fact that my participants see this as a shared understanding consequently shapes when, where, and to whom they discuss their faith.

While symbolic boundaries may be culturally implicit or imagined, symbolic boundaries can also materialise more concretely, especially if they are seen to be crossed or challenged. This was illustrated by Lydia as she recalled a memorable incident at her place of work:

A friend of mine, who's a Christian, spoke at a farewell at work, and he wasn't trying to proselytise directly, but he was using an example about Jesus shepherding goats - it was supposed to be in a funny way and...the moment he spoke the word 'Jesus' - the name 'Jesus'-you could hear a pin drop. I felt like he'd transgressed, you know? It was like \{mimicking a shocked intake of breath\}; even I was like 'oh you really said that name!' \{laughing\}

Lydia's anecdote highlights the moment her workplace abruptly transformed from a 'neutral' space to a secular one. As discussed in the previous section, secular spaces are by definition distinguished from other realms by the absence of religiosity (Casanova 2009, 1049) but they are also discursively constructed as the "neutral or natural way of being in the world" (Gökarıksel 2009, 660). Consequently, I argue that secular space does not come to materialise until the otherwise invisible or implicit boundaries demarcating it are transgressed in some way. As Lamont and Molnar $(2002,168)$ posit, symbolic boundaries are "conceptual distinctions made by social actors to categorise objects, people, practices, and even time and space" and are means by which individuals and groups "struggle over and come to agree upon definitions of reality". For Lydia, her colleagues' reactions to the speech made the implicit understanding that Jesus was off-limits in the workplace explicit. Indeed, Lydia's anecdote highlights that while the simple utterance of Jesus' name temporarily disrupted the social space by challenging the symbolic boundaries at play, it paradoxically also reinforced a secularity that was previously implied or ambiguous. There is an 
irony here in that we can think of the spatial practice at work in Lydia's example as one evoking the sacred. One definition of sanctity after all is "ultimate importance and inviolability" (Oxford Dictionaries, n.d), and "sacred things and places are to be protected from defilement" (Douglas $1966,7)$. Ammerman $(2007,228)$ argues that while there has been differentiation of spheres in modern liberal societies, boundaries around institutional spaces are often permeable; "no institution or group can maintain its own purity so long as individual actors are members of more than one group and can import resources and schema ('rules' or categories of understanding) from one to another". I do not suggest Lydia's workplace, or similar spaces are literally devoid of any religious influence, but rather that the spatial and symbolic work at play seeks to minimise activity that may be seen to violate the sanctity of the space.

Lydia's story further highlights how perceived transgressions of space-or to use Douglas' (1966) term, defilement of space-can generate quite visceral responses from social actors who are not only in space, but are part of the production of space. Far from trivial office politics, I argue that Lydia's colleagues' shocked reaction to hearing the name Jesus is an example of both a challenge to the nature of this social space, and the maintenance of symbolic boundaries which demarcate the space. This is why Lamont and Molnar $(2002,168)$ argue that examining symbolic boundaries (as opposed to social boundaries ${ }^{34}$ ) "allows us to capture the dynamic dimensions of social relations, as groups compete in the production, diffusion, and institutionalisation of alternative systems and principles of classifications".

Lydia also gave another example of visceral reactions to the mention of Christianity in the workplace, but this time experienced by her directly:

I had -not hostility, but just um... maybe I'll find the right word - but I was talking to a good colleague at work and we had a big social function, so we had a few drinks and he asked me what I liked to read. I had asked him what he read, and he asked me what I read and I said 'oh, the bible'. And he said - \{coughs\} - some swear words \{laughing\}, because he just couldn't believe it you know, he was like 'whoa'. I didn't take offence, but... he just couldn't comprehend it...

\footnotetext{
${ }^{34}$ Social boundaries are "objectified forms of social difference" such as class, ethnicity and gender (Lamont and Molnar 2002, 168).
} 
Lydia's narrative indicates her colleague was not expecting her to be Christian. I argue that Lydia's mention of the bible intensified the transgression of symbolic boundaries because her Christian faith was initially concealed. This suggests there is an implicit expectation that a 'religious Other' should be identifiable as such. Jouili (2009) also explores secular space, boundary negotiation and visibility in her ethnographic fieldwork with Muslim women in France and Germany. These women struggle to claim space for salat (prayer) in secular spheres, and consequently develop strategies to find and create space in various institutions. Jouili (2009) also discusses the role the headscarf has in marking the body as Muslim in secular space. As a signifier of Islam, many of the women who did not wear a headscarf in public said this was due to anticipated negative responses if they were to do so. While we can draw some similarities here between these women and my participants' navigation of social space, the primary difference is that Trustpeakers are able to inhabit social space without necessarily evoking religious identity, language, or frameworks. They are not "politicised signifiers" (Jouili 2009, 466), or to put it more crudely: Trustpeakers don't look religious. While this means Trustpeakers can, if they choose to, 'pass' as non-religious, it also generates a set of other challenges when their religious affiliation is revealed, as evidenced by Lydia's anecdote.

Another, more explosive, example of faith, space, and boundaries is presented by Göle (2002), who analyses an incident in Turkey, where a newly elected Muslim Minister of Parliament caused nationwide controversy by walking into Parliament wearing a headscarf. Göle (2002) argues that the incident was indicative of the wider tension between Turkish secularism and Islam at the time, and that The MP, who had access to "powerful symbols of modernity" 35 , caused such an uproar, because of her closeness to secularism (Göle 2002, 180). In this instance, proximity represented an attack on secular space; "only when there is this feeling of a stranger's intrusion into one's own domain, places, and privileges is there an issue of rejection of recognition or difference" (Göle $2002,181)$. In this way, Lydia's cavalier admission to reading the bible can be understood not only as an intrusion into secular space, but also as an intrusion intensified by the fact that Lydia had up until that point presented as 'secular'. As my participants do not have the same religious visibility as those in the examples discussed by Jouili (2009) and Göle (2002), being Christian in secular space

\footnotetext{
${ }^{35}$ For example, she had trained at prestigious Western universities in computer engineering, had lived overseas, was a divorcee, and politically active.
} 
also involves exerting agency as to whether they should identify as Christian. This was conveyed by Simon:

I went to a business meeting of local businesses and so you have to get up and talk about yourself. And so I could've got up and said: "I'm a business man, blah blah blah, I've got four kids", but do I choose to say that I'm a pastor? That I'm a Christian? Because I know that people are going to have perceptions that's instantly going to define, or label you, or box you in a specific [way].

Here Simon indicates that choosing to identify as Christian is a conscious decision and thought process; that arises in every new social location. Strhan $(2015,102)$ describes that for her participants-Evangelical Christians residing in London-revealing that they were Christian in work or social situations was akin to "coming out" as Christian, and experienced as incredibly awkward. Given that coming out as Christian could be experienced as awkward or unpleasant, either due to real or imagined negative responses from others, my participants did not have countless examples of disrupting symbolic boundaries, simply because they chose not to disrupt them. Lydia recalled that she had discussed the idea of praying with some of her colleagues while they did (yoga-based) meditation at work, an idea they seemed open to. However, she had not followed through, explaining:

I don't think they understood that what I meant by prayer is totally different from meditation \{laughing\}. If they really knew what I meant by prayer, I don't think they'd invite me \{laughing\} (...) I think if they knew what I was doing - if they understood the place of prayer - that l'd be interceding for their salvation ${ }^{36}$, I would be praying in that manner, for them. I don't think they would necessarily want me praying for them to be saved to be honest. \{laughing\}

As social actors who, like non-religious individuals, rely on social relationships in their daily lives, they have very little incentive to destabilise their social spaces. Jouili $(2009,460)$ discusses how for her participants, claiming space for prayer would "engender situations that are too difficult and conflict-ridden" and as such, they simply avoided situations where they anticipated negative responses to their religious practice in secular space. Similarly, Trustpeakers don't go about their

\footnotetext{
${ }^{36}$ Intercessionary prayer is a distinct type of Christian prayer that revolves around praying for the needs of others.
} 
daily lives regularly contravening symbolic boundaries; however, as I was reminded by Simon, they may not even be cognisant that a boundary has been crossed, or a secular space defiled:

Jess: Oh, so you think that people are usually surprised to hear [that you're Christian]...?

Simon: Well I don't know to be honest, people don't really say: "I'm surprised that you're like this".

Simon's wry comment reminds us that even if my participants were seen by others to have transgressed symbolic boundaries, non-religious individuals have to balance reinforcing the symbolic boundaries of the space ( by having some kind of averse reaction) with conforming to the social norms and rules of the social space, which likely includes civility and politeness.

This is an important point because spatial practices and symbolic boundary work are very subtle. While Trustpeakers expressed frustration that they couldn't always freely identify as Christian, they were also at pains to emphasise to me that they never feared for their [physical] safety as a result of being Christian ${ }^{37}$. Several of my participants would temper their frustrations by pointing out there are Christians living in other countries who could not publicly identify as such without serious, possibly life-threatening consequences. Thus, while Trustpeakers did not experience fear in relation to their Christian identity, being Christian in New Zealand did involve strategically navigating social space as they go about their daily lives. But what about spaces where my participants don't feel beholden to the same symbolic boundaries that regulate 'secular' social spaces? Can the same parallels be drawn? How is being Christian in 'Christian' social space experienced differently from being Christian in 'secular' social space? I explore these questions in the following section.

\footnotetext{
${ }^{37}$ The notion of 'safety' is subjective. Although my participants are using safety to mean physical safety (such as violent or intimidating actions or threats), it is worth noting that some of my participants did experience anticipated or real threats to their social standing, or work security, as a result of identifying as, or talking about being Christian.
} 


\section{Christian spaces: collapsing the dichotomy?}

I was made aware of the importance of Christian space early into my fieldwork, somewhat ironically by my own unsettling of it. It was Pentecost ${ }^{38}$ and congregants had been invited to the front of the congregation to receive prayer from the Prayer Team ${ }^{39}$ for the express purpose of receiving the Holy Spirit ${ }^{40}$. A woman standing next to me, who I had met for the first time earlier in the service, expressed a sudden change in her body language as congregants began to receive prayer, ostensibly alert to my presence as a non-Christian. She leaned over to ask me, rather sheepishly, if I, as a non-Christian, had ever witnessed anything "like this before". I said no, but tried to downplay the inferred novelty by saying that I had been to a number of church services as a child and teenager. She followed her question by stating, almost by way of an apology, "Well we are Pentecostal Christians after all". Church is a place of worship, but it is also one of the few spaces where Christians can be Christian without inhibition. For this Trustpeaker, I was a disconcerting presence in a space that was routinely referred to as "safe", particularly in reference to prayer.

Trustpeakers communally pray during Sunday church services and on evening worship nights. The nature of prayer varies between services, and between individuals. For example, the congregation might be invited to pray aloud after worship song; some congregants sing or shout loudly, while some quietly whisper their prayer. Congregants could also be asked during the service to come to the front of the room to request and receive prayer, as described earlier for Pentecost.

Before invitations to pray, a church leader usually reminds the congregation that they are in a "safe space". In this safe space, the congregation is told, they should be released from inhibition not only so they can be true to what the Spirit is telling them, but also because they are free from judgement from the congregation. While praying at Trustpeak can be a very private and solidary act, at times it can also turn into quite a public event. Depending on the content of the prayer, and

\footnotetext{
${ }^{38}$ Pentecost is a Christian holiday that commemorates the descent of the Holy Spirit on the disciples of Jesus after his death, and is considered the beginning of the Christian church. Acts II states that the disciples were filled with the Holy Spirit and gained the ability to speak in tongues.

${ }^{39}$ While anyone is free to pray for any other person, The Prayer Team are senior 'verified' members of the church who are practiced in the art of prayer.

40 The Holy Spirit, also known as "the Spirit", is God's force or breath. To receive the Spirit is to allow God's force to enter one's mind, body, and soul.
} 
the degree to which the congregant feels touched by the Spirit, the prayer could result in some perceptible 'effects' (such as crying, shaking, talking in tongues), which will not only be visible to others but potentially require some sort of intervention. By labelling the service specifically as $a$ safe space, the church leaders alluded to the church as a "retreat" from the world at large (Stump $2008,268)$, and that the world is not a space hospitable or tolerable to Christianity.

My apparent disruption of space as a non-Christian, and the reassurances of church as a safe space, seem to conform to dominant discourses that posit the secular and religious in binary terms (Shakman Hurd 2011). Further, secular spaces, embodied in 'the city', or 'the university' for example, have traditionally been constructed as places of $\sin$, temptation and futility in Christian discourse, and this has complicated the study of "urban Christianities" (Strhan 2013). Although my physical presence at church during Pentecost seemed to have mirrored the utterance of 'Jesus' in Lydia's workplace, as I continued my fieldwork, the distinction between secular and Christian, or between sacred and profane, became more and more blurred. As Abigail explained earlier in the chapter, she did not struggle with "embracing parts of the secular world". This is no doubt attributed, in part, to the fact that Abigail goes about her daily life in secular institutions, using secular language, talking with non-religious people. However, I posit this was also enabled by the fact that Trustpeak did not seek to purify its space of anything considered non-Christian. Church services were not only for engaging with what we might consider conventional Christian or spiritual matters (such as the meaning of prayer, or a particular bible verse) but also anything relevant to congregants' lives, whether it be overtly 'spiritual' or not. One participant quipped to me that nothing was off the table when it came to topics or themes to be discussed at church.

The lack of distinction between the secular and the religious, or the sacred and the mundane/profane was particularly evident in prayer. Trustpeakers will pray to God, at church and elsewhere, about the disagreement they had at work, their car that refuses to pass a Warrant of Fitness, a nasty cough that won't clear up-nothing is considered below God's attention. While normative discourses about religion tend to dichotomise religion and the Secular, the reality of lived religion in lived contexts involves complex and overlapping strategies, dispositions, beliefs and options, each of which may themselves be a mixture of secular and religious elements (Ammerman 2007). Similarly, Trustpeakers do not simply drop their worldly, mundane, 'secular' concerns at the door when they arrive at Church on Sunday morning, nor do they leave their faith 
at the altar when the service is over. As Robbins (2011) discusses, Pentecostal-Charismatic Christians tend to avoid making meaningful distinctions between the sacred and profane, and the sacred and mundane, because they believe God cares deeply about all aspects of their lives. Since Trustpeakers tend to think of God as a close friend or companion, who is often literally by their side as they go about their day, they expect "the mundane to be touched by supernatural power" (Robbins 2012, 11). God is seen to be everywhere and in everything.

This was illustrated to me during a Sunday service where congregants were invited to share their experiences of prayer and seeking God with the rest of the church. Included amongst the many stories was one told by an older gentleman, who recounted, in a rather dramatic way, how he could not find his favourite brand of coffee while supermarket shopping one day. After a fruitless search, he did what any Christian should do when they are faced with hardship or confusion: he prayed to God for help in finding this brand of coffee. The man's story was retold with an air of humour; both he and the congregation laughed at points throughout his story. But the culmination of the account was that God answered the prayer-right there in the supermarket. The coffee appeared by God's grace, and this was met with approving nods and whispers of 'hallelujah'.

This example highlights that Trustpeak did not reproduce symbolic boundaries that coalesced around a secular/Christian binary. While my participants were sometimes cautious of bringing Christian faith into certain social spaces, the example like the one above also indicate that in many other aspects of their daily lives, they did not make clear distinctions between the sacred, and the mundane and profane-elements typically associated with the secular sphere. The sacred, the mundane and the profane were bound up with one another, and this highlights how it was ambiguous to my participants how faith and 'secular' practice should be segregated along lines of 'public' and 'private'. Cochran $(2014,6)$ argues that Christianities which cultivate a personal relationship with God paradoxically reinforce the private/public divide propagated by liberal discourses because of the private nature of their faith. Although Trustpeakers' relationship with God is personal and in some ways private, I suggest, contra Cochran (2014), that my participants' practice undermines this normative private/public distinction as opposed to reinforces it - If God and your faith in Him is everywhere and in everything, at what point does faith become 'public'? 
My participants' narratives earlier in this chapter indicated that the nature of 'secular' social space shaped the degree to which they could express their Christian identity or beliefs. However Christian space did not guarantee it would be experienced as such either. As Lydia recalled in our group interview:

Lydia: Um...about music, I've got a really good example about what I've experienced as secular. I was the member of a gospel choir, and this choir was very inclusive, and included a lot of non-Christians who didn't believe in Jesus, but enjoyed the positivity of Christian music. We tried to- I noticed there was not many songs too much about Jesus and the crucifixion, but was sort of 'light touch' songs...and I remember...trying... Whenever I sang these gospel songs I never sang them in faith, it felt [like] I was just singing a song, and when I tried to sing them as I would worshipfully, it didn't quite work...and for me that's a real tangible experience - I felt like I was coming up against something, I had made this division and so I ended up leaving [the choir] because I thought I can't be here, this is not a space that I can worship and sing these words authentically...

Jess: Yeah...so it was almost like it was compartmentalised?

Lydia: Yes! Yes...

Lydia highlighted that for her, being Christian is a verb, not a static identity-it involves consciously choosing to worship and exalt God. It seems self-evident that singing Christian-themed gospel songs in a choir, as a Christian with a strong belief in God, could only be seen and felt as a Christian activity in Christian space. However, for Lydia, as this choir lacked a genuine spiritual connection with God, it impacted her own ability to sing songs in faith. As Ammerman $(2007,224)$ points out, "phenomenologically, something becomes religious because it is understood to be so by those who observe and participate in it. Sometimes the observers and participants readily agree, often because they all share common cultural assumptions. Other times definitions involve negotiation and contention". For some non-religious choir members, this may have felt like an overtly Christian space, but Lydia not only categorised this as a secular activity but also experienced it as secular.

I'd like to now turn to a tension that has been emerging throughout this chapter. While, for the most part, Trustpeakers are cognisant of, and adhere to, dominant cultural understandings about the appropriate place and role of their faith and religious practice, this is often at odds with how 
they conceptualise the role and location of faith in their daily lives. This can result in feelings of fragmentation, as I discuss in Chapter Four; however, I argue that they also resist or subvert these cultural understandings, albeit in ways that can be easy to overlook.

Jouili $(2009,461)$ discusses how Muslim women in France outwardly adhere to the unwritten rules about religion in society, but "invisibly they search for possibilities to circumvent them, to reappropriate these spaces without being recognised, in order to enable their Islamic practice. These micro-practices, appearing so banal that they are easily overlooked, nevertheless 'manipulate space' in significant ways". These practices may be as simple as seeking out empty meeting rooms to conduct salat. Similarly, Trustpeakers often discussed strategies at church for bringing prayer into their daily lives. Finding space, time, and energy for prayer was a challenge to many churchgoers, not only due to a feeling that prayer wasn't acceptable in most spheres outside the church or the home, but also simply as a result of the pressures of modern life. During one particular service, several members shared their techniques with the whole congregation for bringing prayer more systematically into their lives. Some congregants ritually prayer to God at the beginning of their work day when they arrived at their desk, some established prayer groups with colleagues, and others set hourly reminders to stop and pray throughout the day. While these actions may seem insignificant, I suggest they represent an unwillingness to passively accept the confinement of faith into rigid and designated spheres.

\section{The Prayer Room as resistance}

During my fieldwork at Trustpeak, the church designed and opened a space specifically for prayer (aptly named the 'Prayer Room'). The Prayer Room is separate to the main worship hall, but on the same premises as the rest of the church facilities. It can be accessed 24 hours a day and private use of the room can be booked via an online booking page on their website. While rich in traditional Christian iconography, the room is aesthetically modern and ordained with contemporary artwork. It is open and bright, has Swedish-designed furniture, and is stylishly decorated. It looks and feels very chic. The information campaign about the opening of the Prayer Room relied heavily on notions of space and place, "Forgetting your place?"; "In Trustpeak, we've 
made a place for prayer"; "Is there room in your life for prayer?", with the purpose of the room being to provide both space and place for people to pray, reflect, or 'just be'.

It may appear that this room is one of acceptance, not resistance, to the confinement of faith to private spheres. Indeed, I initially saw the Prayer Room as simply being another Christian place of worship; no different from the space created during Sunday morning worship services. However, upon personally experiencing the room, and listening to Trustpeakers talk about the space, I realised that the prayer room was a kind of hybrid space which combined elements of the secular and Christian, and the private and public. Of the room, church documents state:

In a wired world, anyone can reach us anytime, anyplace. We forget that we are embodied creatures, in need of places to meet that are more than virtual. Even, and especially, with God - immortal, invisible - yet the Creator of myriad places for us to inhabit. Who so loved the world he made that he came down to live in it.

The prayer room is a space to meet with God that is not in the private domain of the home, but is also not in a church setting where prayer is often formalised or ritualised. It is a space that allows for spontaneity, but also requires churchgoers to consciously seek it out. The space is Christian but it is also one that appropriates elements more closely associated with secular, modern spaces (for example, 24 hour accessibility, stylish aesthetics and convenience via a booking system). Casanova $(1994,5)$ argues that "religious traditions throughout the world are refusing to accept the marginalised and privatised role which theories of modernity as well as theories of secularisation had reserved for them". This marginalised and privatised role has not only entailed religion's recession from the public sphere, but also conforming to dominant, secular understandings of what 'religion' constitutes. In constructing a space specifically for prayer that is set apart from the main church, and in many ways resembles a 'secular' space, I argue that Trustpeak is resisting the confinement of faith by creating its own space, on its own terms, that does not so easily conform to secular views of what church might or should look like. Trustpeakers' micro-strategies of systematically bringing their faith into their daily lives, as well as their construction of new, subversive Christian spaces, represent a refusal to allow the expression of faith to be entirely restricted to church or private space. 


\section{Conclusion}

Space was central to how both the Secular-as an otherwise elusive sensibility-and Christianity came to materialise for my participants. The understanding that social and public spaces were not hospitable to Christian faith and practice was seen to be culturally implicit, and consequently shaped how many participants navigated these spaces. While in some respects my participants reinforced and reproduced the symbolic boundaries that demarcated secular spaces as those devoid of religious elements, this chapter showed there is a deep tension between the expectation that their faith should not be brought into these spaces, and how my participants themselves think of their faith. For Trustpeakers, their faith permeates all aspects of their lives; it does not suddenly emerge at church. As such, they struggle to draw meaningful distinctions between taken-forgranted binaries such as religious/secular, private/public, and sacred/profane. Since these boundaries are not intuitive from a Pentecostal-Charismatic perspective, I argue that Trustpeakers subvert them not only in their reconceptualisation of the location of faith, but in micro-practices of resistance. Finally, I showed how in reflexively and consciously constructing a space for prayer, one that cannot easily fit into normative categories of secular or Christian, my participants are challenging the expectation that religion should be relegated to the private sphere. 


\section{Chapter Four}

\section{Christian identity work: selves, others, and God}

The higher one's intelligence or education level, the less one is likely to be religious or hold 'beliefs' of any kind.

- Richard Dawkins; The God Delusion (2006)

In the previous chapter my participants indicated that for them, Christianity and the Secular were not polarised, but rather, interrelational, and at times intertwined. What then, does this mean for Christian identity and subjectivity? How do ideas about, or experiences of, the Secular, shape or influence how Christians think and talk about themselves? In what ways do the formation and expression of Christian identities reject or counter discourses of secularism? How do my participants experience identifying as Christian in society in which non-religious adherence is increasingly the norm? This chapter explores how Trustpeakers navigate a complex interplay between competing influences and obligations in forming and managing their identities, or in doing what Snow and Anderson (1987) coined 'identity work'. Identity work refers to the range of activities "individuals engage in to create, present, and sustain personal identities that are congruent with and supportive of the self-concept" (Snow and Anderson 1987, 1348).

As identity is dialogical (LaCapra 2006), it usually involves activities done with or against others. To say "I am a Christian" is also to say "I am not secular", and therefore puts Christian identity not only into conversation with secular others but with another social actor, another other: God. Indeed, my participants' narratives indicate that being Christian in New Zealand requires the rejection, integration, navigation, and management of the real, imagined, and anticipated demands from oneself, Christian and non-Christian others, and God. While all identity work done by individuals and groups is dialogic, the strategies involved in secular and Christian identity work are very different. Those who are not religious do not generally go about their daily lives maintaining a secular identity. As previously discussed, secularism as political and cultural discourse is constructed primarily around the themes of absence and neutrality-consequently, those who are not religious rarely identify as 'secular'. In contrast, my participants indicated that 
their identity work revolves around not only maintaining a Christian identity but also an awareness of how they are, or could be, perceived by non-religious others. In this chapter I show that Trustpeakers' identity work is distinctly Christian both in content and form. While competing demands on Trustpeakers' subjectivities and identities can contribute to a fragmented sense of self, I argue that the Christian identity work discussed in this chapter entails simultaneously rejecting and embracing other-defined or other-applied labels, values, beliefs and sensibilities. The result of which is an agency-driven claim to a counter-cultural identity that is constructed specifically in opposition to secularism.

\section{Identity and subjectivity}

The terms 'identity' and 'subjectivity' are understood and applied inconsistently across, and within, different academic disciplines. In this chapter I use subjectivity to refer to the internal processes involved in constructing, experiencing and thinking about oneself; subjectivity is a "specific cultural and historical consciousness" that is at once psychological and cultural; discursive and agencydriven (Ortner 2005, 34). Subjectivity is reflexive and creates the "distance that allows the individual to become conscious of herself" (Strhan 2015, 47). In contrast, identity is pivoted more towards social interaction than internal formulations of the self. Hall $(1996,7)$ argues that identity arises at the intersection between psychic formulations of the self and the practices of the social field. The social component of identity means it is inherently dialogical; it involves "modes of being with others that range from the actual to the imagined, virtual, sought-after, normatively affirmed, or utopian" (LaCapra 2006, 228). Identity is also constructed against, or in spite of, others, and is often the "marking of difference and exclusion" (Hall 1996, 4). Identities are constantly being transformed, negotiated, tested, examined and reconciled by ourselves and others (LaCapra 2006, 238), and therefore identity is less about who someone is, but who they are becoming. In other words, while identity and subjectivity no doubt overlap and are at times synonymous, for the purposes of this chapter, I see identity as the ongoing negotiation between how others see us (the social) and how we see ourselves (subjectivity). 


\section{The Looking Glass Self and significant others}

So yeah, maybe judgemental, maybe bigoted, homophobic, um...boring \{laughter\}, yeah I don't know. Like maybe anti-intellectual? Proper...

Interspersed throughout Trustpeakers' narratives of being Christian in New Zealand were references to how they thought they were perceived by non-Christians, particularly through evoking stereotypes, and how this shaped their social interactions. My participants were very selfaware, sometimes self-conscious, that identifying as Christian, and as a Pentecostal-Charismatic Christian at that, could evoke, or provoke, often uncomplimentary connotations and assumptions. For some participants, these stereotypes, connotations and assumptions at times overshadowed their social interactions, especially when meeting people for the first time. Fear of conforming to, or being judged by negative stereotypes is known as the "stereotype threat" (Steele and Aronson 1995), and has been demonstrated to have negative outcomes for certain groups in specific contexts $^{41}$. My participants did not necessarily narrate these stereotypes as a threat, but their narratives demonstrate they were continually anticipating, and imagining how people could, or are, responding to them. This acute awareness of how others see Christianity became crucial in my participants' narratives of their subjectivities and identity work. Elijah's list of possible stereotypes shown above was echoed by Esther as she recalled her struggles with publicly identifying as Christian, particularly when she attended university as a teenager:

I was very, very shy. I mean [my husband] will tell you, I was super shy when he first met me. Um, I've definitely come out of my shell since then, but the thing that put me off the most was that whole idea of being put in a box, that if people found out you're a Christian then you're going to be this, this, this and this. And 'oh I don't have time for you, because you're just gonna think this, this, this and this'. So that's the thing that I struggled most with, and: \{whispering\} that they'd just think you were a bit of a freak \{laughing\}. So (...) I think now-actually I'm happy to tell people now and I'll just say: 'oh yeah I go to church and I'm a Christian and I believe in God', but I prefer to get to know someone, and for them to get to know me, and then to find out [that I'm Christian] naturally.

\footnotetext{
${ }^{41}$ For example, women who are worried about the negative stereotype that women are not good at maths or science, are more likely to fare worse in examinations in these areas (Steele and Aronson 1995).
} 
Here Esther recalls her concern at university that if her peers discovered she was a Christian she would be typecast before they got to know her as a person. What her narrative heavily draws on isn't a specific example, but a generalised account that anticipates or imagines what would or could have happened in these scenarios. The role of imagination is central to Cooley's (1902) famous concept of the Looking Glass Self, which posits that not only is identity impacted by how others see us, but how we think others see us, "our own feelings about ourselves are not mere mechanical reflections of others' actual responses, but our own conceptions about others' ideas of us" (Franks and Gecas 1992, 51).

The Looking Glass Self shows how identity is formed by both realised and imagained social interactions. 'Imagined' in this context does not mean 'not real'. It is imagined because it might not materialise as a concrete social interaction, but is real in that it has a tangible effect on identities, subjectivities and social interactions. Cooley $(1902,184)$ states that “...we perceive in another's mind some thought of our appearance, manners, aims, deeds, character, friends and so on, and are variously affected by it". In Esther's example, the possibility that her peers might be thinking negative things about her materially impeded her confidence to identify as Christian.

In discussing secular views of Christianity, many of my participants implicitly took an Other position specifically in relation to the issue of judgement:

Yeah I think people are afraid of judgement, um...and often when you say you're a Christian it's almost like... they perceive you as about to judge them. (Susanna)

However, this stereotype of the judging Christian was something my participants felt was at odds with their understanding of Christianity, and not reflective of their own thoughts when interacting with non-Christians:

(...) people will be like "oh you're so black and white about stuff!", but [we're] really not. I feel like it's God's job to judge, not our job at all, you know? (Esther) 
Lydia expanded on this sentiment using a specific Christian framework:

(...) But if we're really following Jesus - I mean I would like to be like Jesus ultimately...love should like...ooze out of me, you know? We would want people to feel loved and not judged. We'd want to speak Truth, without fear. We would, you know-those sort of boundaries shouldn't matter to us. We would want to lay down our lives if someone needs help, that's who we are as followers of Jesus.

It is important to note a qualifier to the concept of the Looking Glass Self, highlighted by Franks and Gecas $(1992,52)$; people are only impacted by others' (realised or imagined) perceptions, if they are "significant others". That is, we have to value their opinion for it to have an impact on us. As Simon told me:

If someone swears at me, or thinks I'm a, a conservative fundamentalist bigot, I will just think "pfft, well you don't know me, and I'll try to not be like that, but at the end of the day, it's not-“" I don't really care, they're not the ones who define me...

Of course, it is entirely possible that someone calling Simon a "conservative fundamentalist bigot" could, at least subconsciously, impact how he thinks about himself and manages his identity. Nonetheless, Simon reminds us here that subjects do have agency in how they narrate and consciously experience themselves, and respond to the narrations made by others. His comment demonstrates that Christians are not equally affected by real or imagined perceptions of them by others.

When these others are considered significant, and their opinions potentially valid, a challenge arises that can't be so easily explained by stating that "they don't define me". One strategy in attending to this challenge was not to reconcile these disparaging views with what my participants knew to be true of themselves, but rather to shift focus from those expressing negative views of them, to an illegitimate, inauthentic Christian other:

Isaac: I think, to generalise it largely, there's this massive belief in our culture that to believe in God is [to be] a Christian, whereas Jesus specifies that even demons believe in God. So it's more that to be a Christian is to follow Him and to actually devote your life to Him, so there's a lot of people who 
believe in God and call themselves a Christian, but their life doesn't represent that. So meaning they're just like, um....

Jess: It's just like... an identity?

Isaac: Hmm, yeah...

Lydia: A label.

Isaac: Like... \{mimicking a fictional Christian person\} "Yeah sure, I believe God exists, but I'm not going to follow Him. I'm gonna live my life, but I'm gonna go on calling myself a Christian so that everyone I interact with thinks I'm a Christian because I'm calling myself a Christian, but my life isn't actually..." - If you compare that to what Jesus was speaking about, it doesn't actually represent what he was defining as a Christian. So when I encounter [non-religious] people with hostility, a lot of the time the harm's been done by people who called themselves Christians, who would've believed in God but they weren't actually living it [Christianity] out.

Here Isaac draws a distinction between true Christians (such as Trustpeakers) and inauthentic Christians who simply believe in God. For Isaac, to believe in God is not enough to be a genuine Christian; one must embody Christianity in one's actions and devotion to Jesus. Correspondingly, any 'misunderstanding' about Christianity by [significant] non-Christians, is attributed to the misrepresentation of Christianity by these inauthentic Christian others. This narrative thus not only provides a means through which Isaac can contend with the fact that the views of some significant non-Christians do not align with his own views and experiences of Christianity, but also demonstrates another form of identity work that affirms the nature of his identity in contrast to other Christians. Indeed, several of my participants made reference to what we might call "nominal" or "performative" Christianity (Day 2011), which they saw as being in sharp contrast to their own identity. Elijah narrated his mother in these terms, who had become interested in Christianity around the time he converted:

I think she would've called herself a Christian at the time probably, but I don't know if she really knew what that meant for her (...), she didn't seem to have any framework for any of that stuff, it was more just like "oh I go to church, I'm a Christian", you know? 
Isaac and Elijah show that while Christian identity work involves negotiating, reconciling, rejecting, and at times tolerating, stereotypes of Christianity and Christians, they can also express agency in shifting those stereotypes from themselves to who they perceive to be inauthentic Christians.

My participants' identity work did not only involve responding to negative stereotypes about Christianity, but also responding to implicit sensibilities about minute details of Christian identity and subjectivity. Elijah conveyed such an example in relation to his workplace:

Elijah: Just the other day, at the lunch table, someone asked me if I was in a band (because I had told someone else that I used to be in a metal band when I was younger), and I told them that I used to be, and they were like: "what? That's so weird!" \{laughter\}

Jess: Is that weird? \{laughter\}

Elijah: Yeah yeah yeah. Well I guess it was weird for them, maybe because they only know me now, but, I still really love metal by the way...

While the fact that Elijah's colleagues are surprised to hear that he loves metal music might seem insignificant, it highlights LaCapra's $(2006,238)$ observation that "one may have a subject position without experiencing it, and often one's experience of it depends on a recognition, at times an insulting recognition, coming from others". By stating he loves metal music, his subject position as a Christian is evoked and emphasised because it is seen by others to be inconsistent with this music choice. It highlights the role that others play in identity construction and in-/validation. Elijah sees being a fan of metal music and his Christian identity as perfectly compatible. For his colleagues however, Christianity is deemed to permeate and shape all aspects of Elijah's subjectivity, right down to the detail of dictating music choice. While my participants demonstrated agency in shaping narratives and interpretations of themselves, Elijah's example also shows the degree to which one's identity may be predetermined by others, based on criteria out of our control.

These narratives point to the complexities of identity management and intersubjectivity. My participants are both affected by, and seek to counter, subvert and undermine realised and 
imagined views of Christianity by non-Christians. Non-Christians are in turn also interacting with Christians based on how they experience and imagine Christian views of them. In some Christian and non-Christian interactions, it may be only each person's imagining of the other that is at play. Thus, while imaginings may possibly never materialise, they still affect and effect particular social interactions, and shape identity.

\section{Flipping the looking glass: The non-Christian self}

Allow me to briefly segue into an auto-ethnographic account to illustrate the complexities of this identity work but from a different vantage point. While one could argue I have always had a nonChristian subjectivity, I did not have a non-Christian 'identity' until I entered the field. This was an identity ascribed to me by both my participants and myself, but the meaning and strategies behind this identification varied. From my perspective, I actively identified as non-Christian in the field to facilitate learning (i.e. "I am not a Christian and thus am ignorant") and for transparency. For Trustpeakers, labelling me as a non-Christian could have served a number of purposes; it could have also marked me as someone ignorant requiring education (or salvation); it could have been an act of asserting their own Christianity identity; and, it could also have positioned me as representative of the Secular, and hence someone of whom to be wary. Perhaps this is unremarkable. Possibly more surprising was that non-Christians in my personal life demanded that I create and affirm a non-Christian identity as a result of doing this research project. Prior to doing this research, there was no requirement to do so. I suspect that my proximity to Christian others and my apparent unwillingness to engage in sentiments disparaging Christianity made the certainty of my non-Christian status suspect. This highlights how sudden changes in circumstances and contexts can require reformulations of identity, and that the momentum for this reformulation-or in my case, reaffirmation-may come from others. Further, this was beyond a simple labelling issue: for my non-Christian friends and family, to affirm my identity as nonChristian was to confirm that I 'still' adhered to 'our' way of knowing the world and that I had not turned into one of 'them'. While I had no problem with readily identifying, and labelling myself as non-Christian at church, I was hesitant to do so in these conversations outside of the field. In these conversations, being asked to confirm my status as a non-Christian felt like being asked to agree that there was something wrong or deviant with being Christian. Thus, my own identity work in 
and out of the field involved a complex creation and management of a non-Christian identity; an identity which was simultaneously seen to be legitimising and delegitimising Christianity in different contexts; simultaneously given to me, created by me and demanded by others.

\section{The fragmented self}

Although Esther, who spoke of struggling with her identity at university, is now comfortable with her Christian identity, this has only come to pass in adulthood. As a child and teenager, she experienced feelings of fragmentation as she tried to reconcile her strong feelings of faith with her father's atheism. While her mother was an extremely pious Christian, her father, who had deconverted from Christianity, was not only atheist in his beliefs, but would ask Esther how she could, as an intelligent person, possibly believe in God. This created a sense of shame associated with identifying as Christian:

But yeah, it was really interesting growing up with such big extremes and I think it's definitely affected the way that I see myself as Christian-you know, the way that I feel about being a Christian in such a secular society, because it's made me feel ashamed about it. Because of what my Dad has said, in passing comments, in the way he's belittled it, and Mum especially, for her beliefs, because they're so crazy sometimes \{laughing\}. And she's very vocal about what she thinks is true, and I wouldn't agree with everything that she says...

Therefore, Esther's parents came to embody what she saw as two oppositional orientations in the world, pious Christianity and atheism, which acted as two shaping forces in the way she thought about herself. Her narrative also highlights the specific complexities of religious identity work. In contrast to other identities (such as ethnic, national, or gender identities), Christian identity involves both agency (people choose to follow Jesus), and morality (Christians makes exclusive truth claims about the world). This illustrates that while Christian identity work is not necessarily easier or harder, it requires engaging with others in ways that are quite distinct from other types of identity work. Later in the interview Esther added:

Yeah I mean I really respect my Dad, and I think that's why I've myself struggled with doubts because I so respect his wisdom and he's a really good man, really moral, loving, like he doesn't say 'I love you' 
but you can tell, you know, he's just super kind, generous and helpful. Yeah, I've found it quite difficult to reconcile the two things, and so, I think it's definitely shaped me. As a teenager I was really embarrassed to tell people that I was a Christian...

The difficulty in reconciling the beliefs of her parents, but also in reconciling her own beliefs with her father's obvious frustration, not only created a sense of embarrassment and insecurity around her Christian identity but caused Esther to experience what Strhan (2015) calls "subjective fragmentation"; the feeling of a conflicted and fractured, self. While subjectivities are arguably never truly consistent, cohesive, or whole, it remains true that most people experience their subjectivities as such, and if not, they want to (Ewing 1990). The role of fragmentation in Christian identity work was conveyed clearly by Rebecca in narrating her journey and struggles with sexuality; something most people see as an innate or static component of identity (Erzen 2006):

I had my first girlfriend-so, you have probably have heard that lots of Christians aren't okay with being gay, and so growing up with it, that was-yeah. So I knew since I was 13 probably that I was attracted to women. So that was kind of like meeting God and that at the same time funsettled laughter\} and trying to align the two things. So, lots of people would say "well it's not a bad thing to be gay" but I guess from the school of thoughts that I came from, you're saying one thing, and doing another. And that in itself is bad, because that's hypocrisy. So even if you don't disagree with the action, it's like you're saying-or living this life one way, yet at night you're going to be with your girlfriend, and doing all that crap. And so and that was hard (...) I would still read my bible, but deep down, I knew that's not how I wanted to live my life, on two levels-hypocrisy, and because I still don't believe that that was God's intention for humanity...and so that's hard to grapple with...

(...) I guess I'm learning to be more protective about what I share with people because sometimes it can actually be destructive if you share too much. But I will generally talk to anyone about it because I have so many questions, and I've had so many questions about can these two things align? And the decision that I make could really heavily impact the shape that my life goes, the path that it takes. Because if you say no [to God], then that (I thought at the time, I think differently now) was cutting me off from ever having a family, from ever having children that's a really big call to make, at age 19 you know? But I think I've tried, you know, I've talked to so many people, I've talked to Christians who believe it's okay, I've talked to non-Christians who think it's okay, and I've now had the opportunity to meet and talk to Christians who are following Jesus, who don't think it's okay, yet experience those desires as well... 
During the period when she had a girlfriend, Rebecca felt as though she was living two lives, lives that were incompatible with each other, and this was deeply distressing. This is analogous to Erzen's $(2006,10)$ ethnographic study on Christians engaged in a gay de-conversion programme, where a participant asked her to emphasise in her ethnography the utter pain of having your deepest moral beliefs clash with your sexuality. Issues of Christianity and homosexuality are often assumed to be ones of identity politics, as a discussion by Ganzevoort et al. $(2011,213)$ illustrates:

\begin{abstract}
Homosexuals claim acceptance as homosexuals, not just as citizens, and it is for that reason that they insist on describing homosexuality as identity. Religious groups claim the right to take positions that might otherwise be labelled as discriminatory, because their religious identity needs to be protected. As a result, they deny their opponents' identity status in order to render them powerless.
\end{abstract}

However, Rebecca's beliefs around homosexuality and faith challenge this narrative that Christians are often against homosexuality due to faith-informed political beliefs, or that Christianity and homosexuality are positioned at opposite sides of an identity debate. Contra Ganzevoort et al. (2011), what is salient in Rebecca's dilemma is a feeling of personal distress and conflict with what she sees as two irreconcilable modes of being. Her narrative is not about denying a categorised group (homosexuals) a claim to an identity, but what her own relationship to that identity is, or could be, given her Christian faith.

Strhan argues (2015, 50-51), drawing on Georg Simmel (1997), that religion contributes "to the experience of fragmentation [by] introducing orientations that sit in tension with those developed through participation in other social structures". This is further exacerbated by the fact that modern life is secularised in the "sense of functional differentiation, with life separated into public and private spheres" (Strhan 2015, 106). Christianity can also specifically contribute to the experience of a fragmented self due to the emphasis on individuals' inability to invariably meet the moral obligations stipulated by Jesus (Strhan 2015, 144). However, Christianity also positions fragmentation, using idioms such as 'brokenness' and 'sinfulness', as inherent to human nature, and intimately tied to salvation and God's grace ${ }^{42}$. My participants often spoke of their faith

\footnotetext{
42 "As it is written: "There is no one righteous, not even one..."”-Romans 3:9-10
} 
offering them a way to address their brokenness. By discussing her concerns with being gay in reference to both hypocrisy and what she felt was God's intention, Rebecca's narrative problematises Simmel's (1997) claim that fragmentation is simply the incompatibility between two moral structures-her distress must be understand within a specific Christian context.

Both Rebecca's conceptualisation of her sexuality, and those in the gay de-conversion programme discussed by Erzen (2006), challenge the idea that sexuality is an innate component of identity. The participants in Erzen's (2006) study did not tend to see homosexuality as an identity, but rather as a set of desires and attractions, or as a lifestyle. While these desires may never truly dissipate, their relationship with God was emphasised as being more integral to their identity than any gay relationship could ever be (Erzen 2006, vii). Similarly, while Rebecca recognised that for others being gay was integral to their identity, for her, her sexuality was a struggle with the way she was living her life, rather than an innate aspect of her identity.

Rebecca's identity work has involved a complex and at times turbulent negotiation between self-generated identity work and other-imposed expectations of not only what a Christian is or should be, but also what identity is.

\section{The other Other}

Rebecca's struggle with being Christian and having desires seen or felt to be incompatible with a Christian identity involved not only negotiating between the expectations of other people and her own autonomy, but also the expectations of a specific other: God. To ask how God might impact and shape religious identity and subjectivity may seem obvious. However, as Bialecki (2014) points out, anthropologists-particularly anthropologists of religion-tend to avoid talking about God. Despite God(s) arguably being the most important actor(s) in religious adherents' lives, anthropologists of religion overwhelming take a methodological atheist approach as their default position (Bialecki 2014, 34). As mentioned in Chapter One, methodological atheism assumes a distinct ontological reality in which all religious concepts are considered human externalisations (Bialecki 2014, 33). However, as Strhan $(2015,138)$ argues, God is a social actor as far as those who believe in Him are concerned, and what they consider Him to want or need from them shapes their "practices, desires, and the formations of their subjectivities". 
When Simon and I discussed the practice of evangelicalism he told me: "God gives, He's very gracious-He/She, is very gracious to us, to let us choose whether we want to follow Him or not". Simon articulates God as a being with both agency and personality, but also uses a collective 'us' to denote that it is all people [Christian and non-Christian] who are being impacted and affected by the action of God to allow 'us' to believe in Him. For Trustpeakers, it is a phenomenological reality that God is not only real, but that they are in a deeply personal relationship with Him.

Elijah, who converted to Christianity when he was in his first year of university, emphasised the agency of God in explaining how his worldview changed post-conversion:

I try to, just whatever I'm doing, or whatever I'm thinking, or whatever-l'm real into reading and history, and there's this theologian called John Calvin, and he wrote about living Coram Deo, which is like 'before the face of God', in everything that he did. Um, and it's not supposed to be this fear thing, it's not supposed to be that God is watching everything that you do, so 'be careful' sort of thing. It's not that at all, it's like... you've been saved, He's done this incredible gracious act for you, and He's now made you a child of His. So now you get the privilege and the honour of living a life for His glory. And that's what Coram Deo was about. And so I guess I try to have that mindset of everything I do, being for His glory, meaning trying to make Him look great. And that's constant failing, and forgetting \{laughter\} to do that all the time. But that would sum up the worldview change I guess, because before it's you're not doing that obviously \{laughter\} -but not only that, I guess it's more that you're living for your own glory, rather than God's, you know? And so that would like drastically change the motivations for doing things, and what words you would choose to use maybe, what you would say to certain people. And yeah, I guess I try to-most of my life's at work, at my job, you know, so I try to be a good witness to what a Christian should be at work.

Elijah's explanation conveys that God is more than simply an object of worship. God is a being who acts in the world and on people. He has saved Elijah, and they are now in a reciprocal relationship where Elijah is attempting to live a life for His glory in exchange. God's 'actions' and what happens in their relationship (conversations, arguments, journeys), directly shapes both Elijah's experiences and how he thinks about himself. For Elijah, going to work is no longer a non-religious activity, but one that has transformed to be specifically Christian in nature. As an elder at the church once explained to me, "if you're Christian, then you're not Christian and a 
builder, you're a Christian builder". Although for some participants, such as Rebecca, the expectations of God can contribute to the feeling of a fragmented self, Elijah's narrative also points to how the active role of God in all aspects of Christians' lives can also be the means by which they can experience their subjectivity as cohesive and consistent.

\section{A counter-cultural identity and cultural critique}

Trustpeakers' identity work involves a complex management of the real, imagined and anticipated demands, expectations and responses from a range of actors. Thus far, my discussion has shown how my participants contend with negative or incorrect understandings of themselves and Christians, by attempting to subvert, undermine or reject these understandings. In other words, I have focused on identity work that is ultimately motivated toward a goal of changing the ways people think about them, or Christians generally. It is critical to explore, however, the ways in which Trustpeakers maintain a Christian identity that embraces alterity and processes of othering. I argue this, somewhat paradoxically, is both a means of resistance to dominant discourses about Christianity, and an engagement in cultural critique.

Several of the interview vignettes discussed earlier in the chapter convey how my participants were eager to minimise discourses of difference, especially in relation to stereotypes and otherdefined understandings of Christianity. However, my participants were, often concurrently, equally eager to set their Christian selves apart from others. The subtle alterity of a Christian identity was conveyed in this exchange between Isaac and Susanna:

Isaac: But I know with my studies, in a class of about 30, I can probably think of one other person that's a Christian, and it's nowhere near that $48 \%$ [listed in the census]. One [Christian] that I know of, and there might be others but, I haven't noticed anything from their actions...

Susanna: So that's interesting that you say 'from their actions', because, when we talk about being Christian in a secular world, I like to think that maybe my actions portray a difference, if you know 
what I mean, because of my beliefs, you know, even in the workplace, and, when you think about things like the Fruit of the Spirit ${ }^{43}$, yeah, but it's challenging sometimes...

Isaac: Yeah! \{laughing\} I think same as you-ultimately as Christians we believe that God is Love, and that in our workplaces and in our environments we should be representing that, because we believe that we have God in us. And I would hope that people would see that in me, but at the same I think I should hopefully be able to see that in other Christians as well...

Here Isaac and Susanna highlight what they perceive to be Christianity's minority status, and focus, by referring to actions, on the difference Christians make in the world. Being Christian (identifying and behaving as such) is not only seen as something that sets Christians apart, but something that they want others to recognise. Lindhardt $(2012,75)$ argues in his ethnography on Pentecostal lifeworlds that for "actors who do not occupy central positions in dominant public fields such as politics, economics, education, and cultural production, resistance and protest are often enacted from alternative and less public sites". I argue that my participants resist dominant discourses of Christianity by being in some ways complicit in the othering of Christianity, and in doing what Jensen (2011) calls "capitalisation". Capitalisation entails not necessarily resisting the status of the Other, but resisting the devaluation of negative elements associated with the Other, and "accentuating those dimensions within the ambivalent gaze of the majority which can be ascribed value" (Jensen 2011, 70). For example, I suspect that very few Trustpeakers would encourage the stereotype of the judgemental Christian because this mode of othering cannot "be given local value" (Jensen 2011, 73). The embodiment of the Fruit of the Spirit on the other hand, can be upheld as both a point of difference, and celebration. My participants' narratives highlight that "agency is not some natural or originary will, it takes shape as specific desires and intentions within a matrix of subjectivity_or (culturally constituted) feelings, thoughts and meanings" (Ortner 2005, 41). While Trustpeakers have agency in how they define and experience themselves, this also takes place within, and in relation to, cultural discourses about Christianity that are beyond their control.

My participants' collusion in the othering of Christianity was more apparent as participants spoke of their Christian identity as being explicitly counter-cultural:

\footnotetext{
43 "But the fruit of the Spirit is love, joy, peace, forbearance, kindness, goodness, faithfulness, gentleness and selfcontrol. Against such things there is no law"-Galatians 5:22-23.
} 
Also, like Isaac was saying, to be a Christian is choosing this obedience to a God, who says that this obedience is actually freedom - but there's still a step there of working out what this obedience looks like and I think a lot of people I know get put off by that part, like: "I don't want to sign up to what I feel like the church will ask of me". (Abigail)

Lydia later expanded on Abigail's point:

Lydia: I think the other thing about secularism currently, there's just the big... what we're working against is the sense of self-determination in people. And in our popular culture. So the idea of being accountable to anyone, particularly God- a God- is quite counter-cultural. Very counter. And so we're going against the grain a lot, the idea of 'obedience is freedom' is counter-cultural....

Jess: ...Because everyone should be "self-made"?

Lydia: Yup. Self-expressioning [sic], um, so we are going against that as well...

Isaac: Yeah, I see our culture as a very independent culture, where, the more independent you are, and self-sustaining you are, the better. Whereas Christianity is almost the opposite: you're humbling yourself and fully depending on God, which, yeah, makes it difficult...

Lydia: Yeah, yeah, it's [seen as] a sign of weakness. \{laughing\}

These Trustpeakers narrate their identity as being distinctly counter-cultural, and in doing so, convey a Christian-specific mode of cultural critique. They are not simply pointing out tendencies associated with different groups of people (dependent versus independent). Rather, this discussion can be read as a critique of modern society that posits self-determination, autonomy, self-sufficiency and pride as pivotal attributes of the modern subject-these are attributes that my participants reject for themselves. Trustpeakers help us understand the multi-faceted and sometimes contradictory nature of resistance; attributes that modern secular discourse might associate with domination (such as powerlessness, obedience, sacrifice, and discipline) are appropriated as sources of resistance and identity construction for these Christians. Indeed, as Lindhardt $(2012,153)$ argues, by accepting and at times idealising human powerlessness, 
Pentecostal Christians "defy the logic of secular social and cultural hierarchies and constitute an alternative theological and ontological positions for themselves in the social world".

\section{Conclusion}

In this chapter I showed that my participants' identity work is deeply dialogical-it involves the ongoing negotiation and navigation of real and imagined expectations of the Christian self by my participants, as well as other non-Christian and Christian actors, and God. For some participants, the complex interplay between competing influences, expectations, and obligations involved in Christian identity work led to experiencing the self as fragmented. However, this fragmentation is more complex than simply being pulled between Christian and secular spheres. It must be understood within a Christian framework in which God's demands of the self often cannot be met. My participants were eager to minimise difference between themselves and secular others, by characterising themselves as regular people. Further, since they felt that others' perceptions of them as Christians were often misaligned with their own-especially in relation to negative stereotypes of Christians-a component of their identity work involved attempting to change people's perceptions of them, or of Christians more generally. Paradoxically, however, my participants also sought to set themselves apart as counter-cultural and thus also simultaneously embraced some negative or dominant understandings of Christians. Cultivating a counter-cultural identity also required denouncing positive attributes they saw as being integral to the good modern subject, and consequently can also be seen as a mode of cultural critique. 


\section{Chapter Five}

\section{Reality and knowledge: Reason, belief, doubt and absence}

Yeah, it's like the apex; we've supposedly reached the zenith of thinking, which is secularism.

-Elijah

One day after coffee, Peter ${ }^{44}$ told me he was going to pray to God about me and let me know the outcome. The next Sunday at church, Peter pulled me aside after the service to say that he had prayed to God, and God had spoken to him in reply. God had said "Tell Jess she is my daughter and that I love her", and Peter wanted to let me know. For Peter, and my research participants, God is an ontological reality. He is a palatable presence in their lives: He talks to them, intervenes in events and relationships, loves them, and sometimes asks them to pass on messages to budding anthropologists. I do not highlight this in order to exoticise or Other Trustpeakers. But it is critical to avoid the tendency in anthropology to justify, explain, or rationalise these beliefs in a way that would distort, or even deny, the phenomenological and ontological reality of them for our participants. As Scott $(2013,863)$ argues:

Anthropologists have been amazed by the alterity of the people who could possibly say such things, but have quickly moved to snuff that wonder-and deny that alterity-under functional, hermeneutical, and cognitive representations of what such 'apparent' claims might really be about (emphasis added).

Trustpeakers require us to acknowledge, or at least entertain, that [some] Christians have a distinct ontological reality, and a distinct epistemological framework to understand that reality. This chapter is thus less concerned with whether Trustpeakers' ontological claims are 'actually' true, than with discussing the ways in which these claims are both narrated and experienced as true. In other words, while I take my participants' claims, and the wonder of them seriously, this chapter

\footnotetext{
${ }^{44}$ Peter is an elder at Trustpeak. He was not one of my interview participants, but someone from church with whom I had discussed my project and Christian faith more generally.
} 
explores the equal wonder of the epistemological and ontological frames that enable and produce such claims. In this chapter, I show that Trustpeakers challenge dominant, secular discourses of what constitutes legitimate knowledge and knowledge-making. In describing their faith, they do not position intellectual 'knowledge' and spiritual 'belief' in binary terms. Rather, the intellectual and the spiritual are seen to be complementary, entwined, and even reciprocal. In this way, Trustpeakers undermine not only the intellectual/spiritual dichotomy but also "a number of boundaries that pervade secular discourse" such as belief/knowledge, reason/imagination, and objective/subjective (Asad 2003, 23). Further, in unpacking my participants' epistemological framework, I argue that Trustpeakers also challenge dominant understandings of belief and doubt. For them, belief and doubt are not preconditions for knowledge, nor are they polarised descriptions of religious conviction. Rather, they are both postures towards reality that work together to produce Christian truth. Finally, I argue that Trustpeakers convey the need for a more nuanced view of ontology more broadly. While my participants may have an ontological reality distinct from a secular one, the limits of that reality, and the conceptual tools available to make sense of it are shaped by the current episteme. Thus it is important to recognise that ontologies may be distinct without being monolithic, and that 'other' ontologies do not only exist outside of the West.

\section{[modern] Knowledge}

According to Foucault, all knowledge is discursively produced, and knowledge is always linked to specific historical and cultural moments (Rabinow 1984, 3-4). The current limit of knowledge-the episteme-is both symptomatic, and a contributory cause of modernity. I use episteme as formulated by Foucault $(2002,168)$; it is the collective, unconscious parameters of knowledge, which "define the conditions of possibility of all knowledge, whether expressed in a theory or silently invested in practice". The limit and role of knowledge has been central to the modern project. In this way, modernity can be seen as a global condition (Wittrock 2002, 55) and a distinct episteme, which establishes a dominant epistemological and ontological reality. This reality is structured around a number of dualisms: intellectual/spiritual, belief/knowledge, rational/feeling, objective/subjective, which are not neutral representations of how the world really is, but are tangled up with various moral and political assumptions. As Duara $(1991,67)$ argues, modern 
discourse structures "the perception of the world not only cognitively through the categories of rationality and science, but also by means of such values as progress and secularism, which are often inseparably entwined with the former". Rationality and science establish themselves on principles of naturalism, which posit that there is nothing in (or of) the world but material and physical things (Smith 2008). As such, 'reality' is also a discursively authoritative concept, which is arrived at through a specific paradigm of knowing - that by implication also conveys various moral or ethical orientations. Given that the discursive paradigm of knowing in the current episteme can be glossed as "science" (Rabinow 1986, 235), reality as a discursive concept is arguably deeply secular.

Now, two caveats must be made. Firstly, while the current episteme is deeply tied to the hegemonic status of scientific and rational knowledge, I do not suggest that most people, non-Christian or otherwise, understand and narrate their world by way of complex scientific or evidence-based models. Nonetheless, those in 'Western' liberal societies tend to be taught from a young age that Science is the only universal source of knowledge that can be used to verify claims to truth (Vasconcelos 2008, 14). More deeply, "scientific practices, techniques, knowledges permeate and create the very fibers of social life..." (Asad 2009, 49). Further, given the construction of science as objective and neutral, it is most likely to be deployed to make sense of concepts or claims which we cannot make sense of via our own experience.

Secondly, while Giddens and Pierson (1998), along with many others, reject the claim that we live in a post-modern society (arguing that at best, we are in a period of late modernity), I recognise that there are post-modern movements in anthropology and the social sciences more generally, seeking to destabilise naturalism's authority in defining reality. This post-modern attitude to truth can be seen most prominently in anthropologists focused on phenomenology and ontology, whose work I draw on in this chapter. Notwithstanding these caveats, the current episteme is such that the dominant ontological structure of reality, and the means by which one can arrive at that reality, is inextricably bound up with the hegemonic status of scientific and naturalistic discourses. 


\section{Christian science or scientific faith?}

Given the hegemonic status of naturalism, can science be Christian? And can [Christian] faith be scientific? Normative definitions of science posit it "as objective, logical, and systematic method of analysis of phenomena, devised to permit the accumulation of reliable knowledge" (Lastrucci $1963,6)$, while the definition of faith is "complete trust or confidence in someone or something", or "strong belief in the doctrines of a religion, based on spiritual conviction rather than proof" (Oxford Dictionaries, n.d). Given these definitions, the questions above are seemingly oxymoronic. For my participants however, these questions are not only valid, but would likely be answered with a resounding "yes". I observed firsthand the practical unification of the 'spiritual' and 'scientific' when I attended a Christian apologetics session one evening. Christian apologetics is "essentially a question of how to engage with a non-Christian interlocutor in order to persuade that person of the validity of Christian faith and practice" (Graham 2017, 6-7). The evening began with a presentation focused on how a scientific and mathematical analysis of the Big Bang proves the existence of a Christian God. A discussion followed the presentation, which included casually interested Christians, as well as subject-matter experts. Both the presentation and discussion involved a complex amalgamation of astrophysics, physical cosmology, geometric theory, quantum physics, mathematics, historical analysis, theology, as well as personal experiences and relationships with God. The attendees switched effortlessly between these spheres of knowledge in their discussion. Further, the grouping of these different spheres to make an argument about the existence of God was not viewed as problematic by the discussion group in the slightest. The group's methodology did not favour 'scientific' or 'faith-based' methods or sources of knowledge in answering the question "Does a Christian God exist, and how can we prove it?", because the question itself was not one of faith, but of the nature of reality.

Similarly, Isaac, who was not present at the apologetics discussion, also undermined the dichotomy of 'faith' and 'science' when we discussed whether non-Christians had strong beliefs:

I think a lot of people would have very strong beliefs if we're looking at, for example, science, the creation of the world, Big Bang and everything like that-a lot of people have very strong beliefs that that's how it all took place. And personally I believe that too, that God created science as well. Of course science is not going to disprove Him. I think we both have-whether people identify it or not- 
faith at some point, because you can say "well where did the universe start?", but then you'll go back to saying "how did the big bang start?", and even that's not fully cemented how people think it happened. And you've got to-they've [non-Christians] got strong beliefs, they're like "there is an explanation for it, we just don't know what it is yet", and for me, I still believe science, I believe the Big Bang happened, but my faith comes in that God started the Big Bang...and I think people do have that faith, especially in other areas of science where there are like scientific anomalies, where we're like "we don't know how this happened" but, they've got a firm belief that it's not a miracle, there's a scientific explanation for it...

Isaac's use of belief further complicats the objective/subjective, intellectual/spiritual, and rational/experiential binaries, by applying belief and faith equally to both God and science. Here Isaac's discussion can be seen to enchant 'empirical-based' knowledge and disenchant that which is 'faith-based', dissolving any kind of meaningful distinction between the two. In other words, Isaac believes in God inasmuch as people believe in science.

Another participant, Simon, challenged not the distinction between faith and scientific practice, but between belief and critical thought. For Simon, belief in God requires being critical about Christianity and pursuing truth in a way that goes beyond worship, but ultimately does not compromise on the trust in God:

And, because of those years of me growing up as a Christian and then going “ $\left[I^{\prime} m\right]$ not sure about this", but then having to really dig deep into it and ask the hard questions of life, you know, you read the books you think critically about the world, and about Christianity and your faith, and you think: "I've gotta have some answers, why do I believe in this?" But again I don't think that's what sustains you long term in a deep faith with God, you need to have something more, you need to have-it's hard to describe, it's a wonderful thing...

For Simon, his faith is not only comprised of spiritual encounters, or worship, or prayer, but requires a process of intellectualism and rationality. The experience of God, something he struggles to articulate, is what sustains his rational belief that God exists. This challenges the dominant paradigm of knowledge-making models, which tends to operate "on the presumption that different domains of reality correspond to specific modes of evidence, and on the attribution of different kinds of social power and dignity to those modes" (Vasconcelos 2008, 14). 
Trustpeakers do not employ an exclusively theological mode of evidence to make an ontological claim about God; rather, they see one domain of reality (in which God exists) that can be explained through a complex framework that unifies spiritual experience, theological thought, and empirical evidence. This was further highlighted as my participants made it clear that they did not consider all matters of spirituality to be inherently good or true. As Abigail reminded the group in our interview, "I think for us as a church we're always working out if we're engaging with something which is spiritual, and how we make sense of it and what it looks like to do that as a Christian. That still takes some working out, we don't say everything that is spiritual is good and 'go for it'."

Smith $(2008,881)$ claims that what makes a Pentecostal ontology remarkable is not a correlationist stance, but one of "enchanted naturalism". That is, rather than attempting to correlate theological claims against a scientific yardstick (an approach that some Christians do attempt, and of which Smith (2008) is critical), enchanted naturalism entails that one "does not see the Spirit's care and activity as exceptions or interruptions of the 'normal' ordering of the universe" (Smith 2008, 888). Trustpeakers' epistemological framework is based on an understanding of the world in which the enchanted and the natural are not made of different 'stuff' - rather, the spirit is always at work in and on nature (Smith 2008, 890). It is thereby not paradoxical that my participants believe in both God and science-in general, and specifically in relation to their faith-, and that these are not considered to be separate or polarised spheres. Further, as Isaac and Simon's narratives highlight, the meaning and operation of 'belief' may change in different ontological contexts. They remind us that Christians may not formulate concepts like belief along hegemonic lines. In the following section, I show that the meaning and use of belief in a Christian context requires close examination, and helps us to better grasp my participants' understanding and experience of the world.

\section{Belief}

The conceptual application of belief and its inherent relevance to religion within anthropology has been heavily contested (Bielo 2012; Bialecki 2017; Lindquist and Coleman 2008; Robbins et al., 2007). This debate has in part been spurred by a criticism that anthropologists have conceptualised belief in the Judeo-Christian tradition (as an internal conscious state) and applied it to non-Christian contexts. For example, in Asad's $(2009,47)$ now renowned critique of Geertz' 
paradigm of religion, he argues that Geertz' fallaciously defines religion by centering belief as a state of the mind, rather than a "constituting activity in the world". Asad $(2009,47)$ asserts that this privileges a Christian formulation of religion, arguing that "the [modern] Christian apologist tends not to regard belief as the conclusion to a knowledge process but as its precondition".

While Asad's critique of Geertz' universalism may be fair, some anthropologists of Christianity are not convinced that belief, defined as an internal condition or state, is an accurate representation of Christianity. They argue that belief is better conceptualised as lived commitment (Bielo 2012), transcending faith (Elisha 2008), or trust (Jenkins 2012). Robbins et al. (2007) argues that belief has not been helpful to the anthropology of Christianity because the semantics of the word have not been appreciated. They claim that to say "I believe in God, for example, means to trust it and implies a commitment to act in a certain way toward it"; it conveys a sense of certainty and conviction. In contrast, to say "I believe that..." implies a sense of uncertainty due to its propositional nature (Robbins et al. 2007, 14). I argue that both definitions are problematic. By evoking 'trust' and 'uncertainty', both definitions rely on the implicit binary categories discussed earlier in this chapter. Contra Robbins et al. (2007), I think a more obvious, yet more challenging problem than dissecting the semantics of belief, is considering whether anthropologists can use belief as an analytical concept if to do so requires that a distinction already be made between 'belief' and 'knowledge' - especially when this distinction is not reflective of our participants' views (even though they might use the term), but symptomatic of our own ontological persuasions to naturalism (Lindquist and Coleman 2008, 5). One solution is that we make belief an object of study in and of itself, but not what people believe, or even how they believe, but how they conceptualise and narrate belief.

So far my participants' narratives have demonstrated that for them, belief is not oppositional to the rational. Belief can be drawn upon as a method to understand the world; a method that also sits alongside, interacts with, or includes empirical, scientific, or common-sense based models. But what exactly is belief for them? What does it mean to believe?

I guess because the spiritual requires believing in something that's not tangible. I was talking to a colleague (I'm a teacher) and he's been doing some philosophy with his students, we were just talking 
about that whole aspect of spirituality and how difficult it is to believe in it if you don't believe in something outside of our own tangible world... (Susanna)

Here Susanna highlights that she doesn't see belief in a Christian God to be specifically difficult per se, but rather, it is difficult if the possibility of belief is absent. For her, the Secular is such, not because it rejects the existence of a particular God, but because it rejects the idea of the existence of God. Smith $(2010,33 ; 88)$ argues that Pentecostal Christians have a "deep sense of expectation and openness to surprise" within an ontological worldview of "radical openness". In this way, Susanna demonstrates that belief is not necessarily conviction in the existence or presence of God at all times, but rather an openness to the idea that He might exist. Peter conveyed a sense of this same openness to me over coffee one day. In our conversation I had implied that Christianity was an identity; an idea that Peter seemed sceptical of. "No? What is it then?" I had asked. He didn't say anything at first, but simply thrust his palms in front of him, uplifted, as though cupping a bowl. "It's a posture", he said. To believe is thus a stance, a mode of existence (Lindquist and Coleman $2008,7)$, which is fluid and always-in-the-making. Bialecki $(2017,204)$ suggests that we should define religion as "a kind of relation with or orientation towards beings that are in some ways strikingly more than human" (emphasis in original). However, I would argue, based on my participants' narratives, that religion, and specifically religious belief, is not to have a particular relationship with non-human beings, but with reality. If belief is to have a particular relationship with reality, what role then does doubt-usually articulated as belief's antonym-have in this relationship?

\section{Doubt}

During Rebecca's interview, she traced the genealogy of her relationship with God and faith, which began when her parents each (separately) converted to Christianity when she was about five years old. She told me God had entered her life near the same time as her parent's divorce, and consequently she had developed negative connotations with God until she was older. She narrated a pivotal moment for her in terms of her faith in God:

So then, when I was about 13 or 14, with my mum and my step dad, it was all quite messy, and really, really, hard. I just remember I would cry a lot in third form and fourth form, [l'd] cry all the time. Just 
be in maths; start crying. It was so embarrassing and I absolutely hated it. And I just remember saying to God (which must've meant that I would talk to Him), saying to Him: "I can't do this anymore. You need to show me that you're there." And I said that to Him (...) because I was just done. And then the next day, I woke up and I couldn't cry, and I didn't cry for three months... So I had said to Him "you need to stop this crying", and then it stopped. So for me, that was just-and even when I wanted to cry, you've had that feeling, where tears just wouldn't come out? I was like "I just wanna cry now!" \{laughing\}. I guess lots of people could say that it came about by anything, but for me, that was God...I asked Him to show me that he was there, and He really really did. So I think that's one of the strongest-anytime now that I doubt, "is God there?", that just comes back into my mind straight away, because it was such a tangible experience for me.

How is it possible that in an example intended to illustrate the unequivocal existence of God, in which His presence was tangibly experienced, Rebecca can still talk about doubting? If her inability to cry was undeniably caused by God, how could she question God's existence? Lindquist and Coleman $(2008,5)$ point out the ambiguous and paradoxical nature of belief; "'To believe' is to state a conviction but with the added nuance 'I am not sure'. To state a belief is to open a possibility of doubt". Indeed, doubt is arguably an "intrinsic quality of most, maybe all, religious traditions" (Blanes and Oustinova-Stjepanovic 2015, 8). I agree that doubt is central to questions of Christian conviction, and I argue that it only appears problematic in Rebecca's narrative if we assume that doubt is antithetical to belief. I suggest that, as with belief, we need to situate doubt in the context of a Christian framework in order to understand not only what doubt means to Christians, but also what doubt does.

As Blanes and Oustinova-Stjepanovic (2015) point out, there is a surprising dearth of anthropological literature on doubt as a general phenomena, and I would suggest there is even less so focused on doubt within the anthropology of Christianity. One anthropologist of Christianity who has focused on doubt is Tanya Luhrmann. Luhrmann (2012) argues that while doubt is inherent to the Christian faith, the salience of doubt for Christians in secular societies has increased due to secularisation. This argument aligns with Taylor's (2007) thesis, and posits that Christians are deeply aware that many (ostensibly moral, intelligent, kind) people do not believe in a Christian God, and this causes doubt to feature more strongly in shaping the nature of their faith. However, I argue that role of doubt in Christianity is not simply brought about by an awareness of secular 
doubt. Rather, as Giddens (1991) points out, modernity itself fosters a culture of doubt; a culture that Trustpeakers are also embedded in. We must therefore see their application of scepticism in discovering and producing truth in this wider context. For them, authentic Christianity is not thoughtless trust, or liturgical/cultural practice, but a critical and engaged faith. As Simon and Abigail's vignettes have illustrated, the emphasis on being critical and asking questions was not an attempt to 'verify' their faith for secular sceptics, but rather was an appropriation of dominant knowledge-making models for their own [religious] ends. This shows how the role of doubt in Trustpeakers' conceptual practice is not merely a reaction to an increase in secular doubt, but is firmly shaped by the current episteme. As Harding (1991, 374) reminds us, Christians "do not simply exist 'out there' but are also produced by modern discursive practices".

Thus, when Rebecca says "anytime now that I doubt", this is at once being enacted in the modern Western epistemological spirit of scepticism, and is a distinctly Christian mode of engaging with faith and God. Doubt in this context should "not to be equated with unbelief or disbelief but rather with a vacillation between the two opposites: unbelief and belief" (MacGregor 1987, 424). This vacillation is enabled by the distinctly Christian posture, or openness, discussed above: Trustpeakers are open to the unexpected, to be challenged and persuaded. As Pelkmans (2016, 501-502) posits, the act of doubt both presupposes certainty and animates the search for certainty. Rebecca conveys this paradox with striking similarity in her narrative. Her initial doubt that required her to ask God to show Himself ("I asked Him to show me that he was there") is in itself contradictory because it carries the presupposition that God must exist in order for her to talk to Him and make demands of Him in the first place. But this underlying presupposition of God's existence does not negate doubt, rather it is what enables her to doubt His existence with a view to seeking certainty ("and He really really did"). Therefore, I argue that Trustpeakers' openness to the idea of the possibility of God does not preclude doubt, but rather, it encourages it.

\section{Absence and nonsense}

For Esther, doubt is not as salient in her religious conviction as the spiritual, emotional, and inexplicable experiences of her faith. The fact that what happens to her when she worships, or 
thinks about God, cannot be explained, is not a problem to be solved, but is evidence of the Holy Spirit. As she explained:

Esther: We try to be a deep-thinking church, and I love the way that Joel ${ }^{45}$ talks about things and preaches. It challenges [you] and makes you think deeply about things. But then, on the other hand, we've talked about the intellectual side, [but] the emotional side of Christianity is something that I find, I actually-ugh, how do I explain this? It's probably the thing that, for me, confirms my faith most of all, because I can't explain it. It's inexplicable the kind of strong emotions that I have [which are] in no other area of life. I don't often cry, well when I'm pregnant I cry a lot \{laughing\}, but when I'm in normal day-to-day life, non-pregnant, I'm [a] pretty matter of fact person. Unless something's very upsetting and then I might shed a tear. But every time I think about [God], if I'm in worshipworshipping God at church or at home, with worship music and stuff (...) I'm like choking [the emotion] back. It's that whole emotional side of it, and I believe that's totally the Spirit, the Spirit moving within you, and that's something I can't explain any other way. Nothing else gets to me like that, so I really believe that. That's one way that I really feel God as being really true and real in my life...

Jess: Do you think maybe that's even more so what [non-Christian] people struggle with?

Esther: Yes, because that's the inexplicable, you know, that's the supernatural, and they'll be like: "that's just weird, you're just getting caught up in the hype". But this would happen when I'm just listening to a song by myself at home, it's not like I'm in a big group of people and there's lights, and this really amazing music and it's steamy or something \{laughing\}. But I think you're right, people would struggle with that because that's the weird, eerie, really weird, airy-fairy stuff that no one can understand...

Thus far, I have argued that my participants do not exist independently of the secular modern episteme-that is, they do not independently create their own limits of knowledge. I have shown that while their truth claims appear antithetical to dominant epistemological frameworks and paradigms of truth, they conform more closely to these than secular discourses would posit. However, as mentioned in my introduction, as an anthropologist I need to be wary that in trying

\footnotetext{
${ }^{45}$ Trustpeak's pastor.
} 
to make 'the strange seem familiar', I do not deny the strange altogether. Indeed, it is the strange, weird, and inexplicable that Esther focuses on in her experience of the Holy Spirit. As Leistle (2015, 294) argues, sensory experience is inherently incomplete: "it emerges from a blind spot, one's own body and standpoint, and it can only ever give us a partial hold of the object to which it relates". Esther attributes her emotional experience God's presence but also embraces that this experience and her understanding of this experience, is incomplete. This blindness, and incompleteness, was not avoided by my participants in seeking or knowing truth, but was seen as an inherent component of truth. Put another way: while some truths simply cannot be known for certain, that does not make them any less true. I heard congregants speak at church services of God's miracles in their lives, such as God healing an illness, or bringing about a promotion at work. These stories were almost never presented as a complete narrative of "God healed my illness", but rather "I prayed to God to heal my illness, and two days later, I don't know what happened, but my illness was healed. And that was the work of the Lord". Incompleteness and inexplicability were seen as evidence of the Holy Spirit, not something to be reconciled. As Susanna unapologetically stated of her faith: “it doesn't make sense actually \{laughing\}. It doesn't - it isn't easy to explain at times because...that's the whole aspect of faith."

I argue that this Christian epistemological stance of embracing the absence of meaning and comprehension was embodied in the practice of glossolalia. Glossolalia, or what is more colloquially known as 'speaking in tongues' is a typical practice for a Pentecostal-Charismatic church (Luhrmann 2012). It involves the utterance of "nonsense syllables" as a mode of prayer to God (although some Pentecostal Christians also claim to be speak in a recognised language), or sometimes it is interpreted as an "inspired message or prophecy from God" (Csordas 1990, 23-24). During my fieldwork at Trustpeak, I observed congregants practicing glossolalia at every Sunday church service and Wednesday worship evening. While it occurred at every service I attended, it wasn't widespread in the congregation, and was mostly practised by elders from the church. With that said, I did not get the sense that glossolalia was considered unusual or peculiar by the congregation. The glossolalia I observed was very diverse. It included emphatic and dramatic utterances in utterly foreign languages, but also manifested as whispered murmurs interspersed with intelligible speech. In fact, glossolalia could be so subtle that it once it took me several weeks of attending church services to realize that a particular congregant was speaking in tongues and not in English. 
Csordas $(1990,26)$ examines glossolalia in the context of Pentecostal-Charismatic Christians, arguing that it "facilitates, and is the embodiment of non-verbal thought". For Csordas (1990, 26), it is precisely the absence of intelligibility or semantic meaning that "reveals the gestural meaning of language" and which enables the sacred to become concrete. As my participants have highlighted in this chapter and elsewhere in this thesis, their faith is strongly linked to surrendering to God, and as a result, also to things not always making sense. Speaking in tongues was described to me by a participant as surrendering oneself to speaking God's word, although conveying this word did not necessarily mean that you would understand it. As it is God's word being spoken, for my participants, glossolalia is not nonsense, or symbolic of truth, but can be seen an act of "pure communication, incapable of uttering any "wrong words'" (Csordas 1990, 27). These utterances are more 'true' than any other form of knowledge- by virtue of them being unintelligible to both the speaker (and almost always) the listener ${ }^{46}$. Other forms of knowledge, even the bible, are mediated, and thus, corrupted, by human interpretation.

I disagree with Csordas' (1990) position on the source of glossolalia, however. While he accepts that talking in tongues is a phenomenological reality, he argues that the "preobjective phenomena" that enables glossolalia is "misrecognized as originating in God instead of the socially informed body" (Csordas 1990, 33). To claim with authority that God is not 'actually' the source of these utterances simultaneously denies an ontological reality in which God exists and speaks to people, and ignores Christians' own explanations for how and why speaking in tongues occurs. Contra Csordas (1990), I argue that Trustpeakers think that speaking in tongues is truly a divine message from God not because they have misrecognised some "preobjective phenomena", but because it has been made true by a distinctly Christian way of thinking about what truth is, or could be. While I appreciate Csordas' $(1990,23)$ emphasis on the body as a subject, and thus the locale of culture, the claim that the body is the existential, not the experiential ground of the sacred, inescapably privileges certain types of reality, and in doing so neglects the ontological and epistemological challenges presented by Pentecostal-Charismatic Christians. I argue that we must examine glossolalia, ideally within, but at least in relation to, a Christian epistemology. In this way,

\footnotetext{
${ }^{46}$ One elder told a story during a church service of a time where he spoke in tongues and was advised by a member of the congregation that he had been speaking in Portuguese. The elder did not speak Portuguese and so these words were unintelligible to him, but not to those who understood.
} 
this epistemology enables speaking in tongues to be both a source, and evidence of truth-by way of it not being able to be deciphered as such. Thus, for Trustpeakers, speaking in tongues is the embodiment of nonverbal truth, not nonverbal thought, as Csordas (1990) argues.

In identifying and conveying truth by appealing to absence-the absence of explanation and intelligible meaning-my participants take a demonstrably divergent "epistemic stance" (Luhrmann 2012), and fundamentally challenge dominant understandings of what constitutes the category of knowledge. If for example, my participants claimed that the Holy Spirit existed, moved in them and talked to them, and 'proved' this by an appeal to 'evidence' this would be a distinct ontological claim ("the Holy Spirit exists"), but not a distinct epistemological approach ("we can know the Holy Spirit exists by proving it via evidence"). In claiming that they know the Holy Spirit exists by evoking the fact that they do not, or cannot know, my participants present an epistemological challenge, in addition to an ontological one. Speaking in relation to indigenous knowledge, Gélinas and Bouchard $(2014,49)$ argue that the challenge to anthropologists is to "define knowledge in a way that is, a priori, neutral" so that scientific knowledge and indigenous knowledge can be meaningfully compared-otherwise indigenous knowledge tends to be exclusively seen in terms of belief. But how do we neutrally define knowledge in this instance where the definition of 'knowledge' includes the absence of it? For Trustpeakers, absence and nonsense can be as reliable, legitimate and informative resources in understanding the world as formal empirical theories or scientific models.

\section{Conclusion}

In this chapter I have argued that Trustpeakers have a distinctly Pentecostal ontological reality, and employ a distinctly Pentecostal epistemological framework in understanding that reality. In this reality, God is not only real, but $\mathrm{He}$ acts in, and on, the world-consequently, 'spiritual' domains, such as prayer, become disenchanted as 'regular' domains of knowledge, while domains which tend to be thought of as secular are enchanted with God's power. In this context, making a meaningful distinction between categories like knowledge and belief, faith and reason, and even objective' and 'subjective' becomes very difficult. Attention to my participants' ontological and epistemological stances, I suggest, enables a more nuanced and rich understanding of belief and 
doubt, and how these are deployed in Christian meaning-making. Or put another way, it enables us to consider not only what Christians believe and how they 'believe', but how they themselves understand the process of believing.

While I have argued that my participants' ontological stance diverges from a dominant stance of naturalism, it is evidently not wholly disconnected either. Thus, I would like to conclude this chapter by proposing that anthropologists need to take a more nuanced approach to studying ontology by not assuming ontological divergence only occurs outside the West, and that ontologies do not interact, overlap, and connect. Indeed, the defining voices of the ontological turn ostensibly replicate the dualism they were trying to critique and avoid. Anthropologists such as Holbraad (2012), Viveros de Castro (2015) and Descola (2013) have all focused on 'non-Western' cultures, and insisted that the worlds of these 'non-Western' cultures are ontologically distinct from 'our' Western ontology. This reification is exemplified (in content and in name) in Decola's Beyond Nature and Culture (2013), in which he argues there are four ontological styles: Animism, totemism, analogism, and naturalism, with Western ontology clearly residing in the naturalism category. I note that while ethnographic examples abound throughout this work, no substantial ethnographic examples are given for naturalism, as though 'our' ontology is too obvious and uniform to bother examining ${ }^{47}$. Where might Descola place my modern, Western, educated Christians in his ontological scheme, I wonder? In this chapter I have shown that my participants do not fit comfortably within the type of scheme Descola describes; their ontological reality is not identical with that which dominates the West, but this reality, and the means to make sense of is, is also not entirely foreign either. In my following, and final, ethnographic chapter, I argue that the challenging status of Christians in modern Western societies-as simultaneously same/Other, insider/outsider, familiar/foreign - is exemplified by the idea of a secular imaginary, and the role my participants have in producing that imaginary.

\footnotetext{
47 In the chapter on naturalism Descola $(2013,174)$ himself states: “...the doctrinal corpus of our ontology does not require the in-depth examination that more exotic modes of identification do..."
} 


\section{Chapter Six}

\section{The secular imaginary}

Thus far in this thesis I have shown that the relationship between Christianity and the Secular is much more complex than dominant secular discourses might posit. I have shown that, for my participants, a secular/religious binary is problematised in the navigation of social space, identity negotiation, and ontological distinctions, to the extent that even referring to a relationship 'between' Christianity and the Secular is troublesome. In this chapter, I argue that to see Trustpeakers in dialogue with secular discourses, ideas, people or formations is a simplistic view which still positions Christians and Christianity as somehow outside the secular. In contrast, I assert that we must see Trustpeakers as themselves participating in, contributing to, shaping, and being shaped by, a secular imaginary. To think of the Secular as an imaginary-the way in which people picture their whole social existence and that of others-allows for the simultaneity and complexity of my participants' lived experiences, which are neither outside the imaginary, nor entirely congruent with it either. In this chapter I show that Trustpeakers' imaginings of the Secular simultaneously critique the secular imaginary and are shaped by the imaginary. My participants' primary critique was with what they saw as secular hypocrisy-they claimed that tolerance was extended to other religions in New Zealand, while Christianity was open to derision. However, they drew on an imagining of a secular ideal to make their claims. On the contrary, I argue that the application of a secular imaginary enables a more nuanced approach in how we position religious subjects, including Christians, vis-à-vis the Secular. In this chapter, I seek to show how the Secular imaginary is given shape not only by my participants' imaginings, but also by secular discourses, which act upon Trustpeakers as particular religious subjects.

\section{Imagining the Secular}

The concept of an imaginary to describe social existence was originally proposed by Cornelius Castoriadis, who saw the social imaginary as a society's shared, unifying core concepts (Strauss 2006, 324). Taylor $(2004,23)$ expanded on this notion, with inspiration from Benedict Anderson's 
Imagined Communities (1983), formulating the social imaginary as "the ways people imagine their social existence, how they fit together with others, how things go on between them and their fellows, the expectations that are normally met, and the deeper normative notions and images that underlie these expectations". The thrust of Taylor's argument is that ordinary people primarily conceptualise the nature of their society through collective, implicit understandings, rather than formal theoretical models. Imaginaries are not fantasies, or imitations of how society 'really' is, however. As Langdridge $(2006,646)$ argues, "there is no 'real' social world to be discovered outside of language. The social imaginary operates in a similar way to the discourses of Foucault, both allowing and limiting human expression". Further, while imaginaries may limit human expression, they are not prescriptive or totalitarian; we can speak of global, local and individual social imaginaries, as well as political, liberal, and capitalist imaginaries-each of which may overlap with, inform, reject, or counter one another-what Adams et al. $(2015,17)$ refers to as "unity in a plurality".

A social imaginary is thus how a society collectively tends to think about itself-it is both the product of collective thought and the means by which individuals make sense of the social. As Gaonkar $(2002,11)$ states, "the social imaginary therefore occupies a middle ground between embodied practices and explicit doctrines. The relation between the three is dynamic. The line of influence is not causative but circular". Therefore, an imaginary is at once individual and collective, a mode of understanding and an outcome of that understanding, both normative and contested. As social imaginaries entail how meaning is both collectively instituted, and comes to have instituting force, it is consequently tied up with power relations (Adams et al. 2015).

To speak of a secular imaginary then, is to consider how common understandings and a shared cultural disposition produces secular "ways of understanding the social that become social entities themselves, mediating collective life" (Gaonkar 2002, 4). Thus, in this chapter, I use 'secular imaginary' to refer to a cultural disposition-a collection of "concepts, practices, and sensibilities" (Asad 2003, 16)-that shapes how the Secular is conceptualised and experienced. A secular imaginary is consequently not limited to those who are 'secular' or non-religious.

While Taylor $(2004,35)$ formulates an imaginary as a disposition, or habitus, he does not completely discount the relevance of theory. He argues that theories come to "infiltrate and 
transform our social imaginary", forming the basis of underlying understandings, presumptions and frameworks. This is evident in the influence of twentieth century secularisation theses, which originated with Weber and Durkheim, and became a staple of the sociological canon via Berger $(1969)^{48}$. The permeation of secularisation theses into the imaginaries of almost all Western societies was such that they became to be seen as simple descriptions of fact rather than theories or predictions. As Cannell $(2006,32)$ points out in her discussion on fundamentalism:

All those concerned are acting as though some crude version of Weber's theory of secularisation were an absolute truth. They [fundamentalists] are enacting one particular myth about modernity; they all believe in the essential opposition of modernity to Christianity, or at least fear it to be true. So in considering the relationship between the two, we have to reckon up not only how far it may be true that institutions have changed in the ways that Weber predicted, in any given locality, but also how far it might be true that the people in these localities believed that this would be so and therefore to some extent enacted that belief as history. In that sense, ironically, Weber himself has been treated as prophet.

Similarly, it was evident that my participants took it for granted that secularisation was a social fact, and that New Zealand, as a modern society, would be secular. That which is taken for granted is usually unspoken, and consequently my participants did not necessarily state this in overt terms; however, it is not insignificant that they never proposed a counter narrative-there was an implicit acceptance by them that New Zealand was secular, and had become more secular over time.

Further, while the narratives throughout this thesis have shown that Trustpeakers often attributed their experiences of marginalisation, othering, and even discrimination, to secular sensibilities and biases, not one of my participants ever critiqued the logic or morality of secularism itself, or pined for a more 'Christian' society. On the contrary, some participants stressed that they thought secularism was a good, necessary formulation of society. For example, in our interview, Elijah and I discussed how the place of religion had changed over time. Elijah thought that in contemporary Western societies, religion had largely been pushed out of the public sphere, in contrast to several

\footnotetext{
${ }^{48}$ In the late 90s Berger (1999) changed his view on secularisation, conceding that his predictions that modernization necessarily leads to secularisation were mistaken.
} 
generations ago, where "you would've been in a minority to not be religious, or to be visibly religious". He elaborated on his opinion about this:

(....) so that's really different. I mean I don't think it's a bad thing, because I don't think that religion and the State should ever be-if Christians are not given positions of power because they're Christians, I don't care \{laughter\}. To put it simply. I really don't care. Because I don't think that Christians should be politicians so that they can make a more Christian society, I don't think that's a thing - Jesus said 'my kingdom is not of this world' when he was being taken to trial, and his apostles were trying to save him, to stop him from being killed, and Peter cut off the ear of one of the guards (...) but Jesus told him to stop it, and said 'If I wanted to be saved from this, I could send for a thousand angels to come and rescue me'. You know what I mean? He intended to go there, he wasn't trying to build this military kingdom - he was trying to build a kingdom of saved people. And so if you look down through the Ages, and see the countless examples of Christians trying to claim earthly power, it's never gone down well, it's always failed, and it's actually just done more harm to The Witness ${ }^{49}$, because it makes it look like we're out there for power.

For Elijah, the recession of religion from the public sphere, the separation of religion and the State, and even the absence of Christians from positions of power, are logical, natural and positive characteristics of a modern society. Elijah demonstrates an imagining of the Secular, one that simultaneously deploys formal secular doctrine (the separation of Church and State) and Christian sensibilities about the nature of this world, versus the kingdom of God. Consequently, rather than analysing Elijah's narrative as that of a Christian in dialogue with a secular imaginary, I argue that his narrative must be seen as a Christian both utilising and reproducing a secular imaginary.

\section{Critiquing the Secular/imagining the ideal}

While Trustpeakers drew on a secular imaginary to make sense of the Secular, this does not mean they were never critical of the Secular and secularism. However, this criticism was far from straightforward. I argue that their criticisms of the Secular reflected an awareness of, and

\footnotetext{
${ }^{49}$ Witness in a Christian context can refer to a number of things. It may simply be a shorthand for a practicing Christian (who has witnessed Jesus and/or God): "You shall be witnesses to me in Jerusalem, and in all Judea and Samaria, and to the end of the earth" -Acts 1:8. It may also refer to those who specifically witness for Christ, that is, share God's message with others.
} 
dissatisfaction with, being constructed as particular religious subjects. But, simultaneously, Trustpeakers also drew on the sensibilities of the Secular imaginary to make these critiques. Indeed, my participants' criticisms were generally not of what they perceived to be secularism's core principles-intellectualism, rationalism, and tolerance-but that secular practices or acts largely fail to deliver against these principles, particularly the principle of tolerance. Not only did my participants feel that tolerance was held up as secularism's virtue and Christianity's failing, but also that tolerance in New Zealand was only extended to some religions, and not to Christianity. Specifically, they argued that those religions seen as cultural or ethnic minorities (such as Islam, Hinduism, and especially Māori spirituality) were 'tolerated' in New Zealand society, while Christianity was open to derision. As Susanna put plainly: "Yeah and a lot of Eastern religions...seem more acceptable [in New Zealand] than Christianity". Almost every one of my participants stated or implied that Christianity wasn't treated the same as other religions or forms of spirituality. As Susanna and Lydia discussed in our group interview:

Susanna: Yeah it's interesting, because I'm in education and it's okay to do stuff on other faith's festivals, but we're not really meant to talk about Easter - except for eggs and stuff \{laughing\}- you know, and Christmas. So, that always intrigues me, why those festivals [are okay] and yet we [aren't okay]. We're allowed to do stuff for Diwali and other different [religious] festivals, um...

Jess: So do you think that different religions, or different types of spirituality are treated differently in New Zealand?

Lydia: Well, I think some are more socially acceptable in day-to-day conversation, like Yoga, you know, Yoga and Eastern meditation. Meditation - that's cool.

Susanna expresses frustration that only certain aspects of her faith are seen as culturally acceptable, while other religions' festivals appear to be freely celebrated. Lydia implies it is not that spirituality is inherently unacceptable in social space, but only certain forms of spirituality. Thinking back to my participants' narratives of navigating social space in Chapter Three, it is evident that their understandings of space were inextricably bound up with their imaginings of the Secular. Here, Lydia and Susanna's critique speaks to a double imagining of the Secular-it is conceptualised in its current form as not delivering against a set of principles (which are also imagined), and it is imagined as an ideal (in which all religions are tolerated equally by those who 
are non-religious). Simon also conveyed the idea that religions were not seen equally in New Zealand:

Simon: I think the other thing about New Zealand culture that helps a lot is - I've got a very close friend who's Māori, and they have a deep spirituality. And so every time I go to his house, quite often he'll ask me to pray. And there will be just a whole bunch of non-Christian people, but they'll ask the religious person to pray, and I'm quite happy to do that and so I'll just pray a blessing....

Jess: Because it's traditional?

Simon: It's a traditional thing. And so Pacific Island and Māori culture [is quite spiritual], so there's sort of contradictions to all of this, depending on the context that you're in (...) - If I was to go into a school for example, I should do a prayer in Māori, and it'd be fine-a karakia ${ }^{50}$-they'd be sweet with that, but if I was to do it in English, that's probably not a good idea....

In fact, the place of Māori Christianity and spirituality was cited on several occasions as an illustrative comparison to Pākehā, Judeo-Christianity. This became a focal point of discussion in our group interview:

Susanna: But yet it is [religion] acceptable in a Māori context, you know-a Māori prayer or blessing is okay. It was interesting with one school I was working in, where there was a group of women who were doing Kapa Haka, and they actually taught Māori songs that were Christian Māori songs, but it was okay because it was sung in Te Reo... (...)

Lydia: If you understood what they were chanting in the maraes - they have this sort of dialogue. We have a Māori teacher who told us what's actually happening: they're having a spiritual battle, they are invoking powers there, and someone-they're like Gandalf- the tohunga ${ }^{51}$, they're actually in the middle of spiritual battle, because they believe that they can have power through intercession to change the way things are! They're right into it, they know about it.

\footnotetext{
${ }^{50}$ Karakia is a Māori term that could refer to "prayers, incantations, spells, charms, offertories, ritual words, rites, pleas, invocations and recitations" (Rewi 2012, 15). While the form and content of karakia shifted to be more Christian-centric following colonisation and the adoption of Christianity by Māori, a karakia is not necessarily an appeal to celestial forms, and may concerned with terrestrial events or situations such as food gathering (Rewi 2012, 15).

${ }^{51}$ In this context, tohunga refers to a Māori spiritual practitioner or priest.
} 
My participants are not deriding Māori spirituality, but rather using it to highlight what they perceive to be secular hypocrisy. Of course, the Christian influence on Māori spirituality must be situated within a context of historical and ongoing colonial violence, a context that is beyond the scope of this thesis. In any case, their point is not that these prayers or practices are 'really' Christian-either in origin or practice. Rather, it is that these practices and words are deeply spiritual, and that if the same words were spoken, or actions carried out by an English-speaking Pākehā Christian, it would be seen as inappropriate in the same social context. Fraser's $(2004,92)$ article on Māori spirituality in secular schools uncovered similar sentiments as my participants, noting that the Christian entanglement in karakia was seen to be problematic:

Some non-Christians may, therefore, feel uncomfortable with karakia, not because of the Māori dimension but as a result of the Christian connotation. Conversely, however, from anecdotal observation it seems that some non-Christians often go along with Christian-based karakia and waiata [song] in Māori, finding (for example) Whakaria mai [How great thou art] less offensive and more acceptable when sung or recited in a language other than English. Whether such non-Christians are conscious of complicity is difficult to know. In addition, some Christians who are not Māori have expressed frustration that they cannot say prayers in English in secular schools while their Māori colleagues can say prayers in Māori.

This conversation highlights how the categorisation of certain phenomena as cultural, religious, or spiritual, and consequently the appropriate social settings and responses allotted to this phenomena, is subject to normative understandings produced by discourses within the secular imaginary. Further, these imaginings and understandings are demonstratively bound up with discourses not only of secularism, but liberalism, multiculturalism, biculturalism, postcolonialism, and tolerance ${ }^{52}$.

In highlighting what they see as secular hypocrisy, it may appear that my participants are rejecting or countering the secular imaginary. On the contrary, I argue that their critiques demonstrate an imagining for what the secular should be and judging their experiences against that imagining. As

\footnotetext{
52 The relationship between the politics of postcolonialism in New Zealand and religion are beyond the scope of my research, but my participants' observations raise some important questions. For example, what is the relationship between postcolonialism and discourses of secularism and liberalism? And how has postcolonialism shaped, and/or continues to shape, terrains of tolerance in New Zealand?
} 
Taylor $(2004,25)$ argues, integral to any imaginary is the meeting of certain norms, and "implicit in this understanding of the norms, is the ability to recognize ideal cases (...). And beyond the ideal stands some notion of a moral or metaphysical order, in the context of which the norms and ideals make sense". Consequently, my participants' ideal of the Secular, where tolerance is consistently extended to all religions, is not being imagined in a vacuum. Rather, Trustpeakers' imagining of the Secular reveals the underlying moral and rational context that make this imagining - in both its typical and ideal form-possible. This underlying context includes the sensibilities and expectations about secularism and tolerance as produced by the secular imaginary. Indeed, as Mahmood (2006, 323-324) argues, in discursive narratives of modern secularism, religious tolerance tends to not only be held as a value of secularism, but also that which is brought about by the intervening power of secularism. In the New Zealand context, although Christianity has had a strong foothold, so has a secular imaginary. The nation's secular imaginary has been imbued with discourses of tolerance since its inception:

Principles of religious equality were affirmed as early as 1840 at the signing of the Treaty of Waitangi, which paved the way for British annexation and colonization. Crucially, the colonial New Zealand state never adopted an official state religion, while principles of religious equality and the promotion of social harmony led to the formation of a secular state primary education system beginning in 1877 (Shaver et al. 2016, 5).

Moreover, as Taylor $(2004,28)$ points out, recognising ideals and norms is one feature of an imaginary, but there must also be an understanding "of what makes these norms realizable. This too, is an essential part of the context of action. People don't demonstrate for the impossible, for the utopic". Likewise, while my participants' critiques evoke a secular ideal, this ideal is seen as something that is not only achievable, but should be achieved-precisely due to the normative sensibilities about tolerance discussed above. Thus, in arguing that tolerance in New Zealand is uneven, and that Christians are not subject to the same tolerance as non-Christians, my participants do not reject the Secular outright-but what they see as its hypocritical formulation. As this critique employs the sensibilities of the secular imaginary, I posit that it simultaneously undermines and strengthens the legitimacy of the secular imaginary. 


\section{A circular imaginary: constructing a repugnant Other?}

Simon, Susanna and Lydia's narratives emphasise the circular nature of a secular imaginary described by Gaonkar (2002). He argues that imaginaries are "imagined in the double sense: they exist by virtue of representation or implicit understandings, even when they acquire immense institutional force; and they are the means by which individuals understand their identities and their place in the world" (Gaonkar 2002, 4). Thus, while Trustpeakers' narratives reflect their individual imaginings of a secular ideal, this ideal must be situated within the wider context of the secular imaginary. In other words, while my participants almost certainly have unconscious and conscious biases, motivations, and agendas that shape how the think about the Secular, these biases, motivations, and agendas are themselves shaped by secular discourses and doctrines. It is also true that the Secular, materialised as an imaginary, disposition, political doctrine, and a set of sensibilities, is inclined to discursively produce and narrate particular religious subjects (Harding 1991; Mahmood 2006).

In Olson et al.'s (2013) ethnographic study on young Christians in Scotland, their participants expressed similar sentiments to Trustpeakers. These Scottish Christians thought that those adhering to other 'minority' religions were to free to express their faith, while they were expected to be private about their religiosity. If they were public about their Christian adherence, the young people in this study felt that their Christian identity was suppressed, either by way of outright harassment, or more subtle forms of discrimination. Olson et al. $(2013,1433)$ argue that their findings suggest we should regard so-called postsecular position ${ }^{53}$ with caution, as Postsecularisation is "about the growing importance of the politics of subjection, in which different versions of the religious subject as joyful, patriarch, theist, militant, volunteer, and terrorist are contested" (emphasis added).

Similarly, it is evident from the discussion thus far that my participants believe that the Christian religious subject is treated, represented, and considered differently than other religious subjects in New Zealand. Intuitively, I anticipate that a number of readers might balk at the idea of a

\footnotetext{
${ }^{53}$ Postsecular positions tend to represent a change in consciousness in relation to religion, where religion's presence in 'modern' societies is no longer assumed to be destined for decimation (Habermas 2008).
} 
Christian claiming they are discriminated against more than other religious denominations-or perhaps at the idea of a Christian claiming discrimination in New Zealand at all. To that I would suggest it is worth considering why some groups are deemed a priori worthy of sympathy (academic or otherwise) while others are not. More importantly however, I argue that my participants are not claiming that Christians are discriminated against more than other religious groups. As educated and self-aware individuals, they are as cognisant as any anthropologist that non-Christian religious adherents are subject to both overt and institutional religious discrimination, in New Zealand and worldwide. Rather, their claim is not that Christians are subject to more secular discrimination, but a different expression of secular discrimination. This chapter is not about empirically comparing discrimination between or towards religious groups, and I do not have the data to empirically validate my participants' experiences. However, if we acknowledge that the secular imaginary, like all imaginaries, entails power structures, and almost certainly has institutional force, I consider it worthwhile exploring what my participants' experiences could suggest about how the secular imaginary, as a collection of discourses, sensibilities, ideas, and dispositions comes to create, shape, and act upon religious agents, including my participants.

Harding (1991) argues, based on her ethnography on American Fundamentalism, that religious subjects, or religious others, are discursively constructed. She claims that the Christians she researched are not only constructed as an Other to both modern society and academia, but as a repugnant Other. She argues that Fundamentalist Christians are the wrong kind of Otherrepugnant-because they are "militant, strident, dogmatic, ignorant, duped, backward, rural, southern, uneducated, antiscientific, anti-intellectual, irrational, absolutist, authoritarian, reactionary, bigoted, racist, sexist, anticommunist, war mongers" (Harding 1991, 373). Or, in other words, they represent everything modern society aspires to move away from. Indeed, this idea of 'moving away from' gets at the heart of the modern project, of which the secular and secularism are closely implicated (Asad 2003, 12-14). Hegemonic narratives about modernity are deeply temporal: the values, ideas, beliefs and things, which are held to be at the heart of modernity, are those which are different or a displacement of everything that has gone before $\left(O^{\prime}\right.$ Brien 1998,15$)$. It is these narratives of modernity that enabled secularisation theses to flourish (positing that as societies modernise, religion will dissipate) and conceptually relegate religion to that of the past. Of course religious adherence has not dissipated in the way that was predicted, and thus, if it is not narrated as 'backward', it is seen to have been transformed by the liberating powers of modern 
secularism; "historians of progress relate that in the premodern past secular life created superstitious and oppressive religion, and in the modern present secularism has produced enlightened and tolerant religion" (Asad 2003, 193).

In discussing a possible explanation for what they saw as differential treatment of Christianity by the secular imaginary, Jacob and Lydia evoked notions of temporality:

Jacob: I think the treatment of Christianity compared to other religions is mostly due to the fact that Christianity is 'our' religion. It's considered a Western religion by most people - but that's where we came from, it's not where we are now as a culture-

Lydia: Ah yes!

Jacob: -You know, "we don't need to talk about that, it's part of our past" -

Lydia: "It's embarrassing"

Jacob: -So, some other religions, it's 'their' religion, so we've got to be accepting and nice, and multicultural, and all that side of things. I think people feel subconsciously, or unconsciously, more comfortable with putting Christianity down, because they feel like it belongs to them and they can do what they want with it...

Jess: Even if they're not religious?

Jacob: Yeah. Just as a culture. As part of our cultural...subconscious I suppose.

What is interesting about this discussion is that Lydia and Jacob are occupying a third person, secular, perspective of Christianity in their explanation. It highlights that my participants are attuned to the temporal nature of modern secular discourses about religion ("we don't need to talk about that, it's part of our past"), and use these discourses to make sense of Christianity's place within the secular imaginary. Likewise, Jacob's explanation has striking similarities to that discussed by Engelke (2014) in his ethnography on British Humanists' narration of, and engagement with, Christianity. He argues that for his participants, "what stands behind this charge 
of repugnance is that these Christians have not become secular; they have not become reasonable and modern. These Christians have not broken with the past" (Engelke 2014, 294; emphasis added). However, if refusing to break with the past and to become modern explains the criteria upon which the social imaginary sees Christians as repugnant, shouldn't this apply to all religious subjects? Indeed, the list of unsavoury characteristics which define the Fundamentalist Christian provided by Harding (1991) are not exclusive to Fundamentalism, nor Christianity. So then, what makes the Christian Other, not the 'religious Other', specifically repugnant, as Harding (1991) claims?

Jacob's explanation for Christianity's unique status, in addition to temporal notions, evoked themes of similarity, difference, and ownership: Christianity belongs to a collective 'us', unlike other religions who belong to 'them', and thus 'we' feel comfortable with 'putting it down'. Isaac conveyed a similar sentiment to Jacob in his discussion of non-Christian religions:

With Māori and the Eastern religions, for example, their religion is very tied up into the culture, and whether it's conscious or subconscious, [non-religious] people feel like to reject the religion would be to also reject the culture, or to insult the culture itself. And when it's part of our own culture, like Christianity has been, or at least was in our history, it's like: "well that's our own culture, that's okay", you know? "This is mine, I'm okay with doing this to my culture, I'm okay with rejecting Christianity", but you can't-l'm not Māori so I couldn't reject Māori culture, that would just be rude and racist, but I think there is a tie there, whether it's subconscious or conscious, I'm not sure...

For Isaac, secularism and Christianity in New Zealand belong to the same cultural sphere, and thus, in his analysis, Christianity does not qualify for the same tolerance of difference that religions belonging to other cultural spheres are granted. This echoes Robbins' (2003) discussion of Christianity's uneasy status in anthropology. He argues that left implicit in Harding's (1991) notion of repugnance is not only that Christians are Other, but also that they are also similar too. The discomfort with Christianity can be seen then as a "response to an anomalous mixture of the similar and the different" (Robbins 2003, 193), evoking Douglas' (1966) theory of dirt as matter out of place. In this way, it is not that the Christian subject is more Other than non-Christian religious subjects, but rather the Christian is more unsettling. While Robbins (2003) doesn't continue with Douglas' theory any further, I argue that what makes the Christian Other repugnant is not necessarily a mixture of difference and similarity per se, but precisely that this mixture 
challenges the conceptual categories of us/them, modern/non-modern, rational/cultural, which underlie the sensibilities of secular imaginaries. As Douglas $(1966,38)$ points out, challenges to cultural classifications are not inherently unpleasant or intolerable, as with certain works of art. However, a culture must confront "anomalous" events or ideas which seem to defy its fundamental assumptions-either by reconciling or amending categories to be more accommodating, or labelling these events or ideas as dangerous (Douglas 1966, 40). With this in mind it is likely not happenstance that the stereotypes Trustpeakers encountered about Christianity were those that implied disobedience to the virtues associated most intimately with the Secular.

Robbins' (2003) discussion largely revolves around anthropology's fraught history with Christianity as opposed to a more general analysis of the social construction religious subjects. Indeed, I suggest that examining the uneasy status of Christianity in anthropology in the context of my participants' narratives illustrates not only how formal theories come to infiltrate the imaginary, as Taylor (2004) argues, but also how an imaginary comes to act upon theories and formal institutions too.

\section{"Christianity can no longer be avoided"54: the secular imaginary in academic practice}

Christians seemingly present an intriguing ethnographic opportunity: despite the confidence of secularisation theses, Christianity has not only continued, but flourished in the most unlikely forms (fundamentalism) and in the most unlikely places (the West). Despite this, Christianity has only been seriously pursued by Anthropologists in the last 10-15 years, and was the last major religion to be considered in ethnographic inquiry (Cannell 2006, 8). Just over ten years ago, Hann (2007, 384) noted that the bulk of the anthropology of Christianity was focused on "Christian communities that result from missionary encounters in locations remote from the religion's home territory. We still do not have much by way of ethnographic studies of mainstream Christianity in countries such as Britain and the United States (...)". Although several anthropologists have since examined Christianity in more 'mainstream' Western setting $5^{55}$, literature in this area remains

\footnotetext{
${ }^{54}$ (Gariott and O'Neill 2008, 381).

${ }^{55}$ See, for example, Bialecki (2017), Strhan (2015), and Bielo (2012).
} 
limited, and rarely examines the relationship between Christianity and the Secular in lived contexts.

Harding $(1991,375)$ claims that the underdevelopment of Christianity in Anthropology can be attributed to the fact that anthropology considers some Others to be "sanctioned others", explaining "it seems the antiorientalizing tools of cultural criticism are better suited for some 'others' and not other 'others' - specifically, for others constituted by discourses of race/sex/class/ ethnicity/colonialism but not religion, at least not Christian religion". Harding $(1991,375)$ argues this disposition is not only a theoretical bias, but also culturally ingrained in anthropology, which she highlights by quoting her colleagues: "Are you now or have you ever been a born-again Christian?" Coleman $(2015,1)$, who studied an evangelical/neo-charismatic church in Sweden, also discusses how he has found himself defending to other anthropologists why he was "studying such crap". Here parallels can be drawn between Harding's discussion and my participants' claims that religious tolerance in New Zealand is disparate-this suggests that Anthropology is also bound up, at least to some degree, in a secular imaginary and is consequently inclined to study some religions and not others.

Robbins (2003) argues that anthropology's avoidance and othering of Christianity can be explained by the fact that the same factors which make them 'repugnant', are also what makes it difficult to study Christians. He claims this is because Christians draw on the same cultural tradition as anthropologists, but also value the aspects of this tradition that have "arisen in critical dialogue with the modernist ideas on which anthropology is founded" (Robbins 2003, 192). Or in other words, Christians are intellectually opposed to anthropologists but the resources employed in this opposition are derived from the same cultural milieu (Garriott and O'Neill 2008, 306). Robbins (2003, 192) illustrates this in his comparison between studying the Urapmin religion and Christianity:

Since the traditional religion of, say, the Urapmin of Papua New Guinea does not take any position on modern claims concerning the bases of knowledge or the importance of tolerance, an anthropologist can endeavor to understand that religion on its own terms without challenging one's own. But when studying many kinds of Christians, including Urapmin charismatics, anthropologists have to reckon with the fact that they do have universalist arguments about the bases of truth and the limits of tolerance ready to hand. Because of this, to claim, as anthropologists must, that 
Christians make sense in their own terms is at least to admit that it is possible to argue in a reasonable way that anthropologists do not make sense in their own.

Robbins' (2003) explanation suggests that the anthropological unease with Christianity is because Christians both contribute to, and are shaped by, the secular imaginary-but are simultaneously also critical of it. In this way, it is not just that Christians are in critical dialogue with revered anthropological values, but that they are in competition with anthropologists "in attempts to define and describe religious and even apparently secular realities" (Coleman 2008, 43; emphasis added). In Fountain's $(2013,313)$ critique of anthropology's aversion to theology, he argues that anthropologists have imagined religion as a domain separate from society, so it can be "observed, mapped and catalogued without posing any threat to the observer". The ethnographic examples presented throughout this thesis highlight that the distinctions between 'the religious' and 'the secular', do not neatly apply to the lived experiences of those who adhere to a faith. Confining Christianity, or any religion, to the realm of 'the religious' not only neglects the complexity and depth of Christian lifeworlds, but as Fountain (2013) points out, is bound up in the invention and reproduction of the idea of the Secular itself.

The 'threat' posed by Christianity is bound up not only with anthropology's relationship with the secular imaginary, but is also inextricably linked to the fact that anthropology has been shaped both by the push early in its history to distinguish it from theology (Cannell 2006; Fountain 2013), as well as the undeniable influence of a Christian intellectual tradition on its thinking (Sahlins 1996). Similarly, as alluded to at the beginning of this chapter, modern configurations of secularism too can be traced to Christian theological shifts in the seventeenth and eighteenth centuries (Taylor 2007). As Mahmood $(2009,858)$ succinctly states:

As much recent scholarship suggests, contrary to the ideological self-understanding of secularism (as the doctrinal separation of religion and state), secularism has historically entailed the regulation and re-formation of religious beliefs, doctrines, and practices to yield a particular normative conception of religion (that is largely Protestant Christian in its contours).

Perhaps the aversion to Christianity by anthropologists (and 'secular society' more generally) can thus be explained by a cultural desire to dissociate from a tradition that, although formative to its intellectual basis, is now seen as incongruent with its principles. To that I cannot provide an 
answer; however, I argue that the conclusions often made from the fact that Western liberal secularism is informed by a Christian intellectual and cultural history require more nuance. For example, in Kayaoğlu's $(2014,247)$ exploration of the European Court of Human Rights' jurisprudence regarding Islam, he argues that the post-/secularism informing the Court's decisions are both Eurocentric and Christian-centric, and consequently "its jurisprudence concerning religious freedom has tended to accommodate Christian-but not Muslim-demands". Relatedly, Shakman Hurd $(2004,255)$ claims that:

Secularism disparages non-Western approaches to the negotiation of religion and politics. It views religion in public life, and in particular Islam, with disdain. It legitimates the repression of non-Western negotiations of the relationship between religion and politics.

I do not disagree with Mahmood (2009), Kayaoğlu (2014) or Shakman Hurd (2004) that Western forms of secularism have a particular Christian history and bias, and that they discursively act upon and construct non-Christian religious subjects. Kayaoğlu (2014) discusses one example of this. However, the implication made by these discussions is that as a result of Christian history, bias, or sensibility, Christian subjects in Western secular societies must thereby be privileged in some way, or inevitably seen as more legitimate religious subjects. Directly contradicting the idea of some sort of hegemonic privilege, my participants claim the opposite-that they are disadvantaged by New Zealand's secular imaginary; that they are not seen as the right kind of religious subject.

There is an underlying assumption in the arguments referenced above that the relationship between secular discourses and Christian subjects is straightforward, as well as an implication that Christianity is homogenous. As Coleman $(2008,41)$ points out, this assumption is possibly another reason why anthropology has felt uneasy studying it: "Christianity can be too easily dismissed as a form of 'intrusive' hegemony, associated not only with the evils of missionaries, capitalism, and colonialism, but also with a form of irrationality because frankly, it should know better". Of course we should be cautious of representing the subjective experience of Trustpeakers as social fact; however, I suggest that we should also be careful to not dismiss their claims as having no cultural insight. Indeed, although I cannot attest to whether my participants are truly constructed as 'repugnant Others' by the current secular imaginary, they-like all religious subjects-are certainly 
shaped its discursive power, and this demands ethnographic attention. Arguably because of Christianity's proximity to secularism, not despite it.

As Asad $(2003,183)$ claims, those religions which are seen as publicly acceptable in secular, liberal states, are those which have accepted the assumptions of liberal discourses and "are able and willing to enter the public sphere for the purpose of rational debate with opponents who are to be persuaded rather than coerced". Likewise, I argue that Trustpeakers' reflections on the secular imaginary, and their place within it, suggest that it is only the configurations of religiosity (Christian or otherwise) which conform to particular expressions, in particular settings, that are constructed as legitimate in New Zealand's secular imaginary.

\section{Conclusion: \\ "Because I'm a person and I believe in God, you know? I'm not just a Christian."}

I conclude with this quote from Rebecca because it plainly articulates what is at stake for my participants in this discussion. Trustpeakers are not conceptually, socially, culturally, or ontologically confined to a Christian realm. They are fully embedded in New Zealand society, and thus do not abstain from participating in 'secular' matters. Further, while their faith is of paramount importance to them, this does not mean they do not become frustrated when the complexity of their lives was distilled down to simply being 'Christian'-especially when they felt that to be Christian entailed being seen as an unsavoury kind of religious other. Trustpeakers argued that there was secular hypocrisy in New Zealand society, in that other religions were accepted, but Christianity was open to derision. They raise interesting questions about the nature of religious tolerance-who does the tolerating and who does it apply to, and in what contexts? And how is tolerance used as a discursive tool? In this chapter, I have analysed my participants' claims about, and experiences of the Secular via the idea of a secular imaginary. I argue that a secular imaginary shows how the secular is given shape by both my participants' imaginings of the Secular, and secular discourses, which act upon Trustpeakers as particular religious subjects. Secular discourses shape perceptions and understandings of Trustpeakers, but Trustpeakers also utilise secular discourses, understandings and sensibilities to make sense of the world, while simultaneously critiquing them. Indeed, I have argued that it is precisely due to Christianity's 
proximity to the Secular that some Christians are constructed as an unsettling-repugnantreligious Other. Consequently, Trustpeakers point to the need for anthropologists to take a postsecular approach in studying Christianity. This approach requires we simultaneously avoid reifying categories like 'religious' and 'secular' and "expand beyond religious discourses/venues" (Fountain 2013, 316) in our exploration of Christian lifeworlds. My participants highlight that religious subjects are produced through a discursive and complex layering of sensibilities, understandings, and biases, which transcend a simple antagonism between 'religious' and 'secular' realms. 


\section{Chapter Seven}

\section{Conclusion}

This thesis has explored how Christianity and the Secular come to materialise and interact in the lives of a small group of Pentecostal-Charismatic Christians. I have attempted to convey the rich and multifaceted complexity of Christian lives, while showing that these lives are not confined to religious realms. Indeed, the nature of this complexity involves not just Christian understandings, interactions with, and relations to the Secular, but also 'being' secular too. Further, being secular and Christian are not mutually exclusive modes that Trustpeakers switch between, but represent sets of sensibilities, frameworks and dispositions which are often held concurrently as they go about their daily lives.

The notion of 'being secular' is possibly dubious for some readers, but in exploring Christian experiences of the Secular, I have sought to illustrate how the Secular imbues particular ways of thinking about the world-it is not a residual state that has succeeded the vanquish of religion. Entailed in a secular way of thinking is the assumption that the Secular and the religious are fundamentally separate; a notion I have challenged throughout this thesis. My participants' experiences and imaginings of the Secular and of their faith, demonstrate that relationship between religion and the Secular is complex, and that they are often reciprocal and entwined.

That is not to say that my participants' faith is not important to them. As discussed in Chapter Three, Trustpeakers have an intimate, personal relationship with God, and He is seen to permeate all aspects of life. It is precisely because of God's ubiquitous nature that the separation of their Christian faith from 'secular' spaces and practices is not always intuitive to them. While at times, my participants struggled with navigating secular space, they also highlighted the complex and contradictory nature of being Christian in New Zealand, in that they themselves reproduced the symbolic boundaries demarcating spaces as secular and religious. The entanglement of the Secular and Christianity was also evident in Trustpeakers' messy identity work discussed in Chapter Four. For my participants, being Christian involved navigating the real, imagined, and anticipated expectations oneself, non-Christians, other Christians, and God. Although my participants 
attempted to change secular perceptions of them, at times they also sought to set themselves apart by cultivating a counter-cultural identity. In Chapter Five I explored Trustpeakers' meaningmaking practices, arguing that they have a distinct Pentecostal ontological reality, in which God is really real. I showed how this reality, and the epistemological tools used to make sense of it, were not wholly disconnected from the Secular. My participants relied on a complex configuration of knowledge domains such as science, rational thought, belief, doubt, evidence, and nonsense, to make sense of a world in which God exists. I showed how we should recognise and explore Christian epistemological frameworks when understanding practices like belief, doubt, and glossolalia, or we risk shoehorning them into a secular, naturalist paradigm. The final ethnographic chapter sought to illustrate, via the idea of a secular imaginary, that Trustpeakers are not confined to a Christian realm-they also participate in, and reproduce the Secular. I argued that Christianity's proximity to the Secular, and thus its disruption of a number of binaries fundamental to secularism, makes Christians into a particular kind of religious subject-one that is unsettling, and even repugnant.

A reoccurring theme implicit throughout this thesis has been that the Secular and secularism are cultural resources that are used to produce and represent different religious subjects. I have argued that this production is inherently discursive; not only in that it entails privileging certain types of knowledge, truth, and morality, but also that it produces particular kinds of religious subjects as legitimate or illegitimate. Trustpeakers highlight how this discursive production plays out in everything from debates about homosexuality, to the role of faith in the workplace, to even their choice in music. While a central argument to this thesis is that my participants problematise a number of conceptual boundaries central to the Secular, it does not mean that these distinctions do not have salience in their lives. Indeed, even in countering, critiquing, and rejecting the Secular, it was evident that it remained a significant force in shaping their ontological stance, spatial practices, identities, and relationships. Thus, I see this research making a contribution to both the anthropologies of Christianity and secularism, with the former underdeveloped yet growing, and the latter in its infancy. The irony is that one would expect that the distinctions anthropologists have made around religion would encourage engagement with the Secular-for if religion is demarcated as its own realm, it surely makes sense to explore its Other? Yet, the Secular has remained markedly absent from the anthropology of Christianity, especially in ethnographic research. Of course this absence is partially attributed to the fact that secularism revolves around 
notions of neutrality, absence and innateness, and is thus reproduced in practices that are characterised as 'normal'. Anthropologists like Engelke (2014) and Blanes and OustinovaStjepanovic (2015) make important contributions to the anthropology of secularism by primarily exploring formalised secular institutions and groups. However, as narratives in this thesis have emphasised, there is an important difference between studying secular people (such as motivated humanists and atheists), and how the Secular comes to impact on, and take shape through, people's lives. If we are to study the latter, as I think we should, we must understand how the Secular operates as an imaginary and as it is embedded in everyday, unthought practice-we need to take seriously Asad's (2003) advice to investigate the Secular through its shadows.

This research has focused on the views, experiences and imaginings of only a small group of Christians from one Christian church in New Zealand. Other Christians, from both the PentecostalCharismatic, and other traditions, undoubtedly have had different experiences to my participants. Further, the focus of this thesis is local: while influenced by political, social, and intellectual traditions elsewhere in the West, the Secular in New Zealand has a particular formation informed by its colonial history, amongst other factors. Thus, we should be cautious in drawing generalisations from this research. Indeed, any further ethnographic research into Christianity and the Secular would be strengthened by including Christians from a range of denominations, as well as those who are not religious.

Despite these limitations, Trustpeakers still raise important questions about how the secular comes to actualise in Christians' lives, particularly; What is the meaning of tolerance in modern liberal societies, and to whom does it apply, and when? How are conceptual categories like 'religious', 'spiritual', 'cultural' and 'secular' constructed, applied, and in what contexts? How is a religious (and/or secular) identity lived out, and reproduced in everyday life? How does the Secular, as an imaginary, disposition, idea, and set of discourses, operate in social life?

In this thesis, I have presented an ethnographic analysis of how the Secular comes to materialise in the lives of a small group of Pentecostal-Christians. I have argued that we must not take conceptual categories like 'secular' and 'religious', for granted, but rather explore what they mean, and how they operate in daily lived experience. I have shown that Trustpeakers problematise the innate separation between the Secular and religious, and pose a number of anthropological 
challenges to how we study Christian lifeworlds. Trustpeakers show how religious subjects are produced via a discursive and complex layering of sensibilities, understandings, and biases-which transcend a simple antagonism between 'religious' and 'secular' realms. 


\section{Reference List}

Adams, S., Blokker, P., Doyle, N. J., Krummel, J. W., \& Smith, J. C. 2015. "Social Imaginaries in Debate." Social Imaginaries 1 (1): 15-52.

Ahdar, R. J. 2006. "Reflections on the Path of Religion-state Relations in New Zealand." Brigham Young University Law Review 2006 (3): 619-59.

Ammerman, N. T. 2007. "Studying everyday religion: Challenges for the future." In Everyday Religion: Observing Modern Religious Lives, edited by Nancy Ammerman, 219-238. New York: Oxford University Press.

Anderson, B. 1983. Imagined Communities: Reflections on the Origin and Spread of Nationalism. London: Verso.

Asad, T. 1999. "Religion, Nation-state, Secularism." In Nation and Religion: Perspectives on Europe and Asia, edited by Peter van der Veer and Hartmut Lehmann, 178-96. Princeton: Princeton University press.

Asad, T. 2003. Formations of the Secular: Christianity, Islam, Modernity. Stanford: Stanford University Press.

Asad, T. 2009. Genealogies of Religion: Discipline and Reasons of Power in Christianity and Islam. Baltimore: Johns Hopkins University Press.

Bandak, A., \& Jørgensen, J. A. 2012. "Foregrounds and Backgrounds-Ventures in the Anthropology of Christianity." Ethnos 77 (4): 447-458.

Barbour, R. 2008. Doing Focus Groups. London: Sage.

Berger, P. L. 1969. The Social Reality of Religion. London: Faber.

Berger, P. L. 1999. "The Desecularization of the World: A global Overview." In The Desecularization of the World: Resurgent Religion and World Politics, edited by Peter Berger, 1-18. Washington: Ethics and Public Policy Center.

Bialecki, J., Haynes, N., \& Robbins, J. 2008. "The anthropology of Christianity." Religion Compass 2 (6): 1139-1158. 
Bialecki, J. 2014. "Does God Exist in Methodological Atheism? On Tanya Lurhmann's When God Talks Back and Bruno Latour." Anthropology of Consciousness 25 (1): 32-52.

Bialecki, J. 2017. A Diagram for Fire: Miracles and Variation in an American Charismatic Movement. California: University of California Press.

Bielo, J. S. 2007. "The Mind of Christ': Financial Success, Born-again Personhood, and the Anthropology of Christianity." Ethnos 72 (3): 316-338.

Bielo, J. S. 2011. Emerging Evangelicals: Faith, Modernity, and the Desire for Authenticity. New York: NYU Press.

Bielo, J. S. 2012. "Belief, Deconversion, and Authenticity Among US Emerging Evangelicals." Ethos 40 (3): 258-276.

Bielo, J. S. 2015. Anthropology of Religion: the Basics. Oxon: Routledge.

Blanes, R. L., \& Oustinova-Stjepanovic, G. 2015. "Godless People, Doubt, and Atheism." Social Analysis 59 (2): 1-19.

Cannell, F. 2006. "Introduction. The Anthropology of Christianity." In The Anthropology of Christianity, edited by Fenella Cannell, 1-50. London: Duke Univeristy Press.

Cannell, F. 2010. "The anthropology of Secularism." Annual review of Anthropology 39 (1): 85-100.

Casanova, J. 1994. Public Religions in the Modern World. Chicago: University of Chicago Press.

Casanova, J. 2008. "Public Religions Revisited" In Religion: Beyond a Concept, edited by Hent de Vries, 101-119. New York: Fordham University Press.

Casanova, J. 2009. "The Secular and Secularisms." Social research 76 (4): 1049-1066.

Cochran, C. E. 2014. Religion in Public and Private Life. Oxon: Routledge.

Coffey, A. 1999. The Ethnographic Self: Fieldwork and the Representation of Identity. London: Sage.

Coleman, S. 2006. "When Silence isn't Golden: Charismatic Speech and the Limits of Literalism." In The Limits of Meaning: Case Studies in the Anthropology of Christianity, edited by Matthew Engelke and Matt Tomlinson, 39-62. New York: Berghahn Books. 
Coleman, S., \& Collins, P. 2006. Locating the Field: Space, Place and Context in Anthropology. New York: Berg.

Coleman, S. 2008. "The abominations of anthropology: Christianity, ethnographic taboos and the meanings of 'science'." In On the Margins of Religion, edited by edited by Frances Pine and João de Pina-Cabral, 39-58. New York: Berghahn Books.

Coleman, S. 2015. "Borderlands: Ethics, Ethnography and 'Repugnant' Christianity." HAU: Journal of Ethnographic Theory 5 (2): 275-300.

Collins, P., \& Gallinat, A. 2010. "The ethnographic self as resource: an introduction." In The Ethnographic Self as Resource: Writing Memory and Experience into Ethnography, edited by Peter Collins and Anselma Gallinat, 1-22. New York: Berghahn Books.

Connolly, W. E. 1999. Why I Am Not a Secularist. Minneapolis: University of Minnesota Press.

Comaroff, J. 2009. "The Politics of Conviction Faith on the Neo-liberal Frontier." Social Analysis 53 (1): 17-38.

Cooley, C. H. 1902. Human Nature and the Social Order. New York: Scribner's.

Csordas, T. J. 1990. "Embodiment as a Paradigm for Anthropology." Ethos 18 (1): 5-47.

Daswani, G. 2013. "On Christianity and Ethics: Rupture as Ethical Practice in Ghanaian Pentecostalism." American Ethnologist 40 (3): 467-479.

Day, A. 2011. Believing in Belonging: Belief and Social Identity in the Modern World. Oxford: Oxford University Press.

Day, A., Cotter, C.R, \& Vincett, G. 2013. "Introduction. What Lies Between: Exploring the Depths of Social Identities between the Sacred and the Secular" In Social Identities Between the Sacred and the Secular, edited by Abby Day, Christopher R. Cotter and Giselle Vincett, 1-4. London: Routledge.

Dawkins, R. The God Delusion. Boston: Houghton Mifflin Company.

Douglas, M. 1966. Purity and Danger. London: Pelican Books.

Descola, P. 2013. Beyond Nature and Culture. Chicago: University of Chicago Press. 
Droogers, A. 2002. "Methodological Ludism: Beyond Religionism and Reductionism." In Conflicts in Social Science, edited by Anton Van Harskamp, 44-67. London/New York: Routledge.

Duara, P. 1991. "Knowledge and Power in the Discourse of Modernity: The Campaigns Against Popular Religion in Early Twentieth-Century China." The Journal of Asian Studies 50 (1): 67-83.

Elisha, O. 2008. "Faith Beyond Belief: Evangelical Protestant Conceptions of Faith and the Resonance of Anti-humanism." Social Analysis 52 (1): 56-78.

Elisha, O. 2010. "Taking the (inner) City for God: Ambiguities of Urban Social Engagement Among Conservative White Evangelicals." In The Fundamentalist City: Religion and Urbanism in the New Global Order, edited by Nezar AlSayyad and Mejgan Massoumi, 235-256. London: Routledge.

Elisha, O. 2011. Moral Ambition: Mobilization and Social Outreach in Evangelical Megachurches. California: University of California Press.

Ellis, C., \& Berger, L. 2003. "Their story/my story/our story: Including the researcher's experience in interview research." In Inside interviewing: New lenses, New Concerns, edited by James Holstein and Jaber Gubrium, 467-493. California: Sage.

Engelke, M. 2004. "Discontinuity and the Discourse of Conversion." Journal of Religion in Africa 34 (1): 82-109.

Engelke, M. 2014. "Christianity and the anthropology of secular humanism." Current Anthropology 55 (10): 292-301.

Erzen, T. 2006. Straight to Jesus: Sexual and Christian Conversions in the Ex-gay Movement. California: University of California Press.

Ewing, K. P. 1990. "The Illusion of Wholeness: Culture, Self and the Experience of Inconsistency." Ethos 18 (3): 251-278.

Ewing, K. P. 1994. "Dreams From a Saint: Anthropological Atheism and the Temptation to Believe." American Anthropologist 96 (3): 571-583.

Foucault, M. 2002. Archaeology of Knowledge. London: Routledge.

Fountain, P. M., Kindon, S. L., \& Murray, W. E. 2004. “Christianity, Calamity, and Culture: The Involvement of Christian Churches in the 1998 Aitape Tsunami Disaster Relief." The Contemporary Pacific 16 (2): 321-355. 
Fountain, P. 2013. "Toward a post-secular anthropology." The Australian Journal of Anthropology 24 (3): 310-328.

Franks, D. D., \& Gecas, V. 1992. "Autonomy and Conformity in Cooley's Self-Theory: The LookingGlass Self and Beyond." Symbolic Interaction 15 (1): 49-68.

Fraser, D. 2004. "Secular Schools, Spirituality and Maori Values." Journal of Moral Education 33 (1): 87-95.

Gaonkar, D. P. 2002. “Toward New Imaginaries: An Introduction.” Public Culture 14 (1): 1-19.

Gallinat, A. 2010. "Playing the Native Card: The Anthropologist as Informant in Eastern Germany." In The Ethnographic Self as Resource: Writing Memory and Experience into Ethnography, edited by Peter Collins and Anselma Gallinat, 25-44. New York: Berghahn Books.

Garriott, W. \&. O'Neill, K.L. 2008. "Who is a Christian? Toward a Dialogic Approach in the Anthropology of Christianity." Anthropological Theory 8 (4): 381-398.

Ganzevoort, R. R., van der Laan, M., \& Olsman, E. 2011. "Growing Up Gay and Religious. Conflict, dialogue, and religious identity strategies." Mental Health, Religion \& Culture 14 (3): 209-222.

Gedicks, F. 1992. "Public Life and Hostility to Religion." Virginia Law Review 78 (3): 671-696.

Gélinas, C., \& Bouchard, Y. 2014. “An Epistemological Framework for Indigenous Knowledge.” Journal of Humanities of Valparaiso (4): 47-62.

Giddens, A. 1991. Modernity and Self-identity: Self and Society in the Late Modern Age. Standford: Stanford University Press.

Giddens, A., \& Pierson, C. 1998. Conversations with Anthony Giddens: Making Sense of Modernity. Standford: Stanford University Press.

Gieseking, J., Mangold, W.J., Katz, C., Low, S., \& Saegert, S., Eds. 2014. The People, Place, and Space Reader. New York: Routledge.

Göle, N. 2002. "Islam in Public: New Visibilities and New Imaginaries." Public Culture 14 (1), 173190.

Gökarıksel, B. 2009. "Beyond the Officially Sacred: Religion, Secularism, and the Body in the Production of Subjectivity." Social \& Cultural Geography 10 (6): 657-674. 
Gorski, P., Kim, D.K., Torpey, J., \& VanAntwerpen, J., Eds. 2012. The Post-Secular in Question: Religion in Contemporary Society. New York: NYU Press.

Graham, E. 2017. Apologetics without Apology: Speaking of God in a World Troubled by Religion. Oregon: Cascade Books.

Habermas, J. 2008. “Notes on Post-secular Society." New perspectives quarterly 25 (4): 17-29.

Hann, C. 2007. "The Anthropology of Christianity per se." European Journal of Sociology/Archives Européennes de Sociologie 48 (3): 383-410.

Hall, S. 1996. "Introduction: Who Needs Identity?" In Questions of Cultural Identity, edited by Stuart Hall and Paul du Gay, 1-17. London: SAGE.

Harding, S. 1991. "Representing Fundamentalism: The Problem of the Repugnant Cultural Other." Social Research 58 (2): 373-393.

Harding, S. F. 2000. The Book of Jerry Falwell: Fundamentalist Language and Politics. Princeton: Princeton University Press.

Holbraad, M. 2012. Truth in Motion: the Recursive Anthropology of Cuban Divination. Chicago: University of Chicago Press.

Hovland, I. 2016. "Christianity, Place/Space, and Anthropology: Thinking Across Recent Research on Evangelical Place-Making." Religion 46 (3): 331-358.

Holstein, J. \& Gubrium, J. 2003. "Active Interviewing." In Postmodern Interviewing, edited by Jaber Gubrium and James Holstein, 66-80. Thousand Oaks: SAGE.

Jenkins, T. 2012. "The anthropology of Christianity: Situation and critique." Ethnos 77(4): 459-476.

Jensen, S. Q. 2011. "Othering, Identity Formation and Agency." Qualitative Studies 2 (2): 63-78.

Jouili, J. 2009. “Negotiating Secular Boundaries: Pious Micro-practices of Muslim Women in French and German Public Spheres." Social Anthropology 17 (4): 455-470.

Kayaoğlu, T. 2014. "Postsecularism, Islam, and Religious Freedom: Cases from the European Court of Human Rights." In Towards a Postsecular International Politics. Culture and Religion in International Relations, edited by Luca Mavelli and Fabrio Petito, 243-262. New York: Palgrave Macmillan. 
Keane, W. 2002. "Sincerity, 'modernity', and the Protestants." Cultural Anthropology 17 (1): 6592.

Keane, W. 2007. Christian Moderns: Freedom and Fetish in the Mission Encounter. California: University of California Press.

Kitzinger, J. \& Barbour, R. 1999. "Introduction: The Challenge and Promise of Focus Groups." In Developing Focus Group Research, edited by Rosaline Barbour and Jenny Kitzinger, 1-20. London: SAGE.

Knott, K. 2005. "Spatial Theory and Method for the Study of Religion." Temenos-Nordic Journal of Comparative Religion 41 (2): 153-184.

Knott, K. 2010. "Religion, Space, and Place: The Spatial Turn in Research on Religion." Religion and Society 1 (1): 29-43.

LaCapra, D. 2006. "Experience and identity." In Identity politics reconsidered, edited by Linda Alcoff and Paula Moya, 228-245. New York: Palgrave Macmillan.

Lamont, M., \& Molnár, V. 2002. "The Study of Boundaries in the Social Sciences." Annual review of sociology 28 (1): 167-195.

Langdridge, D. 2006. "Ideology and Utopia: Social Psychology and the Social Imaginary of Paul Ricoeur." Theory \& Psychology 16 (5): 641-659.

Lastrucci, C. L. 1963. The Scientific Approach: Basic Principles of the Scientific Method. Cambridge: Schenkman Publishing Company.

Lebner, A. B. 2015. "The Anthropology of Secularity Beyond Secularism." Religion and Society 6 (1): 62-74.

Lefebvre, H. 1991. The Production of Space. Translated by Donald Nicholson-Smith. Oxford and Cambridge: Blackwell.

Leistle, B. 2015. "Otherness as a Paradigm in Anthropology." Semiotica 2015 (204): 291-313.

Lindhardt, M., Ed. 2011. Practicing the Faith: the Ritual life of Pentecostal-Charismatic Christians. New York and Oxford: Berghahn Books.

Lindhardt, M. 2012. Power in Powerlessness: a Study of Pentecostal Life Worlds in Urban Chile. Leiden: Brill. 
Lindquist, G. \& Coleman, S. 2008. "Against belief?" Social Analysis 52 (1): 1-18.

Luhrmann, T. M. 2012. "A Hyperreal God and Modern Belief: Toward an Anthropological Theory of Mind." Current Anthropology 53 (4): 371-395.

Lynch, M. 2000. "Against Reflexivity as an Academic Virtue and Source of Privileged Knowledge." Theory, Culture \& Society 17 (3): 26-54.

Lyon, D. 2010. "Being Post-secular in the Social Sciences: Taylor's Social Imaginaries." New Blackfriars 91 (1036): 648-662.

MacGregor, G. 1987. "Doubt and Belief." The Encyclopedia of Religion 4: 424-430.

Mahmood, S. 2006. "Secularism, Hermeneutics, and Empire: The Politics of Islamic Reformation." Public culture 18 (2): 323-347.

Mahmood, S. 2009. "Religious Reason and Secular Affect: An Incommensurable Divide?" Critical Inquiry 35 (4): 836-862.

Marshall, R. 2014. "Christianity, Anthropology, Politics." Current Anthropology 55 (S10): S344S356.

Martin, David. 2002. Pentecostalism: Their World Their Parish. Oxford: Blackwell.

Massey, D. 1992. “Politics and space/time.” New Left Review (196): 65-84.

Meyer, B. 2004. "Praise the Lord": Popular Cinema and Pentecostalite Style in Ghana's New Public Sphere." American Ethnologist 31 (1): 92-110.

O'Brien, M. 1998. "The Sociology of Anthony Giddens: an Introduction" In Conversations with Anthony Giddens: Making Sense of Modernity, by Anthony Giddens and Christopher Pierson, 1-27. Cambridge: Polity Press.

Ortner, S. B. 2005. "Subjectivity and cultural critique." Anthropological Theory 5 (1): 31-52.

Olson, E., Hopkins, P., Pain, R., and Vincett, G. 2013. "Retheorizing the Postsecular Present: Embodiment, Spatial Transcendence, and Challenges to Authenticity Among Young Christians in Glasgow, Scotland." Annals of the Association of American Geographers 103 (6): 1421-1436. 
Oxford Dictionaries, s.v. "sanctity (n.)," accessed October 2, 2017, https://en.oxforddictionaries.com/definition/sanctity

Oxford Dictionaries, s.v. "faith (n.)," accessed October 20, 2017, https://en.oxforddictionaries.com/definition/faith

Pelkmans, M. 2016. "The Restlessness of Doubt, and the Tenacity of Belief." HAU: Journal of Ethnographic Theory 6 (1): 499-503.

Pew Research Center. 2011. "Global Christianity: a Report on The size and Distribution of The World's Christian Population." Pew Forum on Religion, \& Life. Accessed June 3 2017, http://www.pewforum.org/2011/12/19/global-christianity-exec/

Pohl, C. D. 1999. Making Room: Recovering Hospitality as a Christian Tradition. Grand Rapids: Eerdmans Publishing Company.

Rabinow, P. 1984. The Foucault Reader. New York: Pantheon Books.

Rabinow, P. 1986. "Representations are Social Facts: Modernity and Post-modernity in Anthropology." In Writing culture: The poetics and politics of ethnography, edited by James Clifford and George E. Marcus, 234-261. Berkeley: University of California Press.

Rewi, P. 2012. "Karakia Māori: Māori invocations to spiritual authorities." He Pukenga Korero, 9 (2): $15-20$.

Robbins, J. 2003. "What is a Christian? Notes Toward an Anthropology of Christianity." Religion 33 (3): 191-199.

Robbins, J. 2004a. "The Globalization of Pentecostal and Charismatic Christianity." Annual Review of Anthropology 33: 117-143.

Robbins, J. 2004b. Becoming Sinners: Christianity and Moral Torment in a Papua New Guinea Society. Berkeley: University of California Press.

Robbins, J., Barker, J., Cannell, F., Coleman, S., Eriksen, A., Garma, C., Harris, O., Howell, B.M., Keller, E., Luhrmann, T. \& MacCormack, S. 2007. "Continuity thinking and the problem of Christian culture: Belief, time, and the anthropology of Christianity." Current Anthropology 48 (1): 5-38.

Robbins, J. 2010. "Anthropology, Pentecostalism, and the New Paul: Conversion, Event, and Social Transformation." South Atlantic Quarterly 109 (4): 633-652. 
Robbins, J. 2011. "The Obvious Aspects of Pentecostalism: Ritual and Pentecostal Globalization." In Practicing the Faith: The Ritual life of Pentecostal-Charismatic Christians, edited by Martin Lindhardt, 49-67. New York: Berghahn Books.

Robbins, J. 2012. "TRANSCENDENCE AND THE ANTHROPOLOGY OF CHRISTIANITY." Suomen Antropologi: Journal of the Finnish Anthropological Society 37 (2): 5-23.

Robbins, J. 2014. "The Anthropology of Christianity: Unity, Diversity, New Directions: An Introduction to Supplement 10." Current Anthropology 55 (S10), S157-S171.

Ryang, S. 1997. "Native Anthropology and Other Problems." Dialectical Anthropology 22 (1): 23 49.

Sahlins, M. 1996. "The Sadness of Sweetness: The Native Anthropology of Western Cosmology." Current Anthropology 37 (3): 395-428.

Scott, M. W. 2013. "The Anthropology of Ontology (Religious Science?)." Journal of the Royal Anthropological Institute 19 (4): 859-872.

Shah, A. 2017. "Ethnography? Participant Observation, a Potentially Revolutionary Praxis." HAU: Journal of Ethnographic Theory 7 (1): 45-59.

Shaver, J. H., Troughton, G., Sibley, C. G., \& Bulbulia, J. A. 2016. "Religion and the Unmaking of Prejudice toward Muslims: Evidence From a large National sample." PloS one 11 (3): 1-25.

Simmel, Georg. 1997. "Religion and the Contradictions of Life". In Essays on Religion, edited by Horst Jürgen Helle, 36-44. New Haven: Yale University Press.

Shakman Hurd, E. 2004. "The Political Authority of Secularism in International Relations." European Journal of International Relations 10 (2): 235-262.

Shakman Hurd, E. 2011. "A Suspension of (dis)Belief: The Secular-Religious Binary and the Study of International Relations." In Rethinking Secularism, edited by Craig Calhoun, Mark Juergensmeyer and Jonathan Van Antwerpen, 166-184. Oxford: Oxford University Press.

Sikic-Micanovic, L. 2010. "Foregrounding the Self in Fieldwork Among Rural Women in Croatia." In The Ethnographic Self as Resource: Writing Memory and Experience into Ethnography, edited by Peter Collins and Anselma Gallinat, 45-62. New York: Berghahn Books.

Smith, J. K. A. 2008. "Is the Universe Open for Surprise? Pentecostal Ontology and the Spirit of Naturalism." Zygon 43 (4): 879-896. 
Smith, J. K. A. 2010. Thinking in Tongues: Pentecostal Contributions to Christian Philosophy. Grand Rapids: Eerdmans Publishing Company.

Smith, J. K. A. 2014. How (not) to be Secular: Reading Charles Taylor. Grand Rapids: Eerdmans Publishing Company.

Snow, D. A., \& Anderson, L. 1987. "Identity Work Among the Homeless: The Verbal Construction and Avowal of Personal Identities." American Journal of Sociology 92 (6): 1336-1371.

Statistics New Zealand. 2013. "RESULTS OF A CENSUS OF THE DOMINION OF NEW ZEALAND." Census: 1871-1916. Last modified 21 August 2013. https://www3.stats.govt.nz/ historic_publications/1911-census/1911 resultscensus.html?_ga=2.188986219. 1555322046.1518568316-1805926435.1516672103

Statistics New Zealand. 2014. "2013 Census QuickStats about culture and identity". Profile and Summary Reports. Last modified 15 April 2014. http://archive.stats.govt.nz/Census/2013census/profile-and-summary-reports/quickstats-culture-identity/religion.aspx

Steele, C. M., \& Aronson, J. 1995. "Stereotype Threat and the Intellectual Test Performance of African Americans." Journal of Personality and Social Psychology 69 (5): 797-811.

Strauss, C. 2006. "The Imaginary." Anthropological theory 6 (3): 322-344.

Strhan, A. 2015. Aliens and Strangers?: The Struggle for Coherence in the Everyday Lives of Evangelicals. New York: Oxford University Press.

Strhan, A. 2013. "The Metropolis and Evangelical life: Coherence and Fragmentation in the 'Lost City of London'." Religion 43 (3): 331-352.

Stump, R. W. 2008. The Geography of Religion: Faith, Place, and Space. Maryland: Rowman \& Littlefield Publishers.

Taylor, C. 2004. Modern Social Imaginaries. London: Duke University Press.

Taylor, C. 2007. A Secular Age. Cambridge: Harvard University Press.

Van Ginkel, R. 1994. "Writing Culture From Within: Reflections on Endogenous Ethnography." Etnofoor (1): 5-23. 
Van Ginkel, R. 1998. "The Repatriation of Anthropology: Some Observations on Endoethnography." Anthropology \& Medicine 5(3): 251-267.

Van Houtum, H., \& Van Naerssen, T. 2002. "Bordering, Ordering and Othering." Tijdschrift voor economische en sociale geografie 93 (2): 125-136.

Vasconcelos, J. 2008. "Homeless Spirits: Modern Spiritualism, Psychical Research, and the Anthropology of Religion in the Late Nineteenth and Early Twentieth Centuries." On the Margins of Religion, edited by Frances Pine and João Pina-Cabral, 13-37. New York: Berghahn Books.

Viveiros de Castro, E. 2015. The Relative Native: Essays on Indigenous Conceptual Worlds. Chicago: University of Chicago Press.

Whitehouse, H. 2006. "Appropriated and Monolithic Christianity in Melanesia." In The Anthropology of Christianity, edited by Fenella Cannell, 295-307. London: Duke University Press.

Wittrock, B. 2002. "Modernity: One, None, or Many? European Origins and Modernity as a Global Condition." Polis. Political Studies 1(1): 141-159.

Yong, A. 2012. "Observation-Participation-Subjunctivation: Methodological Play and MeaningMaking in the Study of Religion and Theology" Religious Studies and Theology 31 (1): 17. 